\title{
FATORES DIETÉTICOS E CÂNCER ORAL: UM ESTUDO CASO CONTROLE NA REGIÃO METROPOLITANA DE SÃO PAULO.
}

\author{
DIRCE MARIA LOBO MARCHIONI
}

Tese de Doutorado apresentada ao Departamento de Nutrição da Faculdade de Saúde Pública da Universidade de São Paulo para obtenção do Grau de Doutor

Área de Concentração: Nutrição

Orientadora: $\operatorname{Prof}^{\mathrm{a}} \mathrm{Dr}^{\mathrm{a}}$ Regina Mara Fisberg Co-orientadora: Prof ${ }^{\mathrm{a}} \mathrm{Dr}^{\mathrm{a}}$ Maria do Rosário Dias de Oliveira Latorre

São Paulo 2003

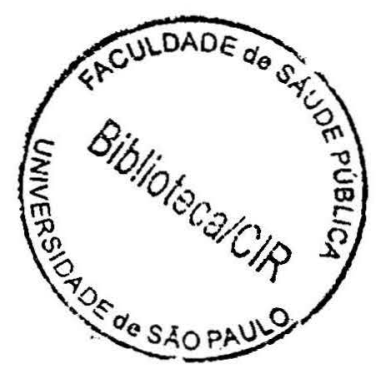


Autorizo, exclusivamente para fins acadêmicos e cientificos, a reprodução total ou parcial desta tese, por processos fotocopiadores Assinatura Data $43889 / 2003$ doc 


\section{dedicatória}

Só sel viver se for por você...

Djavan

Ao meu marido, Osmar, companheiro de todas as horas. e aos meus filhos, Mariana e Guilherme, que dão sentido à minha vida. 


\section{agradecimentos}

À Regina Mara Fisberg, pela orientação e por tudo o mais. Sua participação no meu crescimento profissional é imensurável. Sou-lhe grata por todos os momentos de estudo, pelo seu apoio, pela presença constante nos momentos de alegria e de dificuldade e, especialmente, pela amizade preciosa.

À Maria do Rosário Dias de Oliveira Latorre, fundamental na minha formação nesta Faculdade, Mestra não só em Estatística, mas em lições essenciais de vida e amizade.

Ao Prof Dr Victor Wünsch, por ter me proporcionado a oportunidade de participar deste Estudo, pelo incentivo e pelo auxílio em todas as etapas deste trabalho.

Ao Prof Dr Julio César Rodrigues Pereira, por partilhar seus conhecimentos, por ter me levado à descoberta de novas possibilidades para compreensão e análise deste objeto de estudo e pelas sugestões para melhoria deste trabalho.

Aos Professores Paulo Boffetta e Paulo Brennan, pela orientação durante o periodo de estudos na Agencia Internacional para Pesquisa do Câncer (IARC) 
À queridissima Betzy, amiga "Qualis A", presença forte, estimulante e companheira. Conselheira constante, em assuntos científicos e aleatórios!

À Daniela Maria Alves Chaud, pela amizade, pelo incentivo e pelo apoio essencial para que pudesse cumprir as etapas deste trabalho, em especial a bolsa sanduíche.

Aos meus amigos do IARC, que me acolheram e tornaram o periodo que fiquei longe de minha família e amigos menos penoso: Raika, Mia, Emanuela, Mauricio, Noemi, François e Olaf.

À CAPES - Coordenadoria de Aperfeiçoamento de Pessoal de Nivel Superior, pelo apoio financeiro. 


\section{agradecimentos}

À Regina Mara Fisberg, pela orientação e por tudo o mais. Sua participação no meu crescimento profissional é imensurável. Sou-lhe grata por todos os momentos de estudo, pelo seu apoio, pela presença constante nos momentos de alegria e de dificuldade e, especialmente, pela amizade preciosa.

À Maria do Rosário Dias de Oliveira Latorre, fundamental na minha formação nesta Faculdade, Mestra não só em Estatística, mas em lições essenciais de vida e amizade.

Ao Prof Dr Victor Wünsch, por ter me proporcionado a oportunidade de participar deste Estudo, pelo incentivo e pelo auxílio em todas as etapas deste trabalho.

Ao Prof Dr Julio César Rodrigues Pereira, por partilhar seus conhecimentos, por ter me levado à descoberta de novas possibilidades para compreensão e análise deste objeto de estudo e pelas sugestões para melhoria deste trabalho.

Aos Professores Paulo Boffetta e Paulo Brennan, pela orientação durante o periodo de estudos na Agencia Internacional para Pesquisa do Câncer (IARC)

Aos membros da banca, Profa Dra Anita Sachs, Profa Dra Nélida Formes, pelas contribuições oportunas para melhoria do conteúdo desta tese.

À queridissima Betzy, amiga "Qualis A", presença forte, estimulante $e$ companheira. Conselheira constante, em assuntos científicos e aleatórios! 


\begin{abstract}
À Daniela Maria Alves Chaud, pela amizade, pelo incentivo e pelo apoio essencial para que pudesse cumprir as etapas deste trabalho, em especial a bolsa sanduiche.
\end{abstract}

Aos meus amigos do IARC, que me acolheram e tornaram o periodo que fiquei longe de minha familia e amigos menos penoso: Raika, Mia, Emanuela, Maurício, Noemi, François e Olaf.

À CAPES - Coordenadoria de Aperfeiçoamento de Pessoal de Nivel Superior, pelo apoio financeiro. 


\section{RESUMO}

Marchioni DML. Fatores dietéticos e câncer oral: um estudo caso-controle na região metropolitana de São Paulo. São Paulo, 2003. [Tese de Doutorado - Faculdade de Saúde Pública da USP]

Objetivo. Investigar o papel da dieta no câncer oral. Métodos. Este estudo utilizou dados do Município de São Paulo obtidos em um estudo multicêntrico tipo caso-controle de base hospitalar. Participaram 845 indivíduos (366 casos incidentes de câncer oral e 469 controles). Os dados de consumo alimentar foram obtidos por um questionário de freqüência alimentar (QFA). Verificou-se o risco associado ao consumo de alimentos e de grupos de alimentos definidos a priori e a posteriori, por análise fatorial, estes últimos denominados "fatores". O primeiro fator, rotulado como "prudente", caracterizou-se pelo consumo de vegetais, frutas, queijo e carne de aves. O segundo, "tradicional", pelo consumo de arroz e massas, feijão e carne; o terceiro fator, pelo consumo de pão, manteiga, embutidos, queijos, doces e sobremesas. O último fator, "monótono", associou-se negativamente ao consumo de frutas, vegetais e alimentos lácteos. Após categorização dos fatores dietéticos em tercis, foram estimados os valores da Razão de Chances e Intervalos de Confiança de 95\% por regressão logística múltipla não condicional. Resultados. Verificaram-se associações inversas para o consumo mais elevado de feijão e vegetais crus e para o tercil intermediário de arroz e massas; e diretas para o consumo de ovos, batata e leite. O padrão tradicional associou-se inversamente ao câncer oral, e o monótono positivamente. Nossos dados sugerem que a dieta tradicional do brasileiro, composta por arroz e feijão, além do consumo de frutas, vegetais e quantidades moderadas de carnes, pode conferir proteção 
para o câncer oral, independente de fatores de risco reconhecidos, como o fumo e o consumo alcoólico.

Descritores: Câncer oral. Nutrição. Dieta. Alimentos. Análise Fatorial. Fatores de risco. 
Marchioni DML. Fatores dietéticos e câncer oral: um estudo caso-controle na região metropolitana de São Paulo. [Dietary factors and oral cancer: a case controle study in a metropolitan region of São Paulo]. São Paulo (BR), 2003. [Tese de Doutorado - Faculdade de Saúde Pública da USP]

Objective: to identify dietary factors related with oral cancer in the city of São Paulo, Brazil. Methods: this study is part of a Latin American multicentre hospital based case-control. Participated 366 incident cases of oral cancer in Sao Paulo City, and 469 controls, frequency matched with cases by sex and age. The dietary data was collected by a food frequency questionnaire (FFQ). The risk associated to the intake of food and food groups, defined a priori and a posteriori, through factor analysis (so-called factors) was analyzed. The first factor, labeled "prudent", was characterized for the intake of vegetables, fruits, cheese and poultry. The second, "traditional", for the intake of rice, pasta, pulses and meat, while the third, named "snacks" was characterized for the intake of bread, butter, salami, cheese, cakes and desserts. The last, "monotonous", was associated inversely with the intake of fruits, vegetables and most of the others food items. After categorization of the food items and the scores of the factors into tertiles, the Odds Ratio and $95 \%$ Confidence Interval were calculated by unconditional multiple logistic regression. Results: The intake of rice, beans and raw vegetables was associated with lower risk, whereas eggs, potatoes and milk were associated with increased risk. The traditional pattern was inversely related with the oral cancer, while the monotonous was positively associated. Conclusions: Our data suggest that 
the Brazilian traditional habit of eating meals composed by rice and beans, plus moderated quantities of meat, may confer protection against the oral cancer, independent of other risk factors, as alcohol and tobacco consumption.

Descriptors: Oral cancer. Nutrition. Diet. Factor analysis. Risk factors. 
CONEP Comissão Nacional de Ética em Pesquisa

FFQ Food Frequency Questionnaire

FOSP Fundação Oncocentro de São Paulo

HPV Papilomavirus Humano

IAMSPE Instituto de Assistência ao Servidor Público Estadual

IARC International Agency for Research on Cancer

(Agencia Internacional para Pesquisa do Câncer)

ICAVC Instituto do Câncer Arnaldo Vieira de Carvalho

IMC indice de Massa Corporal

INCA Instituto Nacional do Câncer

OMS Organização Mundial da Saúde

OPAS Organização Panamericana de Saúde

POF Pesquisa de Orçamento Familiar

QFA Questionário de Freqüência Alimentar

SEADE Fundação sistema Estadual de Análise de Dados

USP Universidade de São Paulo

WCRF World Cancer Research Fund

WHO World Health Organization 
TABELA 1. Taxas de incidência de câncer de cavidade oral e faringe, para países da América do Sul.

TABELA 2. Distribuição do número e porcentagem de casos e controles, segundo características sociais e demográficas, São Paulo, 1998-2002.

TABELA 3. Distribuição do número e porcentagem dos casos segundo a localização do tumor e hospital de origem. São Paulo, 19982002

TABELA 4. Distribuição do número e porcentagem dos controles segundo diagnóstico, São Paulo, 1998-2002.

TABELA 5. Distribuição do número e porcentagem de casos e controles segundo as variáveis relacionadas ao consumo de tabaco. São Paulo, 1998-2002.

TABELA 6. Distribuição de casos e controles segundo as variáveis relacionadas ao consumo de bebida alcoólica. São Paulo, 19982002.

TABELA 7. Distribuição do número e porcentagem de casos e controles segundo consumo de chimarrão. São Paulo, 1998-2002.

TABELA 8. Caracterização da freqüência de consumo de alimentos entre casos e controles. São Paulo, 1998-2002. 
TABELA 9. Tabela 09 - Valores de Odds Ratio e Intervalo de Confiança de 95\% para câncer oral obtidos por regressão logística não condicional, univariada e múltipla aproximados de alimentos lácteos selecionados.

TABELA 10. Valores de Odds Ratio e Intervalo de Confiança de $95 \%$ para câncer oral obtidos por regressão logística não condicional, univariada e múltipla aproximados de alimentos fontes de carboidratos simples e complexos, São Paulo, 1998-2002.

TABELA 11. Valores de Odds Ratio e Intervalo de Confiança de $95 \%$ para câncer oral obtidos por regressão logística não condicional, univariada e múltipla aproximados de alimentos de origem animal, São Paulo, 1998-2002.

TABELA 12. Valores de Odds Ratio e Intervalo de Confiança de $95 \%$ para câncer oral obtidos por regressão logística não condicional, univariada e múltipla aproximados de alimentos de origem vegetal, São Paulo, 1998-2002

TABELA 13. Tabela 13 - Valores de Odds Ratio e Intervalo de Confiança de 95\% para câncer oral obtidos por regressão logística não condicional múltipla, aproximados de grupos de alimentos, São Paulo, 1998-2002.

TABELA 14. Valores de Odds Ratio e Intervaio de Confiança de $95 \%$ para câncer oral obtidos por regressão logistica não condicional múltipla,em tercis aproximados de grupos de alimentos, São Paulo, 1998-2002.

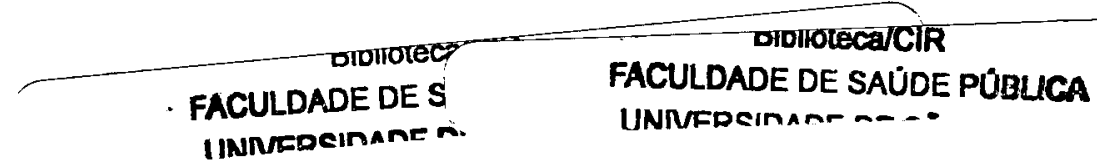


TABELA 15. Valores de Odds Ratio e Intervalo de Confiança de 95\% para câncer oral obtidos por regressão lcgística não condicional múltipla, em tercis aproximados de grupos de alimento, São Paulo, 1998-2002.

TABELA 16. Valores de Odds Ratio e Intervalo de Confiança de $95 \%$ para câncer oral obtidos por regressão logística não condicional múltipla, em tercis aproximados de grupos de alimentos, São Paulo, 1998-2002.

TABELA 17. Valores de Odds Ratio e Intervalo de Confiança de 95\% para câncer oral obtidos por regressão logística não condicional múltipla, em tercis aproximados de grupos de alimentos definidos "a posteriori" por análise fatorial, São Paulo, 19982002 
QUADRO 1 Estudos tipo coorte analisando a associação entre câncer oral e dieta 1990-2002.

QUADRO 2 Estudos caso-controle analisando a associação entre câncer oral e dieta 1990-2002.

QUADRO 3 Grupos de alimentos (fatores) derivados por analise fatorial, respectivos eigenvalues e porcentagens de variância e cumulativas

QUADRO 4 Matriz de factor loadings para casos e controles participantes do estudo. São Paulo, 1998-2002

QUADRO 5 Categorias e pontos de corte das variáveis de controle utilizadas

QUADRO 6 Média, desvio padrão e valor do $p$ para os testes estatísticos para a variável "peso dois anos anteriores à entrevista", relatada por casos e controles. São Paulo, 1998-2002. 
FIGURA 1 Individuos recrutados, excluídos e amostra final do estudo casocontrole. São Paulo, 1998-2002.

FIGURA 2 Scree plot - Gráfico de dispersão dos valores de eigenvalues dos fatores retidos 


\section{ÍNDICE}

1. INTRODUÇÃO 1

$\begin{array}{ll}\text { 1.1. Fatores de risco } & 7\end{array}$

1.1.1.Fatores de Risco não dietéticos $\quad 7$

1.1.1. Tabaco

1.1.1.2. Álcool 11

1.1.1.3. Saúde oral 14

1.1.1.4. Ocupaçäo 16

1.1.1.5. Outros fatores de risco 16

$\begin{array}{ll}\text { 1.1.2. Fatores associados à dieta } & 17\end{array}$

1.1.2.1. Frutas e vegetais 25

$\begin{array}{ll}\text { 1.1.2.2. Carne } & 27\end{array}$

1.1.2.3. Alimentos básicos 28

1.1.2.4. Doces 29

1.1.2.5. Bebidas não alcoólicas 29

1.1.2.6. Padrões alimentares 30

2. JUSTIFICATIVA 34

3. OBJETIVOS 36

4. MATERIAL E MÉTODOS 38

4.1. Delineamento 39

4.2. Casuistica 39

4.3. Definição de caso $\quad 40$

4.4. Definição de controle 40

4.5. Cálculo do tamanho da amostra 41

4.6. Coleta de Dados 42 
4.7. Inquérito Dietético 43

7.8. Definição de grupos e alimentos 44

4.8.1. Grupos de alimentos definidos a priori 44

4.8.2. Grupos de alimentos definidos a posteriori 44

4.8.2.1. Análise fatorial $\quad 44$

4.9. Variáveis do estudo $\quad 51$

4.9.1.Variável dependente $\quad 51$

4.9.2. Variáveis independentes 52

4.9.2.1. Variáveis de interesse 52

4.9.2.2. Variáveis de controle $\quad 52$

4.10. Análise estatística 55

4.10.1. Medidas de associação $\quad 55$

4.10.2. Efeito dose-resposta 57

4.10.3. Programa estatístico 57

4.11. Aspectos éticos $\quad 57$

5. RESULTADOS

5.1. Descrição dos indivíduos participantes do estudo 59

5.2. Caracterização dos fatores de risco reconhecidos 62

5.2.1. Tabaco 62

5.2.2. Consumo de Bebidas 64

5.3. Caracterização das variáveis de consumo alimentar 65

5.4. Associação entre fatores dietéticos e câncer oral 67

$\begin{array}{ll}\text { 5.4.1. Alimentos } & 67\end{array}$

5.4.2. Grupos de alimento definidos a priori $\quad 75$

5.4.3. Grupos de alimentos definidos a posteriori 80

6. DISCUSSÃO 82 
6.2. Grupos de alimentos $\quad 89$

6.3. Padrões alimentares 90

6.4. Considerações metodológicas 93

6.5. Viés de confundimento 96

$\begin{array}{lr}\text { 6.6. Limitações } & 97\end{array}$

$\begin{array}{ll}\text { 7. CONCLUSÕES } & 101\end{array}$

$\begin{array}{ll}\text { 8. REFERÊNCIAS } & 104\end{array}$

ANEXOS

Anexo 1 Relação provisória de diagnósticos (como razão de admissão ambulatorial ou hospitalar) não elegiveis para o estudo

Anexo 2. Modelo do Questionário

A4

Anexo 3. Parecer da Comissão Nacional de Ética em Pesquisa A34

Anexo 4. Parecer do comitê de ética- COEP A36

$\begin{array}{ll}\text { Anexo 5. Formulário para consentimento esclarecido } & \text { A38 }\end{array}$ 
introdução 


\section{INTRODUÇÃO}

As neoplasias malignas, também chamadas de câncer, passaram a representar no século XX uma importante causa de morte, que vem aumentando à medida que ocorre o controle progressivo de outras doenças e o conseqüente envelhecimento populacional (SEADE 1999).

No Brasil a mortalidade por câncer passou de quinto lugar na década de 30 para terceiro na segunda metade da década de 80 (AZEVEDO e MENDONÇA 1992, INCA 2000). O câncer é a segunda causa de morte no Estado de São Paulo, depois das doenças cardiovasculares (FONSECA, 1996). Em 1998, neste Estado, os óbitos por câncer corresponderam a $14,3 \%$ dos óbitos, ultrapassando as causas externas como causa de morte. No Brasil, o câncer de cavidade oral representou aproximadamente $4 \%$ do total de mortes por câncer em homens e $1 \%$ em mulheres, segundo o Instituto Nacional de Câncer, INCA, baseando-se em dados dos periodos de 1979 a 1983 e de 1995 a 1999. Em São Paulo, a mortalidade por câncer de cavidade oral se manteve estável, em torno de $4,5 \%$ por cento em homens, porém observou-se um expressivo aumento em mulheres, passando de 0,96 para $3 \%$ no periodo mencionado (INCA, 2002).

Os cânceres de cavidade oral e faringe combinados, excluidos os de nasofaringe, são responsáveis por aproximadamente 270.000 casos novos por ano em homens, cerca de $5 \%$ de todos os tipos, e 140.000 casos novos 
por ano em mulheres, correspondendo à $2,5 \%$ de todos os cânceres neste gênero (FERLAY et al., 2001). É a oitava incidência no mundo entre homens e a $12^{\text {a }}$ entre mulheres. É uma doença rara antes dos 30 anos (WÜNSCHe CAMARGO, 2001) e, no Brasil, da mesma forma, a distribuição por faixa etária mostra concentração acima dos 40 anos (INCA, 2002).

Os cânceres de cavidade oral e faringe são tratados, muitas vezes, como uma única entidade, e referidos como câncer oral, em decorrência da dificuldade de avaliar a localização de origem, em especial em cânceres avançados. No entanto, quase todos são neoplasias de células escamosas, e compartilham os mesmos fatores de risco, em especial hábito de fumar e consumo de bebida alcoólica, com exceção dos cânceres de lábios e nasofaringe (BLOT et al., 1996). Neste texto, câncer oral será considerado como câncer de cavidade oral e faringe.

A incidência de câncer oral tem uma grande variabilidade ao redor do mundo, sendo quase duas vezes maior nos paises desenvolvidos em relação aos paises em desenvolvimento (LA VECHIA et al., 1997). Na União Européia, em 1996, variou de 5,0 na Grécia, a 34,5 na França, entre os homens. Para mulheres, no mesmo periodo, variou de 1,39 na Grécia a 5,0 em Luxemburgo (taxas por 100.000 habitantes, padronizadas pela população mundial). A mais alta incidência é verificada na França, com taxas anuais de mais de 40 por 100.000 habitantes em cidades como Bas-Rhin e Calvados. A América do Sul tem taxas intermediárias, mas como pode ser observado na Tabela 1, nota-se igualmente grande variação geográfica. Entre os homens, as maiores taxas tanto para o câncer de cavidade oral 
quanto de faringe são verificadas no Brasil, seguido pelo Uruguai. As menores taxas são apresentadas pela Guiana, Peru e Equador (FERLAY 2001).

Tabela 1 -Taxas de incidência de câncer de cavidade oral e faringe, para paises da América do Sul.

\begin{tabular}{lccccccc}
\hline & \multicolumn{3}{c}{ Cavidade oral } & & Faringe & \\
\cline { 2 - 7 } & Feminino & Masculino & $\begin{array}{c}\text { Razão de } \\
\text { gênero } \\
\text { H:M }\end{array}$ & Feminino & Masculino & $\begin{array}{c}\text { Razão de } \\
\text { gênero } \\
\text { H:M }\end{array}$ \\
\hline Argentina & 1,73 & 6,53 & $4: 1$ & 0,28 & 2,11 & $7,5: 1$ \\
Bolivia & 4,16 & 6,42 & $2: 1$ & 0,50 & 0,79 & $1,5: 1$ \\
Brasil & 2,89 & 10,52 & $4: 1$ & 1,11 & 7,86 & $7: 1$ \\
Chile & 1,05 & 3,09 & $3: 1$ & 0,20 & 1,28 & $6: 1$ \\
Colômbia & 2,48 & 3,55 & $2: 1$ & 0,67 & 1,84 & $3: 1$ \\
Guiana & 0,68 & 2,34 & $3,5: 1$ & 0,36 & 1,11 & $3: 1$ \\
Equador & 1,41 & 2,15 & $1,5: 1$ & 0,18 & 1,10 & $6: 1$ \\
Paraguai & 1,59 & 4,95 & $3: 1$ & 0,39 & 2,77 & $7: 1$ \\
Peru & 2,86 & 2,58 & $1: 1$ & 0,32 & 0,51 & $1,5: 1$ \\
Suriname & 2,98 & 4,66 & $2: 1$ & 0,84 & 2,35 & $3: 1$ \\
Venezuela & 2,21 & 3,53 & $2: 1$ & 0,59 & 1,83 & $3: 1$ \\
Uruguai & 1,73 & 10,39 & $6: 1$ & 0,46 & 4,43 & $9: 1$ \\
\hline
\end{tabular}

Taxa anual ajustada por idade, padronizada pela população mundial, por 100.000 Fonte: Ferlay et al., 2001

A incidência é sistematicamente maior entre os homens que mulheres, sendo que a razão de gênero no mundo é de 2:1 e na América do Sul é de 3:1 (FRANCESCHI et al., 2000; FERLAY et al., 2001). No entanto, também há variação segundo localização geográfica: no Peru, o câncer oral ocorre de forma proporcional em homens e mulheres, mas, no Uruguai, é seis 
vezes maior em homens que mulheres. No Brasil, os homens têm quatro vezes mais câncer de cavidade oral, e sete vezes mais câncer de faringe que mulheres. Porém, dados temporais relativos à São Paulo, mostram uma consistente elevação nas taxas entre as mulheres, a partir de 1993 (MIRRA et al., 2001).

Nas últimas duas ou três décadas tem se observado uma reversão da tendência anterior de queda da incidência, com aumento em muitos paises desenvolvidos no sul e leste da Europa (FRANCESCHI et al., 2000). A incidência de câncer oral está decrescendo nas Américas Central e do Sul, porém as cidades de Montevidéu, no Uruguai, e São Paulo não compartilham desta tendência. (COLEMAN et al. 1993, WÜNSCH e CAMARGO 2001). Em São Paulo, a incidência aumentou em ambos os gêneros no período de 1969 à 1993, aproximadamente dobrando no caso de mulheres (MIRRA 1999).

No Brasil, o INCA, baseado em dados de oito Registros Populacionais de Câncer (Belém, Brasilia, Goiânia, Fortaleza, Salvador, São Paulo, Campinas e Porto Alegre), estimou para 2002 uma taxa bruta de incidência do câncer de cavidade oral habitantes de 4,48 por 100 mil para homens e 1,16 por 100 mil para mulheres. É a sexta incidência no pais entre os homens. As maiores taxas são observadas nas regiões Sul e Sudeste do pais. No entanto, WÜNSCH, 2002, analisando dados de Registros de Câncer das cinco regiōes brasileiras, destaca que em Fortaleza e Belém, estas localizações são proporcionalmente expressivas, dado que se configuram como a quarta incidência entre homens. 
A incidência de câncer de boca relatada pelo Registro Populacional de Câncer de São Paulo em 1993 foi de 25,3 por 100.000 para homens e 4,9 por 100.000 para mulheres, taxas padronizadas pela população mundial (MIRRA 1999), o que coloca o Municipio de São Paulo entre as cidades de maior incidência no mundo.

Também para as localizações anatômicas observam-se variações quanto à situação geográfica (HINDLE et al. 1996, JOHNSON e WARNAKULASURIYA 1993). O câncer de assoalho de boca e gengiva é o mais comum entre homens e mulheres latino-americanos. No entanto, no Brasil observa-se uma outra situação: a lingua é a localização mais freqüente (PARKIN et al. 1996). Levantamento realizado pela Fundação Oncocentro de São Paulo (FOSP), tendo por base os registros hospitalares de câncer no Estado de São Paulo em 2000, igualmente aponta a língua como localização anatômica mais freqüente, seguida do assoalho de boca (FOSP, 2002). NEVES, 1994, estudando a mortalidade por câncer oral entre os residentes do Estado de São Paulo entre 1979 e 1982, verificou que, para ambos os sexos, o câncer de lingua constituiu a principal causa de mortalidade.

É extremamente alto o percentual dos casos diagnosticados em estágios avançados, fato que, em principio, implica em um tratamento mais agressivo e, portanto, com maiores probabilidades de seqüelas estéticas elou funcionais nos pacientes. Dados da FOSP revelam que $74 \%$ dos casos são registrados como estágios III e IV. Levantamento, baseado no Registro Hospitalar de Câncer do Hospital do Câncer do INCA, corroboram o 
observado em São Paulo: 64\% dos casos diagnosticados nos estágios III e IV (FOSP 2002).

Apesar dos recentes avanços nos tratamentos para câncer, houve pouca mudança nas tendências de sobrevida nas últimas décadas, em todo o mundo. O câncer oral é altamente letal, com taxa de sobrevida de cinco anos menor que $50 \%$, taxa considerada baixa em relação às dos principais tipos de câncer (NEVES, 1994). O estágio da doença no momento do diagnóstico, bem como a disponibilidade e qualidade do tratamento influenciam as taxas de sobrevivência (BOYLE et al., 1995)

FRANCO et al., 1993, em um estudo de seguimento com 4.527 pacientes diagnosticados com câncer de boca entre 1953 e 1980, verificaram que raça e gênero eram fortes preditores da evolução da doença no diagnóstico e tratamento, sendo mais vantajosos para mulheres

LEITE e KOIFMAN, 1998, em estudo no Rio de Janeiro, verificaram que a menor taxa de sobrevida foi verificada em pacientes com câncer de língua. Neste estudo, os homens tiveram maior sobrevida que as mulheres.

RIBEIRO et al., 2000 estudando uma coorte de 110 pacientes com câncer oral em São Paulo, evidenciaram o impacto de co-morbidades, sintomas e caracteristicas pessoais de pacientes no prognóstico de sobrevida por cinco anos, variando de $8,4 \%$ a $64,6 \%$. Neste estudo, pacientes com câncer de língua apresentaram taxa de sobrevida de 5-anos de apenas $15 \%$, e para cânceres de outras localizações da boca, $28 \%$. 
As diferenças demográficas reforçam a hipótese de fatores ambientais modificando os padrões de incidência, portanto, passiveis de modificação.

\subsection{Fatores de Risco}

O câncer ocorre devido à interação de múltiplos fatores de risco: hereditariedade, exposição freqüente a agentes carcinogênicos químicos ou ambientais, virus e defeitos imunológicos. Entre os fatores ambientais, a dieta, o consumo de álcool e o tabagismo podem ser citados (PORTH 1998). Acredita-se que a carcinogênese química é responsável pelo maior número de casos de câncer (SGARBIERI, 1999).

O fumo e álcool são considerados os principais fatores de risco para o câncer oral (MARSALL et al.1992, WINN 1995, MARSHALL e BOYLE, 1996), mas outros fatores ambientais podem contribuir para explicar as marcantes diferenças observadas quanto às freqüências de distribuição da morbidade e mortalidade do câncer oral.

\subsubsection{Fatores de risco não dietéticos}

\subsubsection{Tabaco}

Há um vasto conjunto de evidências estabelecidas quanto à associação causal entre o hábito de fumar e o risco de câncer oral. O tabaco é considerado o maior fator de risco para este câncer afetando as localizações anatômicas de lingua, boca, e faringe, mas não glândula salivar (IARC, 1986) 
Existem diversos produtos à base de tabaco, cujos usos variam tanto geograficamente quanto ao longo do tempo: os cigarros manufaturados; os feitos a mão, como o cigarro de palha; charutos e cachimbos, todos com alto conteúdo de nicotina e alcatrão. No entanto, os cigarros manufaturados e os feitos à mão correspondem a $85 \%$ do consumo global de tabaco (KUPER et al. 2002).

O aumento do risco de desenvolvimento do câncer oral é marcante em fumantes, particularmente de tumor de células escamosas (KUPER et al., 2002). O risco relativo (RR) para fumantes, ajustando por consumo alcoólico, é geralmente de 2 a 3 vezes maior que em não fumantes (BARON E ROHAN 1996), mas aumentos de 10 vezes foram relatos em estudos do tipo caso controle de base hospitalar (De STEFANI et al., 1998). Estudos têm demonstrado um efeito de dose-resposta em função da intensidade e duração do hábito de fumar. O risco aparentemente cai com a cessação de fumar, de forma que, após 10 anos de cessação, o risco é semelhante ao de não fumantes (BARON E ROHAN 1996). Usuários de fumo preto e de cigarros feitos à mão estão em maior risco que fumantes de cigarros com filtro. Também o risco é maior para fumantes de charuto (SHAPIRO et al., 2000) e cachimbo (FRANCO et al., 1989).

MERLETTI et al., 1989, em um estudo caso controle de base populacional na Itália, verificaram um aumento de risco para câncer de cavidade oral e orofaringe entre fumantes a partir de 8 a $15 \mathrm{~g}$ de tabaco/dia, sendo o risco atribuivel devido ao tabaco de $72 \%$ em homens e $54 \% \mathrm{em}$ mulheres. 
No Brasil, FRANCO et al., 1989, em estudo do tipo caso controle conduzido em três áreas metropolitanas, São Paulo, Curitiba e Goiânia, verificaram que os consumos de álcool e de fumo foram os fatores de risco mais importantes para o câncer oral, com um risco relativo de 6,3 entre individuos fumantes de cigarros e não fumantes.

MACFARLANE et al., 1995, analisando dados provenientes de três estudos casos controle (pooled analysis) conduzidos na China, Estados Unidos e Itália, observaram que o risco para câncer oral associado com o hábito de fumar era de 1,7 (IC95\% 1,2-2,5) para homens fumantes de menos de 33 pacotes-ano e $3,8\left({ }^{1 \cos \%} 2,5-5,8\right)$ para aqueles que fumavam mais de 33 pacotes-ano, comparados com não fumantes. Também para mulheres foi observado excesso de risco, estatisticamente significativo.

SHAPIRO et al., 2000, examinando uma coorte de 137.555 homens americanos, observaram aumento do risco de morte para câncer oral para fumantes $\left(R R=4,0\left(C_{95 \%} 1,5-10,3\right)\right)$ e para os individuos ex-fumantes. $(R R=$ $\left.2,4\left(\mathrm{IC}_{95 \%} 0,8-7,3\right)\right)$

Há evidências que as localizações anatômicas que têm contato direto com a fumaça do cigarro são mais afetadas pelos carcinógenos. BOFFETTA et al. (1992), relatam uma forte associação com lesões do palato mole, menos evidentes em localizaçōes anteriores, verificadas em estudo caso controle conduzido em hospital dos Estados Unidos.

A maior parte dos produtos à base de tabaco é feita com a espécie Nicotiana tabacum. Mais de 200 compostos químicos foram identificados na 
folha do tabaco, e 55 destes foram avaliados pela Agência Internacional de Pesquisa em Câncer (IARC), como tendo "suficiente evidência para carcinogenicidade", tanto em animais de laboratório quanto em seres humanos. As substâncias carcinogênicas incluem nitrosaminas e compostos aromáticos (IARC 1986).

Apesar do uso do tabaco ser comum em paises desenvolvidos por mais de meio século, em países em desenvolvimento o hábito foi adotado em larga escala nos últimos trinta anos (KUPER et al. 2002). Tem sido verificado um declínio no consumo de tabaco por homens em países desenvolvidos, mas não em paises em desenvolvimento. 0 mercado consumidor da América Latina é particularmente atraente para as indústrias de tabaco, pois há um crescente número de potenciais fumantes, em virtude do aumento na população de adolescentes e jovens adultos, elevadas taxas de urbanização, com estilo de vida fortemente influenciado pela cultura norte americana, maior acesso à educação, e ingresso da mulher no mercado de trabalho (COSTA e SILVA e KOIFMAN 1998).

No Brasil, a prevalência estimada de fumantes na população de adultos maiores de 15 anos pela OMS (Organização Mundial da Saúde) era, em 1989 , de $40 \%$ dos homens e $25 \%$ para mulheres (COSTA e SILVA e KOIFMAN 1998). Chama a atenção a elevada taxa entre mulheres, a segunda entre os paises latino-americanos. Em São Paulo, em um inquérito de base populacional em $1986 / 1987$, foi verificada a prevalência de $44,6 \%$ fumantes entre homens e $31,9 \%$ fumantes entre mulheres (REGO et al., 1990). A prevalência de tabagismo entre adolescentes, verificada em 1997 , 
em estudo de base populacional na área urbana de Pelotas, no sul do Brasil, foi de $12 \%$ entre homens e $10 \%$ em mulheres, sendo observado aumento progressivo com a idade, chegando aos $20 \%$ entre 17 e 18 anos (HORTA et al., 2001).

\subsubsection{2. Álcool}

A evidência de associação entre câncer do trato aéreo-digestivo e álcool é extensiva e consistente. Um aumento no risco de câncer oral foi descrito por numerosos estudos epidemiológicos, tanto coortes quanto casos-controle (BLOT et al. 1988; CHOI e KAHYO, 1991; FRANCESCHI et al., 1994), independente do tipo de bebida alcoólica (WRCF 1997). Muitos estudos investigaram o risco associado ao tipo de bebida e à quantidade de álcool, bem como o possivel efeito multiplicativo entre estes fatores.

BLOT et al., 1988, em um caso-controle conduzido em 4 áreas dos Estados Unidos, compreendendo 1114 casos e 1268 controles, verificaram que os riscos associados ao desenvolvimento do câncer oral variaram de acordo com o tipo de bebida alcoólica, sendo maior entre os indivíduos consumindo destilados ou cerveja que vinho.

MASHBERG et al., 1993, conduziram um estudo do tipo caso controle para investigar o papel do álcool como fator de risco primário no desenvolvimento do câncer. O RR para etilistas, ajustado por tabagismo, foi de 3,$3 ; 15,2$ e 10,6 para aqueles que bebiam menos que seis, seis a nove, ou mais de 10 uísque-equivalentes por dia, respectivamente. Um uísque 
equivalente corresponde ao consumo de aproximadamente $10,2 \mathrm{~g}$ de etanol (BOFFETTA et al, 1992)

KJAERHEIM et al., 1998, em estudo tipo coorte realizado com 10.960 noruegueses acompanhados entre 1968 e 1992, çom o objetivo de verificar - papel da álcool, fumo e dieta nos cânceres do trato aéreo digestivo ras

superior, verificaram que o risco relativo de câncer oral foi de 3,9 $\left(\mathrm{C}_{95 \%}(\mathrm{RR})=[2,1 ; 7,1]\right)$ para o grupo de maior consumo de álcool.

No Uruguai, De STEFANI et al., 1998a, em estudo caso-controle, verificaram que o hábito de beber destilados estava associado com um aumento de risco de $3,6\left(\mathrm{IC}_{95 \%} 2,1-6,2\right)$, enquanto beber vinho unicamente apresentou um RR de 2,1 (IC $95 \% 1,3-3,3)$.

No Brasil, SCHLECHT et al., 1999, relatando os resultados de um estudo caso controle de base hospitalar, descrevem que, para a mesma quantidade de consumo de etanol, maiores riscos estavam associados ao consumo de destilados $\left(6,9\right.$ para $>100 \mathrm{~kg}$ da bebida durante a vida, $1 \mathrm{C}_{95 \%}$ 2,8-17,1) e cachaça $\left(4,5\right.$ para $\left.101-500 \mathrm{~kg}, \mathrm{IC}_{95 \%} 2,2-9,0\right)$

FIORETTI et al. (1999), na Itália, investigaram os fatores de risco para o câncer oral em não fumantes, e verificaram que o consumo de bebida alcoólica, especialmente vinho, aumentou o risco em cerca de três vezes $\left(3,3 \mathrm{IC}_{95 \%}, 1,1-9,6\right)$.

A associação de tabaco e álcool com o câncer do trato aéreo digestivo tem sido ressaltada com freqüência, sendo possivel haver um efeito sinérgico nesta combinação (MARSHAL e BOYLE, 1996, LEITE e 
KOIFMAN, 1998). SCHLECHT et al., 1999, pesquisando o efeito conjunto do álcool e fumo, relatam evidências de interações para os cânceres de faringe, mas não para boca.

Apesar do consumo de bebidas alcoólicas estar declinando na maior parte dos paises desenvolvidos, observa-se aumento em muitos paises em desenvolvimento e em paises da Europa Central e Leste. Os homens dominam o consumo de bebida alcoólica nestes paises, e, na maioria das nações, apresentam um consumo maior que mulheres. No México e Panamá, a prevalência de consumo por adultos chega a ser duas vezes maior em homens (WHO, 2001). No Brasil, em todas as faixas etárias, a prevalência de uso de bebidas alcólicas, estimada em Levantamento realizado em 107 cidades com mais de 200 mil habitantes, foi maior em homens. Como exemplo, $86 \%$ de homens relataram uso de álcool, contra $68 \%$ de mulheres entre 25 a 34 anos (CARLINI et al, 2001). Ressalta-se que o consumo de bebidas alcoólicas entre jovens atualmente tornou-se comum, e está aumentando entre as mulheres. A iniciação ao consumo dá-se em uma idade inacreditavelmente jovem, cerca de 10 anos (WHO, 2001).

A produção de cerveja e de bebidas destiladas se concentra em poucas companhias, a maioria sediada em paises desenvolvidos. Com o declínio do consumo nos paises desenvolvidos, estas companhias intensificaram os esforços para estabelecer novos mercados consumidores, em especial em paises em desenvolvimento, procurando atingir especialmente mulheres e jovens, que tradicionalmente eram abstêmios, ou bebiam muito pouco, investindo pesadamente em propaganda (WHO, 2001) 
O Brasil é sede da quinta maior cervejaria do mundo, Brahma, e de sua concorrente, a Antártica, $12^{a}$ na posição global. O consumo de cerveja ultrapassou o de cachaça. O consumo de puro álcool per capita em adultos em 1996 era de aproximadamente 5 litros. O Ministério da Agricultura estima em 1 bilhão de litros a produção informal anual de pinga, o que eleva a estimativa de consumo para 8,6 litros (WHO, 2001)

Levantamento realizado em uma amostra probabilistica em 24 cidades do estado de São Paulo constatou que o álcool e o tabaco foram as drogas com maiores prevalências de uso, com $53,2 \%$ e $39,0 \%$, respectivamente. Quanto às estimativas de dependentes de álcool as porcentagens estiveram ao redor dos $6 \%$, valores próximos aos observados em estudos de outros paises (CARLINI et al. 2002)

LARANJEIRA e HINKLY, 2002, avaliaram a disponibilidade de álcool em uma região densamente povoada, no subúrbio do Município de São Paulo, conhecido pela violência. Em uma distância de $3,7 \mathrm{~km}$, foram identificados 107 pontos de venda de álcool, sendo a proporção de propriedades que vendiam álcool 1:12. Nesse estudo, a pinga foi a bebida preferida, em especial pelo seu baixo preço.

\subsubsection{Saúde oral}

A saúde oral tem sido associada à etiologia do câncer oral por vários estudos (GRAHAN et al., 1977; MARSAHLL et al. 1992; BLOT et al. 1983).

Individuos com problemas de dentição, como perda de dentes, dentes cariados, uso de próteses e higiene oral deficiente, apresentaram quatro 
vezes o risco de câncer oral que indivíduos com condições adequadas de dentição no estudo tipo caso controle conduzido por GRAHM et al., 1977.

No Brasil, FRANCO et al., 1989, verificaram que dentição deficiente e freqüência irregular de escovação dental eram relatadas com maior freqüência em casos que controles. No entanto, somente escovação deficiente se associou estatisticamente, aumentando o risco em duas vezes $\left(R R=2,3, I_{95 \%} 1,4-3,7\right)$, depois de ajustados por álcool e tabaco.

Dentição e dieta podem estar ligados na determinação do câncer oral, pois alimentação pode ter um impacto na saúde oral, e ao mesmo tempo, perda de dentes ou uso de prótese promovem uma imediata mudança nos hábitos dietéticos. Individuos nessa situação passam a evitar alimentos de textura rigida e que necessitam mastigação como vegetais crus determinadas frutas e certos cortes de carne (BLOT et al, 1996).

O uso de colutórios também foram associados ao câncer oral (WINN et al. 1991, WYNDER el al 1983, WINN et al. 1995, 2001). Porém, os estudos epidemiológicos não são consistentes (BLOT, 1983, KABAT et al., 1989, MASHBERG et al. 1985, MORSE et al., 1997) e não há evidências suficientes para concluir que haja aumento de risco com o uso destes produtos (ELMORE e HORWITZ, 1995). Pode-se adicionar que há um potencial fator de confusão, pois, enxaguadores bucais são freqüentemente utilizados para disfarçar o odor do tabaco e álcool. WINN et al., 2001, investigando o uso de colutórios e câncer oral, em um estudo caso-controle em Porto Rico, verificaram que não houve aumento de risco com a utilização deste produto, porém um excesso de risco, não significativo, foi observado 
entre os individuos que não fumavam nem usavam álcool, entre os quais, um efeito relacionado ao conteúdo alcoólico presente poderia ser mais evidente. Muitos colutórios contém álcool em sua composição, sendo esta a possivel explicação para o aumento de risco.

\subsubsection{Ocupação}

Individuos que ocupam postos em algumas atividades parecem apresentar excesso de risco para o câncer oral. Podem ser citados os trabalhadores de indústrias de madeira, instaladores de carpetes, operadores de máquinas, bombeiros, trabalhadores na industria de construção civil e têxtil (BLOT et al., 1996, WÜNSCH 2002). Trabalhos envolvendo oportunidade para consumo de álcool, como trabalhadores em bares ou indústrias de fabricação de bebidas são associados ao câncer oral (BLOT, 1996).

FRANCO et al., 1989, não encontraram associação entre ocupação e câncer oral, mas foi observado um aumento de risco para individuos expostos à fumaça de fogão a lenha.

\subsubsection{Outros fatores de risco}

Alguns virus têm sido relacionados com o câncer oral: papilovírus humano (HPV), virus Epstein-Barr e herpex simplex (BLOT et al. 1996). No entanto, para definir o verdadeiro papel dos vírus no câncer oral, é necessário ainda que mais pesquisas sejam conduzidas, considerando genótipos particulares e a interação com os fatores de risco conhecidos (WÜNSCH, 2002) 
Também o papel dos genes tem sido evidenciado na última década. A expressão do gene mutante p53 vem sendo freqüentemente associada ao câncer de boca como também a lesões pré-malignas (LEITE e KOIFMAN, 1998)

Vários estudos mostram a agregação familiar relacionada com o câncer oral. No entanto, segundo WÜNSCH, 2002, o maior problema deste tipo de estudo é separar a influência da hereditariedade e dos fatores ambientais compartilhados.

\subsubsection{Fatores associados à dieta}

Estudos etiopatogênicos sobre o câncer oral apontam para o papel protetor de certos elementos da dieta. Alguns destes compostos parecem bloquear a gênese do tumor em suas fases mais precoces, por exemplo, os compostos bioativos de frutas e vegetais, que induzem a ação das enzimas de detoxificação (WRCF, 1997). Outros compostos parecem agir no processo carcinogênico (MARSHALL e BOYLE, 1996; LEITE e KOIFMAN 1998), por meio, por exemplo, pela redução da geração de espécies reativas de oxigênio, que por sua vez podem causar danos no DNA (WRCF, 1997). É possivel que os efeitos preventivos da dieta sejam devido em parte do consumo dos nutrientes e dos componentes bioativos dos alimentos (KAMAT E LAMM 1999, WILLET 2000).

Segundo COHEN, 1987, os mecanismos propostos para explicar as associações entre a dieta, processos digestivos e o câncer incluem: carcinógenos naturais, contaminantes devido aos processos de cocção e 
conservação dos alimentos; ativação ou desativação metabólica dos carcinógenos induzidos pela dieta; formação biológica de carcinógenos in vivo, mediante a flora intestinal; estímulo ou inibição da carcinogênese devido a um desequilibrio nutricional que poderia alterar a imunidade, afetando a capacidade do organismo na resposta à agressão neoplásica.

Em um dos estudos pioneiros sobre dieta e câncer oral, WINDER et al., 1957, observaram um aumento do risco de câncer oral em mulheres com deficiência de ferro e anemia sideropênica, na chamada sindrome PlummerVinson ou Paterson-Keelly. Para estes autores, a dieta do grupo com a doença apresentava quase total ausência de carne e peixe frescos, vegetais verdes e frutas frescas, sendo elevada em leite, batatas, queijo e peixe salgado.

Desde então numerosos estudos epidemiológicos conduzidos em vários continentes investigam tanto alimentos quanto grupos de alimentos e nutrientes, e têm evidenciado o papel de fatores dietéticos no câncer oral. Os Quadros 1 e 2 sumarizam os principais resultados destes estudos. 
Quadro 1 - Estudos tipo coorte analisando a associação entre câncer oral e dieta 1990-2002.

\begin{tabular}{|c|c|c|c|c|c|c|c|c|}
\hline $\begin{array}{l}\text { Primeiro } \\
\text { Autorlano }\end{array}$ & local & $\begin{array}{c}\text { participantes } \\
\text { tempo de seguimento }\end{array}$ & covarlavels & $\begin{array}{c}\text { Coleta de } \\
\text { dados }\end{array}$ & Associação posittiva & $\mathbf{R R}$ & Associação negativa & $\overline{\mathrm{RR}}$ \\
\hline $\begin{array}{l}\text { Kjaerheim } \\
1998\end{array}$ & Noruega & $\begin{array}{l}10,960 \text { homens } \\
1968-1992 \\
\text { ( } 25 \text { anos } \\
71 \text { casos de cåncer de trato } \\
\text { gastro intestinal. }\end{array}$ & $\begin{array}{l}\text { Idade, - } \\
\text { frequiência } \\
\text { de consumo } \\
\text { de álcool. } \\
\text {-nivel de } \\
\text { consumo de } \\
\text { cigarros }\end{array}$ & $\begin{array}{l}\text { QFA } \\
32 \text { itens }\end{array}$ & $\begin{array}{l}\text { Feijäo } \\
\text { Tomates } \\
\text { Alface } \\
\text { Cenoura } \\
\text { Peixe processado } \\
\text { Peixe salgado } \\
\text { Carne processada } \\
\text { Canne bovina } \\
\text { Carne suina } \\
\text { Ovos }\end{array}$ & $\begin{array}{l}1,5 \\
1,7 \\
1,0 \\
1,9 \\
1,1 \\
1,2 \\
1,6 \\
2,8 \\
1,5 \\
1,1\end{array}$ & $\begin{array}{l}\text { Laranja } \\
\text { Maça } \\
\text { Bananas } \\
\text { Uvas } \\
\text { Batatas } \\
\text { Peixe fresco } \\
\text { pão }\end{array}$ & $\begin{array}{l}0,5^{*} \\
0,7 \\
0,7 \\
0,9 \\
0,5 \\
0,8 \\
0,2^{*}\end{array}$ \\
\hline Chyou 1995 & Havai /EUA & $\begin{array}{l}\text { - americanos com } \\
\text { ancestralidade japonesa } \\
\text { - } 1965 \text { a } 1968 \\
-8.006 \text { participantes } \\
\text { - } 93 \text { casos incidentes de } \\
\text { cáncer de célula escamosa } \\
\text { identificado }\end{array}$ & $\begin{array}{l}\text { Idade, } \\
\text { número de } \\
\text { cigarros/dia, } \\
\text { número de } \\
\text { anos de } \\
\text { fumo }\end{array}$ & $\begin{array}{l}\text { QFA } \\
23 \text { itens }\end{array}$ & $\begin{array}{l}\text { Arroz } \\
\text { Vegetais fritos } \\
\text { Picles } \\
\text { Peixe } \\
\text { embutidos } \\
\text { Manteiga, margarina, queijo } \\
\text { Ovos } \\
\text { Café } \\
\text { Chá verde } \\
\end{array}$ & $\begin{array}{l}1,43 \\
1,29 \\
1,13 \\
1,37 \\
1,24 \\
1,08 \\
1,33 \\
1,44 \\
1,14\end{array}$ & $\begin{array}{l}\text { Pão } \\
\text { Pastelarias } \\
\text { Carne } \\
\text { Leite } \\
\text { balas, gelatinas e } \\
\text { refrigerantes } \\
\text { Fruta } \\
\text { Chá preto }\end{array}$ & $\begin{array}{l}0,80 \\
0,78 \\
0,77 \\
0,70 \\
0,61 \\
0,65 \\
0,67\end{array}$ \\
\hline Zheng 1995 & $E \cup A$ & $\begin{array}{l}1986-1992 \\
34,691 \text { mulheres } \\
33 \text { câncer oral. }\end{array}$ & $\begin{array}{l}\text { Idade } \\
\text { fumo } \\
\text { Consumo de } \\
\text { energia }\end{array}$ & $\begin{array}{l}\overline{Q F A} \\
127 \text { itens }\end{array}$ & Carne processada e peixe & 1.3 & & \\
\hline
\end{tabular}

Em destaque: medidas com significado estatistico

* tendência estatisticamente significativa

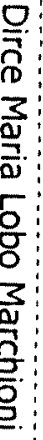




\begin{tabular}{|l|l|l|l|l|l|l|l|l|}
\hline \\
\hline
\end{tabular}

Em destaque:medidas com significado estatístico * tendência estatisticamente significativa 


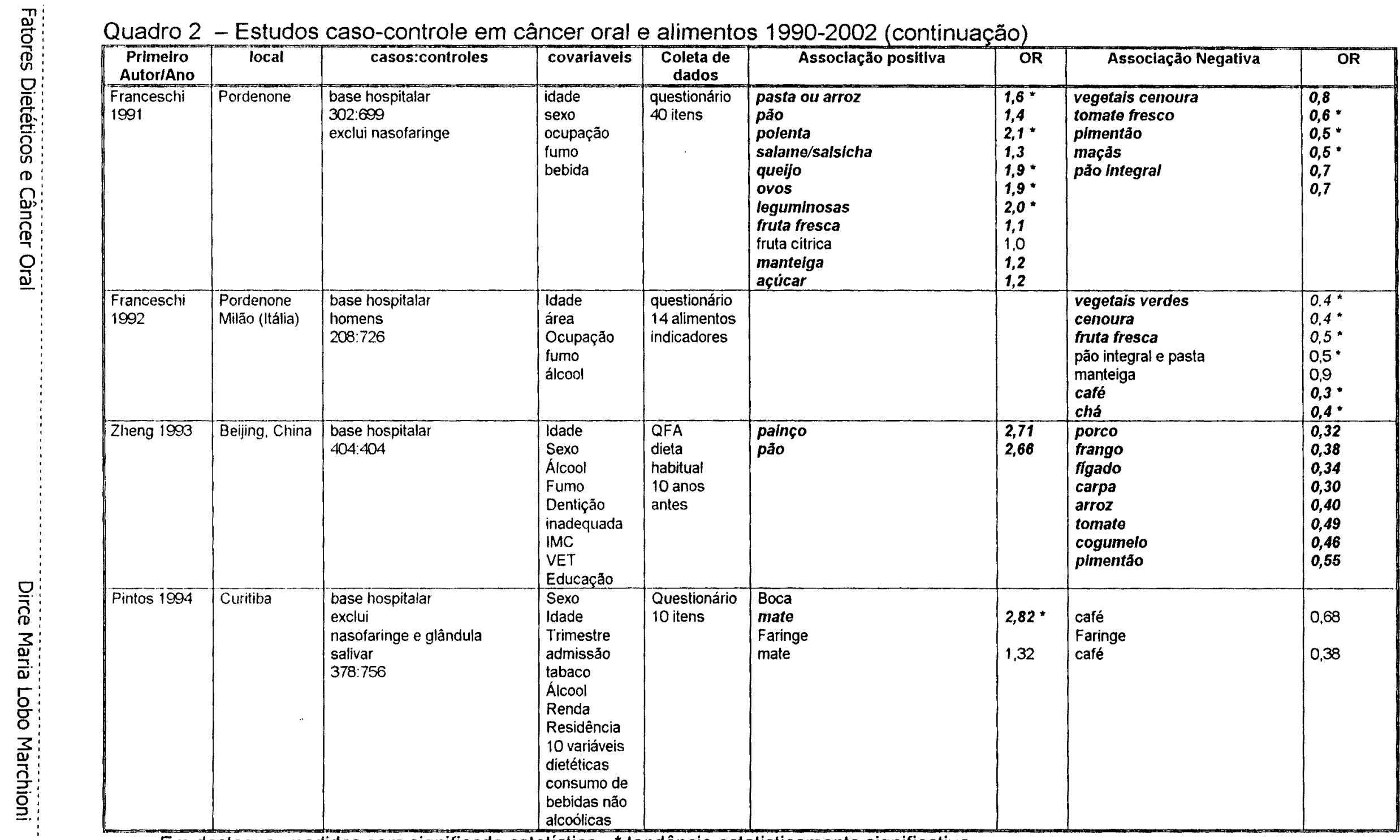

Em destaque: medidas com significado estatistico * tendência estatisticamente significativa 


\begin{tabular}{|c|c|c|c|c|c|c|c|c|}
\hline $\begin{array}{c}\text { Primeitro } \\
\text { Autor/Ano }\end{array}$ & Tocal & casos:controles & covariavels & \begin{tabular}{|c|}
$\begin{array}{c}\text { Coleta de } \\
\text { dados }\end{array}$ \\
\end{tabular} & Assoclaçăo positiva & OR & Assoclaçāo Negativa & or \\
\hline Rao 1994 & India & $\begin{array}{l}\text { base hospitalar } \\
\text { homens } \\
714: 635 \\
\text { exclui lingua e palato mole }\end{array}$ & $\begin{array}{l}\text { Idade } \\
\text { Residência } \\
\text { Fumo } \\
\text { Álcool } \\
\text { Educaçåo } \\
\end{array}$ & $\begin{array}{l}\text { questionário } \\
\text { vegetarianis } \\
\text { mo (sim/não) }\end{array}$ & nảo vegetarlano & $1,39^{*}$ & & \\
\hline \begin{tabular}{|l|} 
Esteve 1996 \\
Hipofaringe \\
Epifaringe
\end{tabular} & \begin{tabular}{|l|} 
Navarra \\
Zaragoza \\
(Espanha) \\
Calvados \\
(França) \\
Geneva \\
(Suiça) \\
Turin e \\
Varese \\
(ltália) \\
\end{tabular} & $\begin{array}{l}\text { base populacional homens } \\
\text { 399:3057 }\end{array}$ & $\begin{array}{l}\text { Lade } \\
\text { Local } \\
\text { status sócio } \\
\text { econômico } \\
\text { Álcool } \\
\text { Tabaco } \\
\text { Energia }\end{array}$ & \begin{tabular}{|l|} 
História \\
alimentar \\
70 itens
\end{tabular} & \begin{tabular}{|l|} 
fruta \\
frutas citricas \\
vegetais \\
peixe \\
óleo
\end{tabular} & $\begin{array}{l}, 84^{*} \\
2,20^{*} \\
\mathbf{1}, 64^{*} \\
1,27 \\
1,5\end{array}$ & $\begin{array}{l}\text { mantelga } \\
\text { carne processada }\end{array}$ & $\begin{array}{l}0,32^{*} \\
0,88\end{array}$ \\
\hline $\begin{array}{l}\text { Takezaki } \\
1996\end{array}$ & $\begin{array}{l}\text { Arclii, } \\
\text { Nagoya } \\
\text { Japãa }\end{array}$ & $\begin{array}{l}\text { base hospitalar } \\
265: 26669\end{array}$ & \begin{tabular}{|l|l|} 
Idade \\
Sexo \\
data da \\
consulta \\
fumo \\
álcool \\
\end{tabular} & questionário & & & $\begin{array}{l}\text { vegetais crus } \\
\text { fruta }\end{array}$ & $\begin{array}{l}0,5^{*} \\
0,5^{*}\end{array}$ \\
\hline Levi 1998 & Suiça & $\begin{array}{l}\text { base hospitalar } \\
156.284\end{array}$ & \begin{tabular}{|l} 
Idadad \\
Gênero \\
Educação \\
Fumo \\
Álcool \\
VET
\end{tabular} & $\begin{array}{l}\text { OFA } \\
79 \text { itens }\end{array}$ & \begin{tabular}{|l|} 
pão \\
sopa \\
ovos \\
carne vermelha \\
carne porco \\
queijo \\
batatas \\
doces e sobremesas \\
\end{tabular} & $\begin{array}{l}1,69 \\
1,42 \\
2,32 * \\
2,14 * \\
3,21 \\
1,19 \\
1,22 \\
1,02 \\
\end{array}$ & \begin{tabular}{|l|} 
leite \\
frango \\
pelxe \\
vegetals crus \\
vegetais cozidos \\
frutas citricas \\
outras frutas
\end{tabular} & $\begin{array}{l}0,38^{*} \\
0,92 \\
0,54 * \\
0,30^{*} \\
0,14^{*} \\
0,388^{*} \\
0,22 *\end{array}$ \\
\hline Rao 1998 & India & $\begin{array}{l}\text { base hospitalar } \\
\text { homens } \\
142: 635 \\
\text { lingua }\end{array}$ & $\begin{array}{l}\text { Idade } \\
\text { Residència } \\
\text { Fumo } \\
\text { Álcool } \\
\text { Educação }\end{array}$ & $\begin{array}{l}\text { questionário } \\
\text { vegetarianis } \\
\text { mo (sim/não) }\end{array}$ & $\begin{array}{l}\text { lingua- anterior } \\
\text { nâo vegetarlano }\end{array}$ & $1,74^{*}$ & $\begin{array}{l}\text { base língua } \\
\text { nâo vegetarlano }\end{array}$ & 0,59 * \\
\hline
\end{tabular}

Em destaque: medidas com significado estatístico * tendência estatisticamente significativa 


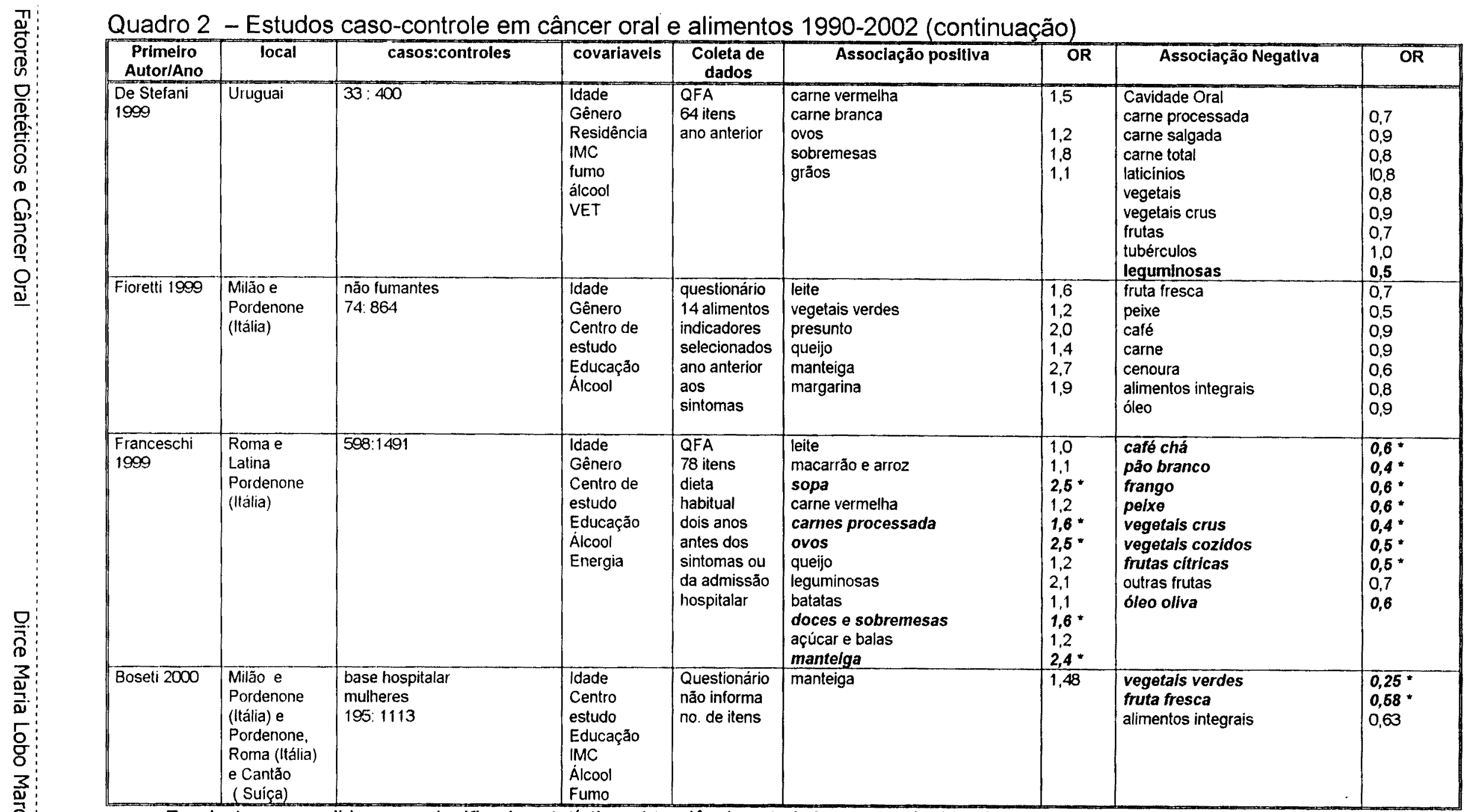

Em destaque: medidas com significado estatistico * tendência estatisticamente significativa 


\begin{tabular}{|c|c|c|c|c|c|c|c|c|}
\hline $\begin{array}{c}\text { Primeiro } \\
\text { AutoriAno }\end{array}$ & local & casos:controles & covarlavels & $\begin{array}{c}\text { Coleta de } \\
\text { dados }\end{array}$ & Assoclação positiva & OR & Associaçăo Negativa & OR \\
\hline Garrote 2001 & Cuba & $200: 200$ & \begin{tabular}{|l|} 
Idade \\
Sexo \\
Área de \\
residència \\
Educação \\
Fumo \\
álcool
\end{tabular} & $\overline{\mathrm{QFA}}$ & $\begin{array}{l}\text { logurte } \\
\text { Pão } \\
\text { Massas ou arroz } \\
\text { Pratos a base de milho } \\
\text { carne bovina } \\
\text { Peixe } \\
\text { embutidos } \\
\text { ovos } \\
\text { queijos } \\
\text { crucileras } \\
\text { leguminosas } \\
\text { maçăs ou peras } \\
\text { bolos e sobremesas } \\
\text { farináceos } \\
\text { alimentos de origem animal }\end{array}$ & $\begin{array}{l}1.16 \\
2.67 \\
1.43 \\
1.94 \\
2.18 \\
1.49 \\
2.03 \\
1.64 \\
1.85 \\
1.11 \\
1.49 \\
1.49 \\
1.0 \\
1.91 \\
2.00\end{array}$ & \begin{tabular}{|l} 
Leite \\
Batatas \\
Vegetais crús \\
Cenouras \\
Tomates \\
Suco de frutas \\
Frutas citricas \\
Banana \\
Vegetais \\
Frutas
\end{tabular} & $\begin{array}{l}0.72 \\
0.95 \\
0.89 \\
0.86 \\
0.63 \\
0.77 \\
0.78 \\
0.62 \\
0.78 \\
0.43\end{array}$ \\
\hline Tavani 2001 & Italia & $132: 148$ & $\begin{array}{l}\text { Sexo } \\
\text { idade } \\
\text { Educação } \\
\text { No. porçōes } \\
\text { fumo } \\
\text { álcool }\end{array}$ & $\begin{array}{l}\text { QFA } \\
25 \text { itens }\end{array}$ & doces & 2,31 & \begin{tabular}{|l|} 
Vegetais verdes \\
Folhosos \\
couve \\
Cenoura \\
Frutas \\
maçãs \\
Frutas \\
Peixe \\
\end{tabular} & $\begin{array}{l}0,37 \\
\mathbf{0 , 3 3} \\
0,67 \\
0,68 \\
\mathbf{0 , 3 4} \\
\mathbf{0 , 2 7} \\
0,72 \\
0,64 \\
\end{array}$ \\
\hline $\begin{array}{l}\text { Petridou } \\
2002\end{array}$ & Grécia & $\overline{106: 106}$ & $\begin{array}{l}\text { IMC } \\
\text { altura } \\
\text { educação } \\
\text { dentição } \\
\text { tabagismo } \\
\text { álcool } \\
\text { café } \\
\text { energia }\end{array}$ & $\begin{array}{l}\text { QFA } \\
110 \text { itens } \\
\text { (ano } \\
\text { anterior) }\end{array}$ & $\begin{array}{l}\text { açúcar e xaropes } \\
\text { vegetais } \\
\text { carne e produtos cárneos } \\
\text { Peixe e frutos do mar }\end{array}$ & $\begin{array}{l}1,25 \\
\mathbf{1 , 1 1} \\
1,2 \\
1,10\end{array}$ & $\begin{array}{l}\text { Cereals, farináreos e ralzes } \\
\text { grãos, nozes e sementes } \\
\text { Frutas } \\
\text { Leite e derivados } \\
\text { Lipidios adicionados }\end{array}$ & $\begin{array}{l}0,69^{*} \\
0,96 \\
0,99 \\
0,87 \\
0,85\end{array}$ \\
\hline
\end{tabular}

Em deslaque: medidas com significado estatístico "tendência estatisticamente significativa 


\subsubsection{Frutas e vegetais}

Especialistas reunidos pelo WORLD CANCER RESERCH FUND (WRCF 1997), baseados em estudos publicados sobre dieta, nutrição e etiologia do câncer oral, declararam que há evidências convincentes que dietas ricas em vegetais e frutas diminuem o risco de cânceres de boca e faringe. WINN, 1995, estima que dietas ricas em frutas promovem uma diminuição entre $20-80 \%$ no risco de câncer oral.

É possivel que dietas com elevado teor de vitamina C, provenientes de frutas e vegetais, possivelmente diminuam os riscos para cânceres nestes sitios. No entanto, estudos com outros componentes da dieta, tais como retinol, folato, vitamina $E$, mostram resultados conflitantes, de forma que ainda não há evidências consistentes para o estabelecimento de julgamentos confiàveis (WRCF, 1997).

O efeito protetor observado para o consumo freqüente de frutas é consistente nos estudos publicados, e com freqüencia apresenta um efeito dose-resposta (Quadros 1 e 2). Efeito estatisticamente significativo para frutas foi observado por GRIDLEY et al., 1990, ESTEVE et al., 1996, TAKEZAKI et al., 1996). Dentre as frutas, as citricas (ESTEVE et al., 1996, LEVI et al., 1998, FRANCESCHI et al., 1999) e frutas frescas (BOSETI et al., 2000) têm sido comumente associadas com decréscimo de risco para câncer oral. Da mesma forma, os vegetais parecem conferir proteção para o câncer oral. Foram observadas associações inversas para vegetais (GRIDLEY et al., 1990; OREGGIA et al., 1991; ESTEVE et al. 1996, DE 
STEFANI et al., 1999), vegetais verdes (GRIDLEY et al. 1990; FRANCESCHI et al., 1992; BOSETTI et al. 2000), vegetais crus (GRIDLEY et al., 1990, TAKEZAKI et al., 1996, LEVI et al., 1998, DE STEFANI et al., 1999, FRANCESCHI et al., 1999) e vegetais cozidos (LEVI et al., 1998, FRANCESCHI et al.,1999). GRIDLEY et al., 1990, verificaram uma associação inversa para cruciferas

Os vegetais freqüentemente observados como protetores foram: cenoura (FRANCESCHI et al.,1991, FIORETTI et al., 1999; BOSETTI et al., 2000), pimentão (FRANCESCHI et al., 1991, ZHENG et al., 1993) e tomate (FRANCESCHI et al., 1991, ZHENG et al., 1993).

No Brasil, FRANCO et al., 1989 observaram um efeito protetor significativo para consumo de vegetais ricos em carotenóides e frutas cítricas, mas não para vegetais verdes em geral.

Os possiveis mecanismos anticarcinogênicos das substâncias presentes em frutas e vegetais incluem efeitos antioxidantes; efeitos na diferenciação celular, aumento das enzimas que detoxificam carcinógenos, bloqueio da formação de nitrosaminas, preservação das matrizes intracelulares e manutenção da reparação normal do DNA (POTTER e STEINMETZ 1996). 


\subsubsection{Carne}

As evidências relacionando dietas ricas em carne e risco de câncer oral é inconsistente, segundo o WRCF, 1997. Este alimento foi relacionado com aumento do risco para câncer oral nos estudos de GARROTE et al, 2001 e UZCUNDUN et al, 2002. GRIDLEY et al., 1990 verificaram aumento de risco para mulheres, mas não para homens. As carnes vermelhas associaram-se positivamente ao câncer oral nos estudos de LEVI et al, 1998, DE STEFANI et al., 1999. Por outro lado, os consumos de frango e peixe associaram-se inversamente ao câncer oral em vários estudos (GRIDLEY et al., 1990, ZHENG et al., 1993, ESTEVE et al., 1996, LEVI et al., 1998; FIORETTI et al., 1999; FRANCESCHI et al., 1999, KJAERHEIM et al., 1998).

FRANCO et al., 1989 observaram um aumento do risco para o consumo freqüente de churrasco, hábito bastante difundido no sul do Brasil.

Os possiveis mecanismos pelos quais estes produtos apresentam estes efeitos não estão claros. É reconhecido que os métodos de cocção afetam o conteúdo de hidrocarbonetos aromáticos policiclicos, nos alimentos (FRANCO et al., 1989). As aminas heterocíclicas, formadas durante a cocção da carne são potentes agentes mutagênicos e carcinógenos em animais. Os seus niveis aumentam com o aumento da temperatura e duração da cocção, particularmente na carne bovina, com as maiores atividades mutagênicas observadas para frituras em frigideiras, grelhados e churrascos. 
As carnes processadas e carnes salgadas foram relacionadas com aumento de risco em vários estudos, tanto caso-controles quanto coortes: FRANCESCHI et al., 1991, ESTEVE et al., 1996, FIORETTI et al., 1999, FRANCESCHI et al., 1999; CHYOU et al., 1995, ZHENG et al., 1995, KJAERHEIM et al. 1998. No entanto, não está claro se os resultados podem ser atribuidos ao elevado conteúdo de sal ou nitrito ou à gordura saturada e colesterol presentes nestes produtos (FRANCESCHI et al., 1999).

\subsubsection{Alimentos básicos}

Em geral, todos os povos e culturas apresentam determinados pratos ou alimentos que são a base de sua alimentação. Por exemplo, os povos da América Central têm o milho, os asiáticos possuem o arroz e os europeus a batata e o trigo. Estes alimentos são em geral mais baratos, e, portanto, consumidos em maior escala pela população mais pobre e menos socialmente favorecida. Estudos epidemiológicos têm investigado a associação entre estes alimentos e o câncer oral.

FRANCESCHI et al., $(1991$, 1999), relataram consistentes e independentes aumentos de risco aparentemente derivados do elevado consumo de itens que representam importantes fontes de calorias na dieta tradicional do nordeste da Itália: alimentos a base de farinha de trigo, grãos, queijo e ovos. No entanto, observam-se resultados inconsistentes nos diversos estudos em relação a certos alimentos, como por exemplo. o pão. Este alimento foi observado protetor nos estudos de FRANCESCHI et al., 
1999, CHYOU et al., 1995, ZHENG et al., 1995, e promotor nos estudos de FRANCESCHI et al., 1991, ZHENG et al. 1993 e LEVI et al., 1998.

Em geral, estes achados são interpretados como indicadores não específicos de uma dieta monótona. A hipótese é que uma dieta mais variada, portanto, com maior conteúdo de vários nutrientes, pode ser protetora contra a carcinogênese oral. Individuos que consomem maior variedade de alimentos estariam provavelmente consumindo maior quantidade de compostos benéficos (LA VECHIA et al., 1997).

\subsubsection{Doces}

Os doces se associaram positivamente com o câncer oral nos estudos de FRANCESCHI et al., 1991 e FRANCESCHI et al., 1999. O consumo freqüente de substâncias ricas em açúcar, como balas, bolos e sobremesas podem estar correlacionadas com má higiene oral e com as conseqüências de uma dentição deficiente, tal como uma limitação no consumo de alimentos (BLOT et al, 1996, FRANCESCHI et al. 1999).

\subsubsection{Bebidas não alcoólicas}

O risco associado ao consumo de bebidas não alcoólicas, tais como chá e café foram investigados em vários estudos, com resultados contraditórios. Os resultados mais consistentes estão relacionados ao consumo de chimarrão. 
FRANCO et al., 1989, observaram excesso de risco para câncer oral em pessoas que consomem chimarrão, normalmente consumido em temperatura elevada, e câncer de cavidade oral. OREGGIA et al., 1991, no Uruguai, também observaram excesso de risco para consumo freqüente deste produto.

PINTOS et al., 1994, analisando dados de um estudo caso controle sobre câncer do trato aerodigestivo conduzido no sul do Brasil, concluíram que o consumo de mate pode estar relacionado a cerca de $20 \%$ de todos os casos que ocorrem nesta região brasileira.

\subsubsection{Padrões alimentares}

Tradicionalmente, a dieta tem sido estudada em termos dos nutrientes que compõem os alimentos. No entanto, deve-se ressaltar que os alimentos contêm outros compostos químicos, alguns conhecidos, alguns mal caracterizados e outros completamente desconhecidos, e, no momento, sem condições de serem medidos. Estes compostos compreendem macro e micronutrientes, aditivos, contaminantes agricolas e outros componentes naturais, como carotenóides e flavonóides. Além disso, os alimentos não são representados unicamente por seu conteúdo nutritivo. Como exemplo, iogurte e leite têm composição nutritiva semelhante, mas efeitos fisiológicos diferenciados. Além da complexa composição do alimento, a diversidade de combinações que podem ser feitas entre os alimentos na dieta pode fazer com que haja competição, antagonismo ou alteração da biodisponibilidade dos nutrientes. Do ponto de vista epidemiológico, a dieta representa um 
complexo conjunto de exposições, que estão altamente correlacionadas. Assim, a verdadeira relação entre um grupo de compostos do alimento e uma doença pode ser erroneamente atribuído a um único composto, devido à multicolinearidade existente entre nutrientes e alimentos (GORDON et al. 1984; WILLET, 2000).

ESTEVE et al., 1996, demonstraram que certos comportamentos alimentares podem diminuir o risco para o câncer de hipofaringe e laringe. Estes autores, em estudo multicêntrico tipo caso-controle conduzido na Europa, com um total de 1147 homens com câncer do trato aéreo-digestivo superior, verificaram que um alto consumo de frutas e hortaliças, óleo vegetal, peixe e baixo consumo de manteiga e produtos cárneos industrializados mostraram associação com redução de risco para câncer, depois de ajustados para álcool, fumo, status socioeconômico e energia proveniente de outras fontes que não o álcool.

FRANCESCHI et al., 1999, verificaram que casos tinham uma dieta significativamente mais rica em sopas, carne processada, ovos, bolos e sobremesas que os controles

De STEFANI et al., 1999, em estudo caso-controle conduzido no Uruguai, verificaram forte associação entre câncer do aparelho aéreo digestivo superior com carne vermelha e uma associação inversa entre para o consumo de frutas (OR 0,$\left.3 ; \mathrm{IC}_{95 \%}(\mathrm{OR})=[0,2 ; 0,6]\right)$, vegetais $(\mathrm{OR} 0,5 ; \mathrm{IC} 95 \%$ $(O R)=[0,3 ; 0,9])$ e leguminosas (OR 0,4; IC $95 \%(O R)=[0,3 ; 0,8])$. Para o câncer da cavidade oral, verificaram associação positiva entre carne vermelha (OR 
1,$\left.5 ; \operatorname{IC}_{95 \%}(\mathrm{OR})=[0,8 ; 3,1]\right)$, ovos $(\mathrm{OR} 1,8 ; \operatorname{IC} 95 \%(\mathrm{OR})=[1,0 ; 3.3])$ e relação inversa para o consumo de leguminosas (OR 0,5; IC $95 \%(O R)=[0,3 ; 0,9]$ ).

LEVI et al., 1998, em estudo caso-controle sobre dieta e câncer oral e de faringe, verificaram tendência significativa de aumento de risco para o consumo freqüente de ovos $(O R=2,32$ para 0 tercil mais alto $\left.I C_{95 \%}(O R)=[1,28 ; 4,22]\right)$, carne vermelha $\left(O R=2,14 I_{95 \%}(O R)=[1,15 ; 3,99]\right)$ e carne de porco mais carne processada $\left(\mathrm{OR}=3,21 \quad \mathrm{IC}_{95 \%}(\mathrm{OR})=[1,66 ; 6,24]\right)$., Risco inverso foi observado para leite $\left(O R=0,38 I_{95 \%}(O R)=[0,21 ; 0,70]\right.$ para o tercil mais alto), peixe $\left(O R=0,54 I_{95 \%}(O R)=[0,30 ; 0,96]\right)$, vegetais crus (OR $\left.=0,30 \quad \mathrm{IC}_{95 \%}(\mathrm{OR})=[0,16 ; 0,58]\right)$, vegetais cozidos $(\mathrm{OR}=0,14$ $\left.I C_{95 \%}(O R)=[0,07 ; 0,19]\right)$ frutas citricas $\left(O R=0,38 I_{95 \%}(O R)=[0,38 ; 0,73]\right) \mathrm{e}$ outra frutas $\left(O R=0,22 \mathrm{IC}_{95 \%}(\mathrm{OR})=[0,11 ; 0,44]\right)$. A adição de uma porção diária de frutas ou vegetais associou-se com redução de aproximadamente $50 \%$ no risco de câncer oral.

Uma opção para fazer as análises, levando em conta a complexidade de intercorrelações entre os alimentos, é o uso de análise de padrões. Esta abordagem utiliza as correlações entre a ingestão de alimentos ou nutrientes para descrever um padrão dietético geral, que, em uma etapa posterior, pode ser relacionado ao risco de doença. Esta abordagem tem particular valor se o efeito da dieta não for mediado por um ou dois nutrientes especificos, mas talvez operarem interativamente (RANDALL et al.1990, KANT 1996; WILLET 1998). 
Duas abordagens têm sido utilizadas para desenvolver um descritor geral do padrão dietético. A primeira abordagem, chamada "a priori", apoiase no conhecimento prévio de efeitos favoráveis ou desfavoráveis de vários constituintes da dieta (HAINES et al., 1999). A outra abordagem, "a posteriori', apoia-se nos dados dietéticos obtidos. A principal técnica para esta abordagem é a análise de componentes principais e subseqüentemente, analise fatorial (factor analysis), que exige modelagem estatística (TRICHOPOULOS e LAGIOU, 2001). O objetivo é transformar um grande conjunto de variáveis correlacionadas em um conjunto menor de variáveis não-correlacionadas, que são chamadas componentes principais. $\mathrm{Na}$ análise fatorial, ao invés de se arbitrar um indicador da dieta, os dados apontam objetivamente como as medidas se agregam. Busca-se com esta técnica identificar a estrutura subjacente à uma matriz de dados, reduzindo os dados para propiciar uma medida sintética da dieta. A análise fatorial deriva dimensões, que, quando interpretadas e compreendidas, descrevem os dados em um número muito menor de itens que as variáveis individuais (PEREIRA 2001; HAIR et al., 1995). 
justificativa 


\section{JUSTIFICATIVA}

Tendo em vista as peculiares caracteristicas da epidemiologia do câncer oral, com intensa variação na sua distribuição espacial e, no Brasil, elevadas taxas de incidência no municipio de São Paulo, este estudo se propõe a analisar a dieta, identificando fatores promotores e protetores relacionados à este tipo de câncer. Busca colaborar para a compreensão e determinação dos fatores ambientais que se associam ao câncer oral, e assim, contribuir para sua prevenção. Para atingir estes objetivos, foram utilizados dados obtidos em um estudo multicêntrico internacional, tipo casocontrole, conduzido sob a coordenação da IARC - Agência Internacional para Pesquisa de Câncer (BOFETTA et. al., 1998). 
objetivos 


\section{OBJETIVOS}

\subsection{OBJETIVO GERAL}

- Investigar o papel de fatores dietéticos no câncer oral.

\subsection{OBJETIVOS ESPECÍFICOS}

- Verificar a associação entre a freqüência de consumo de alimentos o câncer oral;

- Verificar a associação entre a freqüência de consumo de grupos de alimentos e o câncer oral;

- Verificar a existência de relação dose-resposta entre a freqüência de consumo de alimentos e de grupos de alimentos e o câncer oral. 
material e métodos 


\section{MATERIAL E MÉTODOS}

Este estudo utiliza os dados obtidos no "Estudo internacional de fatores ambientais, virus e câncer da cavidade oral e da laringe" Tratase de estudo multicêntrico, coordenado pela Agência Internacional para Pesquisas em Câncer (IARC), e teve por objetivo principal investigar fatores de risco para câncer da cavidade oral e da laringe. No Brasil, o estudo desenvolveu-se em cinco centros: São Paulo, Pelotas, Porto Alegre, Goiânia e Rio de Janeiro. O presente estudo utiliza os dados coletados em São Paulo. Nesta cidade, a coordenação esteve a cargo do Departamento de Epidemiologia da Faculdade de Saúde Pública da USP e do Departamento de Medicina Preventiva da Faculdade de Medicina da USP. Informações detalhadas sobre o desenho do estudo foram descritos em BOFETTA et al.. 1998.

\subsection{Delineamento}

Este estudo é do tipo caso-controle de base hospitalar.

\subsection{Casuistica}

Foram elegiveis para este estudo os pacientes residentes no Município de São Paulo, admitidos para internação ou em tratamento ambulatorial de câncer da cavidade oral nos 7 hospitais participantes do estudo: Hospital das Clínicas, Hospital São Paulo, Hospital AC Camargo, Instituto do Câncer Arnaldo Vieira de Carvalho (ICAVC), Hospital Heliópolis, Irmandade Santa Casa de Misericórdia de São Paulo e Instituto de 
Assistência Médica do Servidor Público Estatual (IAMSPE). Os controles foram selecionados entre pacientes destes hospitais.

\subsection{Definição de caso}

Selecionaram-se casos incidentes, ou seja, casos novos diagnosticados nos hospitais participantes a partir da data de início do estudo ou aqueles diagnosticados fora destes hospitais, porém encaminhados sem tratamento para a doença. Foram incluidos neste estudo os casos de câncer classificados com o código C00 a C14 (cavidade oral e orofaringe) de acordo com o CID-10 (OMS, 1995), com exceção dos casos classificados como $\mathrm{C} 00.0, \mathrm{C} 00.1, \mathrm{C} 00.2$, relativos ao lábio externo e $\mathrm{C} 11$ (nasofaringe). A exclusão destes últimos baseou-se na literatura, que postula que os cânceres nestes sitios não compartilham os mesmos fatores de risco.

\subsection{Definição de controle}

Os controles foram identificados a partir de pacientes internados ou em tratamento ambulatorial nos mesmos hospitais participantes do estudo, em especial nos hospitais gerais: Hospital das Clínicas, Hospital São Paulo, Hospital Heliopólis, Irmandade Santa Casa de Misericórdia e IAMSPE. Os controles foram pareados aos casos segundo sexo e idade (em quinquênios) pela distribuição esperada dos casos (pareamento por freqüência). Os controles não poderiam ter história ou suspeita de câncer de cavidade oral ou de laringe no presente ou passado. Pacientes admitidos no hospital por doenças associadas negativamente ou positivamente com os fatores de risco conhecidos ou suspeitos para câncer de cavidade oral ou laringe não 
foram incluídos no estudo. A lista completa destas doenças encontra-se no Anexo 1.

\subsection{Cálculo do Tamanho da Amostra}

Os cálculos da amostra para o presente estudo, foram feitos estimando-se uma prevalência de consumo de vegetais entre controles de 25\% (FRANCO et al., 1989) considerando um nivel de significância estatística (erro tipo I) de $5 \%$ e um poder estatístico $(1-\beta)$ de $80 \%$, supondo-se uma redução de risco de 40\%. O tamanho estimado foi de 371 casos e 371 controles (SCHLESSELMAN e STOLEY, 1982)

Foram inicialmente convidados a participar do estudo 1097 individuos. Destes, 41 recusaram-se a participar do estudo e 12 apresentaram condições físicas ou mentais que impossibilitaram a realização da entrevista. Quanto ao "status" no estudo, 607 eram potencialmente casos e 505 controles. Foram então excluidos os casos de câncer de laringe, com câncer em ambas as localizações, oral e laringe, bem como os individuos com câncer de nasofaringe, glândula salivar e lábios. Foi também excluído um indivíduo que não forneceu dados de consumo dietético. Assim, a amostra final compõe-se de 835 individuos, sendo 366 casos com confirmação histológica e 469 controles.

A figura 2 mostra através da representação gráfica a composição da amostra. 


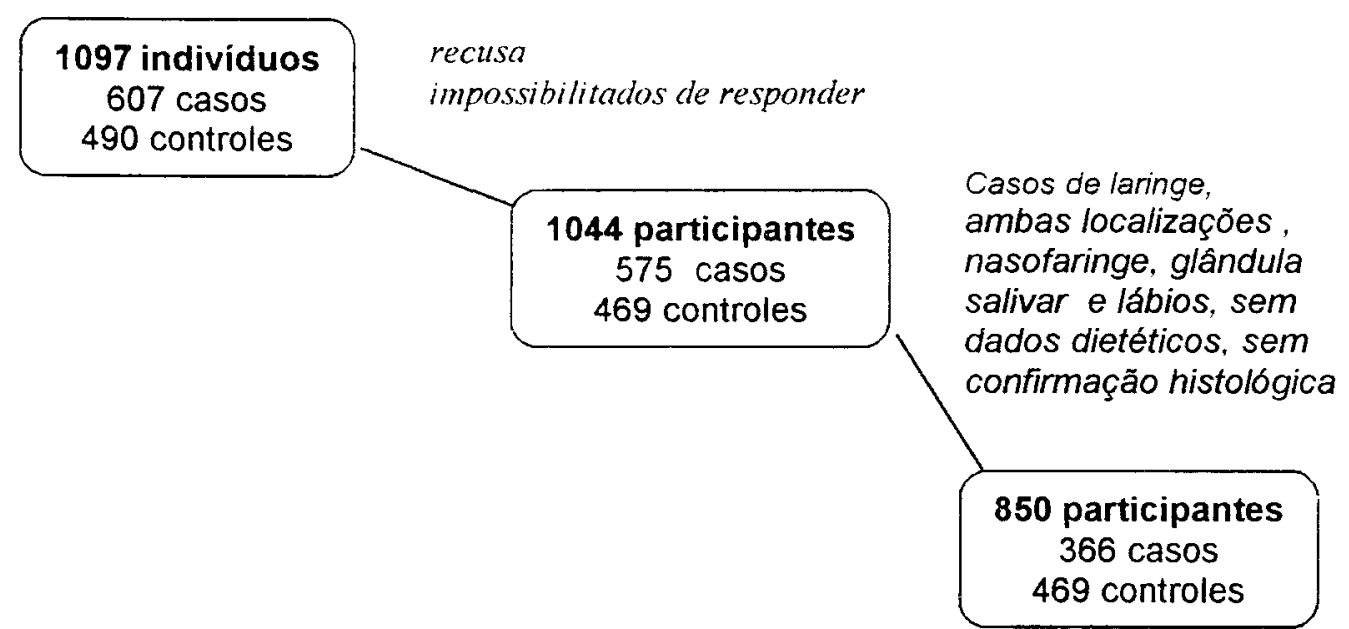

Figura 1. Indivíduos recrutados, excluídos e amostra final do estudo casocontrole. São Paulo, 1998-2002.

Dos indivíduos não participantes do estudo, 43 eram homens e 10 mulheres. Tanto para os potencialmente casos quanto para os potencialmente controles, não houve diferença estatisticamente significativa entre participantes e não participantes com relação à idade (respectivamente $p=0,311$ e $p=0,468)$ e distribuição quanto à sexo $(p=0,148$ e $p=0,258$, respectivamente).

\subsection{Coleta de dados}

O questionário foi desenvolvido para o estudo multicêntrico e inclui indicadores sócio-culturais, uma detalhada história ocupacional, condições de moradia, tabagismo, consumo de álcool e mate, história familiar de câncer, antecedentes de infecções selecionadas e um inquérito dietético que 
inclui questionário de freqüência alimentar. Os casos foram identificados e entrevistados antes do início do tratamento especifico da doença. A coleta dos dados iniciou-se em novembro de 1998 e encerrou-se em março de 2002.

O presente estudo utilizou os dados obtidos no inquérito dietético, dados sócio-demográficos, tabagismo e etilismo.

\subsection{Inquérito dietético}

O inquérito alimentar foi realizado por meio de um questionário de freqüência alimentar (QFA) semi-quantitativo (Anexo 2). A lista de alimentos do QFA possui 27 alimentos, grupos de alimentos ou preparações. Cada participante do estudo foi solicitado a responder, para cada item do QFA, com que média de freqüência semanal aquela quantidade do item alimentar era consumida, antes dos sintomas da doença surgirem. As respostas foram abertas, o que permitiu o tratamento desta variável como contínua. Segundo DE STEFANI et al., 1999, esta forma de relatar o consumo alimentar reflete com maior acurácia o consumo verdadeiro, ao invés de forçar a resposta em categorias pré-estabelecidas. Para cada item, a porção usual de consumo foi estabelecida. Dessa forma, o consumo de cada alimento ou grupo de alimentos foi medido por meio da freqüência de consumo informada. Para cada individuo, analisou-se o consumo semanal do item alimentar. Optou-se, devido ao limitado número de itens do QFA, bem como a impossibilidade de estimar o consumo de energia por este instrumento, em não se analisar o 
conteúdo de nutrientes. Assim, as análises foram focalizadas no consumo dos alimentos relatados e na identificação de grupos de alimentos.

\subsection{Definição dos grupos de alimentos}

Os 27 itens alimentares do QFA foram reagrupados, utilizando as abordagens "a priori" e "a posteriori", descritas a seguir

\subsubsection{Grupos de alimentos definidos "a priori"}

Os alimentos foram agrupados de acordo com a semelhança de conteúdo nutritivo ou composição botânica.

Os grupos foram:

- Cereais e derivados (pães, arroz e massas e milho)

- Raizes e tubérculos (mandioca, farinha de mandioca e batata);

- Laticinios (leite, iogurte e queijo)

- Carne vermelha (carne bovina e suína);

- Carne branca (carne de ave e peixe)

- Carne total (carne vermelha, carne branca e embutidos);

- Vegetais (salada crua, crucíferas, cenoura e tomate);

- Frutas (sucos de frutas, maçãs, banana e cítricos);

- Vegetais e frutas; 
- Alimentos básicos (cereais, raizes e tubérculos e leguminosas);

- Alimentos ricos em amido (cereais, raizes e tubérculos);

- Alimentos de origem animal (laticínios, ovos e carne total);

- Alimentos de origem vegetal (ricos em amido, vegetais e frutas);

A somatória das frequêencias de consumo dos alimentos de cada grupo, discriminou o consumo.

\subsubsection{Grupos de alimentos definidos "a posteriori"}

Nesta abordagem, os grupos de alimentos da dieta foram obtidos por análise fatorial exploratória, a partir dos itens alimentares do QFA.

\subsubsection{Análise fatorial}

A análise fatorial é um nome genérico dado a um método de análise estatística multivariada, que se aplica à identificação de fatores em um conjunto de medidas realizadas que corresponderiam a indicadores. Neste método, todas as variáveis são consideradas simultaneamente, cada uma relacionada com a outra.

As variáveis foram transformadas em seus respectivos logaritmos naturais, e, a seguir, para verificar a adequação do uso da análise fatorial, testou-se a uniformidade dos dados, examinando-se a distribuição das 
variáveis em um gráfico de dispersão, contrastando-se os valores observados e esperados numa distribuição normal (QQ plot).

Para extração dos fatores foi utilizada a análise de componentes principais. Este método estuda a distribuição espacial dos objetos, de forma a reconhecer agrupamentos e relações entre eles. O primeiro fator a ser extraido irá contar com o máximo da variância possivel no conjunto de dados. O segundo componente, independente do primeiro, explica o máximo possivel da variância restante, e assim sucessivamente, sendo que cada componente não está correlacionado aos outros (HAIR et al. 1995, KIM et al., 1978)

A determinação dos fatores a serem retidos baseou-se no gráfico de eigenvalues (scree plot), que é o gráfico de dispersão da variância total associada com cada fator (Figura 2)

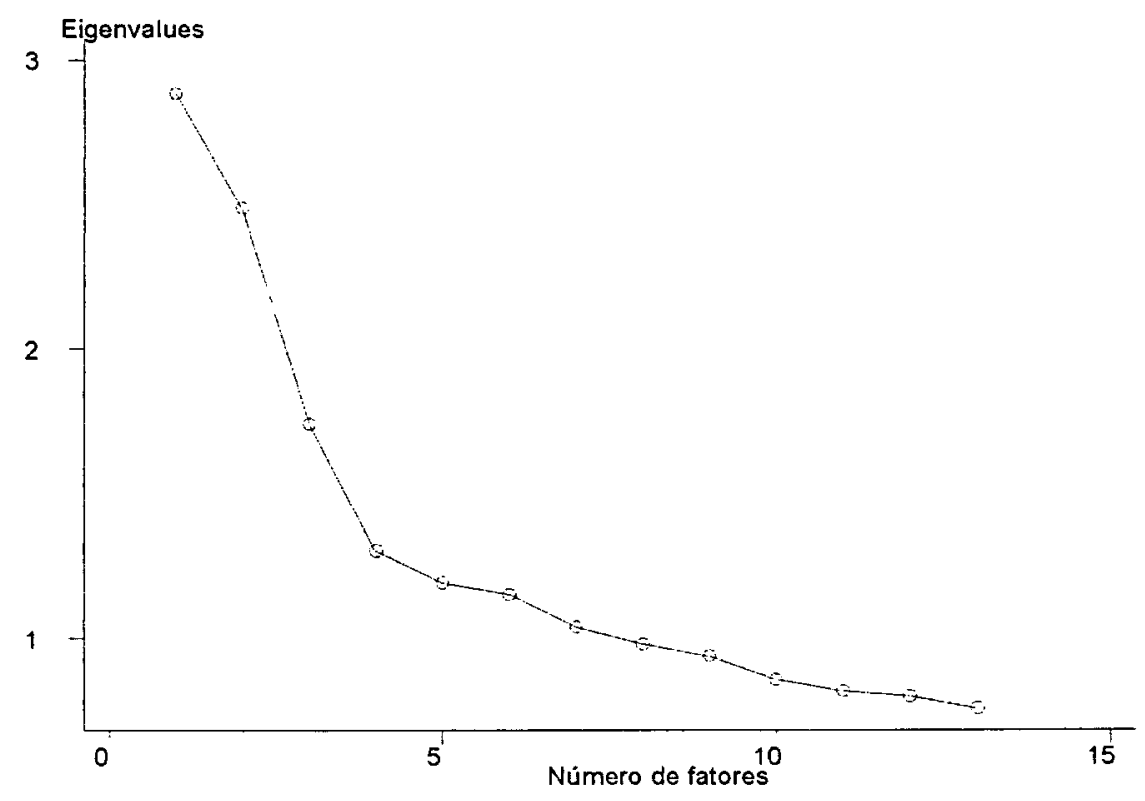

Figura 2 - Scree plot - Gráfico de dispersão dos valores de eigenvalues dos fatores retidos 
O eigenvalue é a medida de quanto da variância total das medidas realizadas pode ser explicada pelo fator. O eingenvalue avalia a contribuição do fator ao modelo construido pela análise fatorial, sendo que um valor pequeno sugere pouca contribuição do fator na explicação das variações das variáveis originais (PEREIRA, 1999). A prática comum é reter os fatores com eigenvalues maiores que 1,0 , indicando que cada fator retido descreve mais da variabilidade dos dados que uma variável original individualmente para o fator (HAIR et al., 1995). No entanto, optou-se por selecionar os fatores acima do ponto de inflexão da curva, pois estes correspondem aos fatores com maior variância conjunta, tendo sido retidos os fatores com eigenvalues maiores que 1,25 Dessa forma, limitou-se o número de fatores de modo a serem obtidos fatores com maior interpretabilidade e significado, em concordância o mesmo procedimento adotado por SLLATTERY et al., 1998 e SCHULZE et al., 2001.

Os fatores derivados por analise fatorial, respectivos eigenvalues e porcentagens de variância de cada fator e acumuladas podem ser observadas no Quadro 03. Os quatro primeiro fatores escolhidos representam $40 \%$ da variância total, ou seja, explicam juntos $40 \%$ das variações das medidas originais (PEREIRA 1999). 
Quadro 3 - Grupos de alimentos (fatores) derivados por analise fatorial, respectivos eigenvalues e porcentagens de variância e cumulativas

\begin{tabular}{|c|c|c|c|c|}
\hline Fator & Eigenvalue & Diferença & $\begin{array}{c}\% \\
\text { variância }\end{array}$ & $\begin{array}{l}\text { \% variância } \\
\text { acumulada }\end{array}$ \\
\hline 1 & 2,86350 & 0,37866 & 0,1364 & 0,1364 \\
\hline 2 & 2,48484 & 0,74529 & 0,1183 & 0,2547 \\
\hline 3 & 1,73956 & 0,43308 & 0,0828 & 0,3375 \\
\hline 4 & 1,30648 & 0,11252 & 0,0622 & 0,3997 \\
\hline 5 & 1,19396 & 0,03629 & 0,0569 & 0,4566 \\
\hline 6 & 1,15767 & 0,10762 & 0,0551 & 0,5117 \\
\hline 7 & 1,05005 & 0,07086 & 0,0500 & 0,5617 \\
\hline 8 & 0,97919 & 0,03764 & 0,0466 & 0,6083 \\
\hline 9 & 0,94155 & 0,08369 & 0,0448 & 0,6532 \\
\hline 10 & 0,85786 & 0,03882 & 0,0409 & 0,6940 \\
\hline 11 & 0,81904 & 0,02251 & 0,0390 & 0,7330 \\
\hline 12 & 0,79653 & 0,03665 & 0,0379 & 0,7710 \\
\hline 13 & 0,75988 & 0,04114 & 0,0362 & 0,8071 \\
\hline 14 & 0,71875 & 0,07341 & 0,0342 & 0,8414 \\
\hline 15 & 0,64534 & 0,02297 & 0,0307 & 0,8721 \\
\hline 16 & 0,62237 & 0,01799 & 0,0296 & 0,9017 \\
\hline 17 & 0,60438 & 0,04157 & 0,0288 & 0,9305 \\
\hline 18 & 0,56281 & 0,07546 & 0,0268 & 0,9573 \\
\hline 19 & 0,48735 & 0,07848 & 0,0232 & 0,9805 \\
\hline 20 & 0,40888 & 0,40888 & 0,0195 & 1,0000 \\
\hline 21 & 0,00000 & . & $-0,0000$ & 1,0000 \\
\hline
\end{tabular}

${ }^{*}$ os fatores destacados correspondem aos fatores retidos. 
Os factor loadings representam medidas da correlação entre os fatores derivados e as medidas originais. Dentro de um fator, loadings negativos indicam que o grupo de alimentos está negativamente correlacionado com o fator, enquanto loadings positivos indicam uma correlação positiva. Quanto maior o factor loading de um alimento, maior a contribuição do alimento para o fator, já que o quadrado do factor loading corresponde ao percentual da variância do item alimentar (variável original) que é explicada pelo fator.

Os factor loadings foram analisados após rotação. A rotação é uma ferramenta importante para interpretar os fatores. Esta operação permite obter uma estrutura mais simples, pela redistribuição da variância explicada entre os componentes individuais e, assim, aumentando o número de factor loadings mais altos e mais baixos. Após a rotação, em geral, obtém-se uma solução fatorial de mais fácil interpretação. Optou-se pela rotação ortogonal, na qual os eixos são mantidos em $90^{\circ}$, ou seja, cada fator é tratado como independente um do outro, considerando-se então que os fatores não estarão correlacionados. O método selecionado foi o VARIMAX(HAIR et al., 1995).

Factor loadings maiores que 0,25 foram considerados como contribuindo significativamente para o fator. Este critério foi adotado levandose em conta o tamanho da amostra, o número de variáveis que estavam sendo analisadas e o número de fatores (HAIR et al., 1995). Os factor loadings obtidos após a rotação, para as variáveis dietéticas selecionadas, 
utilizando-se os dados dos casos e controles participantes do estudo encontram-se no Quadro 04.

Quadro 04 - Matriz de factor loadings para casos e controles participantes do estudo. São Paulo, 1998-2002

\begin{tabular}{|c|c|c|c|c|c|}
\hline \multirow{3}{*}{ Variáveis } & \multicolumn{4}{|c|}{ Fatores } & \multirow[t]{3}{*}{ comunalidade } \\
\hline & 1 & 2 & 3 & 4 & \\
\hline & Prudente & Tradicional & Lanches & Monótono & \\
\hline \multirow{5}{*}{$\begin{array}{l}\text { leite } \\
\text { manteiga } \\
\text { pão } \\
\text { arroz e massas } \\
\text { carne bovina }\end{array}$} & 0,00 & $-0,04$ & 0,26 & $-0,48$ & 0,70 \\
\hline & $-0,10$ & 0,10 & 0,65 & $-0,22$ & 0,51 \\
\hline & $-0,10$ & 0,12 & 0,64 & $-0,27$ & 0,49 \\
\hline & 0,01 & 0,95 & 0,02 & $-0,02$ & 0,10 \\
\hline & 0,01 & 0,95 & 0,02 & $-0,02$ & 0,10 \\
\hline carne suina & $-0,03$ & 0,05 & 0,32 & 0,25 & 0,83 \\
\hline \multirow{2}{*}{$\begin{array}{l}\text { aves } \\
\text { embutidos }\end{array}$} & 0,25 & 0,21 & $-0,20$ & $-0,11$ & 0,84 \\
\hline & 0,24 & $-0,09$ & 0,48 & 0,26 & 0,63 \\
\hline \multirow{2}{*}{$\begin{array}{l}\text { ovos } \\
\text { queijos }\end{array}$} & 0,11 & 0,15 & 0,38 & 0,09 & 0,81 \\
\hline & 0,39 & $-0,17$ & 0,41 & 0,01 & 0,65 \\
\hline \multirow{2}{*}{$\begin{array}{l}\text { cruciferas } \\
\text { cenouras }\end{array}$} & 0,63 & $-0,02$ & $-0,10$ & 0,02 & 0,59 \\
\hline & 0,71 & $-0,08$ & $-0,06$ & $-0,10$ & 0,47 \\
\hline \multirow{2}{*}{$\begin{array}{l}\text { tomate } \\
\text { sucos }\end{array}$} & 0,59 & 0,02 & 0,11 & $-0,08$ & 0,63 \\
\hline & 0,35 & $-0,06$ & 0,22 & $-0,37$ & 0,69 \\
\hline \multirow{4}{*}{$\begin{array}{l}\text { maçã } \\
\text { banana } \\
\text { batata } \\
\text { vegetais crus }\end{array}$} & 0,41 & $-0,10$ & 0,11 & $-0,35$ & 0,68 \\
\hline & 0,10 & 0,10 & 0,07 & $-0,64$ & 0,57 \\
\hline & 0,41 & 0,14 & 0,16 & 0,27 & 0,71 \\
\hline & 0,57 & 0,12 & $-0,05$ & $-0,16$ & 0,63 \\
\hline \multirow{3}{*}{$\begin{array}{l}\text { frutas citricas } \\
\text { feijão } \\
\text { doces e } \\
\text { sobremesas }\end{array}$} & 0,18 & 0,09 & 0,18 & $-0,57$ & 0,61 \\
\hline & $-0,11$ & 0,65 & 0,11 & 0,02 & 0,56 \\
\hline & 0,08 & 0,11 & 0,44 & 0,01 & 0,79 \\
\hline $\begin{array}{l}\text { \% variância } \\
\text { explicada }\end{array}$ & 14 & 12 & 8 & 6 & \\
\hline $\begin{array}{l}\text { \% variância } \\
\text { cumulativa }\end{array}$ & 14 & 26 & 34 & 40 & \\
\hline
\end{tabular}

Foram sombreados os valores maiores que 0,25 , considerados contribuindo significativamente para o fator. 
O passo final da análise fatorial é a interpretação dos fatores, baseada na análise das correlações observadas na matriz fatorial rodada. No primeiro fator, contribuiram significativamente os vegetais, frutas, queijo e carne de aves. Este fator foi rotulado como prudente. O segundo fator denominou-se tradicional, pois os alimentos que contribuíram significativamente foram o arroz e massas, leguminosas e carne bovina. 0 terceiro fator caracterizou-se pela contribuição significativa de pães, manteiga, queijos, embutidos, ovos e carne suína, e foi nomeado como lanches. No quarto fator, poucos alimentos contribuíram: embutidos e batatas; no entanto, neste fator foram observadas correlações negativas com frutas e vegetais e alimentos lácteos, e foi, portanto, denominado monótono.

A seguir, foram computados os valores de escores (factor scores). Factor escores são medidas compostas estimadas para cada individuo em cada fator extraído na análise fatorial, e foram utilizados para representar os fatores nas análises subseqüentes (HAIR et al, 1995).

\subsection{Variáveis de estudo}

Foram consideradas no estudo:

4.9.1. Variável dependente: caso de câncer de cavidade oral e faringe A variável é dicotômica e apresenta-se como sim (caso $=1$ ) ou não (controle = 2). 


\subsubsection{Variáveis independentes}

\subsubsection{Variáveis de interesse:}

Freqüência de consumo de alimentos (porções por semana): leite, iogurte, manteiga, pão, macarrão ou arroz, pratos a base de milho (ex. polenta, creme de milho), mandioca, farinha de mandioca. carne bovina, carne suína, frango, peixe, embutidos, ovos, queijos, batata, vegetais crus e saladas, cruciferas, cenoura, tomate, feijão e leguminosas, suco de frutas, maçã ou pêra, frutas citricas, banana, bolos e doces. Estas variáveis foram categorizadas em tercis de freqüenncia de consumo da distribuição apresentada pelos controles.

Freqüência de consumo de grupos de alimentos definidos a priori (porções por semana): laticinios, cereais e derivados, raízes e tubérculos, carne total, carne vermelha, carne branca; carne total, vegetais, frutas, vegetais e frutas, alimentos básicos, alimentos ricos em amido, alimentos de origem animal e alimentos de origem vegetal. Também estas variáveis foram analisadas em tercis da freqüência do consumo de acordo com a distribuição da população de controles.

\section{Freqüência de consumo de grupos de alimentos definidos a posteriori} (escores): foram utilizados os grupos identificados através da análise fatorial dos alimentos. As análises foram feitas em tercis dos escores dos quatro fatores retidos: prudente, tradicional, lanche, monótono.

\subsubsection{Variáveis de confusão:}


Foram utilizadas as variáveis de pareamento do estudo, sexo e idade (BRESLOW e DAY,1980) e as variáveis já reconhecidas como fatores de risco: tabagismo e etilismo. Adicionalmente, foram selecionadas para a modelagem estatística outras variáveis possivelmente de confusão (KLEINBAUM et al., 1998): grau de instrução, região de nascimento, peso relatado dois anos antes da entrevista e o número total de porções dos itens alimentares consumidos.

A variável tabagismo foi mensurada levando-se em conta a experiência de fumo durante todo o período de vida, definido como a exposição cumulativa para o número de pacotes de cigarros consumidos diariamente (FRANCO et al., 1989): tabaco em maços $x$ ano (pack years). Foram considerados o consumo de cigarro, charuto e cachimbo. Considerou-se que $1 \mathrm{~g}$ de tabaco corresponde a um cigarro; 1 charuto a 4 cigarros e 1 cachimbo a 3 cigarros (IARC, 1986). Estabeleceu-se o consumo médio diário de pacotes de cigarro e multiplicou-se pelo número de anos como fumante.

Para o etilismo, considerou-se o consumo médio de álcool em gramas por dia. Assim, inicialmente transformou-se o consumo de bebidas relatado pelo individuo em gramas de álcool, utilizando-se a seguinte correspondência em gramas de álcool por litro: cerveja, $40 \mathrm{~g}$; vinho, $96 \mathrm{~g}$; cachaça, $328 \mathrm{~g}$ e licores, $240 \mathrm{~g}$ de álcool. (IARC, 1986).

O Quadro 05 apresenta os pontos de corte e categorias das variáveis de controle. 
Quadro 05 - Categorias e ponto de corte das variáveis de controle utilizadas na modelagem estatística.

\begin{tabular}{|c|c|}
\hline Variáveis de controle & categorias \\
\hline \multirow[t]{2}{*}{ sexo } & feminino * \\
\hline & masculino \\
\hline \multirow[t]{5}{*}{ Idade (anos) } & $<40^{*}$ \\
\hline & $401-50$ \\
\hline & $501-60$ \\
\hline & $601-70$ \\
\hline & $\geq 70$ \\
\hline \multirow[t]{5}{*}{ Consumo alcoólico médio $(\mathrm{g} / \mathrm{d})$} & Não bebe* \\
\hline & $0-40$ \\
\hline & $40-80$ \\
\hline & $80-120$ \\
\hline & $>120$ \\
\hline \multirow[t]{4}{*}{ Consumo de tabaco (maçoxano) } & $01-1$ * \\
\hline & $11-25$ \\
\hline & $251-50$ \\
\hline & $>=50$ \\
\hline \multirow[t]{3}{*}{ Nivel educacional } & Baixo (analfabeto) \\
\hline & Médio (ensino fundamental) \\
\hline & $\begin{array}{l}\text { Alto (ensino médio e } \\
\text { universitário)* }\end{array}$ \\
\hline \multirow[t]{3}{*}{ Macro região de nascimentos } & Norte, Nordeste e Centro Oeste ${ }^{\star}$ \\
\hline & Sul/sudeste \\
\hline & Estrangeiro \\
\hline Número de porções & tercil ${ }^{\star \star}$ \\
\hline $\begin{array}{l}\text { Peso dois anos antes da } \\
\text { entrevista }\end{array}$ & contínua \\
\hline
\end{tabular}




\subsection{Análise estatística}

Inicialmente foi utilizada a estatística descritiva (freqüência, medidas de tendência central e dispersão). A comparação de duas médias entre as variáveis contínuas foram feitas através do teste $t$ de Student. Quando as variáveis não atenderam os pressupostos de distribuição normal e homocedasticidade, foi utilizado o teste não paramétrico de Mann-Whitney.

\subsubsection{Medidas de Associação}

\section{Análise bruta}

A associação entre a variável dependente e as variáveis independentes foi verificada por meio do teste de associação pelo Quiquadrado.

\section{Análise múltipla ajustada}

Foi estimado o risco associado com o consumo de alimentos e grupos de alimentos, por meio do cálculo da Razão de Chances (Odds Ratio - OR). Utilizou-se regressão logística múltipla não condicional ajustada para calcular as estimativas por ponto e o Intervalo de Confiança de $95 \%$ (I ${ }_{95 \%}$ ) (HOSMER E LEMESHOW, 1989). 


\section{Modelagem estatistica}

Para a análise multivariada selecionaram-se as variáveis de controle cujos valores de $p$ (nivel de significância descritivo do teste) foram menores ou iguais a 0,20 na análise bruta. A seguir, estas variáveis foram introduzidas no modelo de regressão por meio do procedimento "stepwise" (KLEINBAUM et al., 1998). Foram mantidas no modelo as variaveis que permaneceram significativas depois do ajuste pelas outras variáveis. No entanto, apesar da variável educação não ter alterado nenhuma associação, optou-se por mantê-la no modelo, pois esta variàvel pode ser considerada um indicador de status social e econômico, e, portanto, importante fator na seleção dos alimentos para consumo. Foram ainda incorporadas no modelo estatístico as variáveis utilizadas no pareamento. Segundo BRESLOW e DAY (1980), estas variáveis devem ser incorporadas na análise como variáveis de confusão.

Foram testadas as interações (modificação de efeito) incluindo-se termos multiplicativos entre as variáveis do modelo e verificando-se seu significado estatístico (BRESLOW e DAY, 1980). Não foram observadas interações entre elas.

Assim, as estimativas de risco associadas às variáveis dietéticas estão ajustadas por sexo, idade, consumo de tabaco, consumo de álcool, peso relatado pelo individuo dois anos antes da entrevista, somatória do número de porções dos itens alimentares consumidos, macroregião de nascimento e educação (Quadro 5). 


\subsubsection{Efeito Dose-resposta}

Espera-se que a força de uma associação verdadeira aumente tanto com o aumento do nivel de exposição quanto com o aumento do tempo de exposição (BRESLOW e DAY, 1980). O efeito dose-resposta foi testado pelo teste $\chi^{2}$ para tendência linear, ajustado para o sexo, idade, tabagismo e etilismo (BRESLOW e DAY, 1980).

\subsubsection{Programa estatístico}

Todas as análises foram feitas no programa estatístico Intercolled STATA for Windows 98/95/NT.

\subsection{Aspectos éticos}

Este estudo foi analisado pelo Comitê de Ética em Pesquisa da Faculdade de Saúde Pública da USP (ofício COEP 070/01). O "Estudo Internacional sobre ambiente, virus e câncer de cavidade oral e de laringe", do qual foram retirados os dados, foi aprovado pela Comissão de Ética em Pesquisa - CONEP (Parecer n 004/99) e pelo Comitê de Ética em Pesquisa da FSPIUSP (Parecer $n^{\circ} 245 / 98$ ), conforme documentos apresentados no Anexo 03.

Conforme as normas éticas internacionais, cujos princípios são corroborados pela Norma Brasileira 196/96, é garantida a autodeterminação do sujeito da pesquisa (OPAS 1996). Para tal, antes da entrevista foi feito o esclarecimento da finalidade da pesquisa (Anexo 04). 
resultados 


\section{RESULTADOS}

\subsection{Descrição dos individuos participantes do estudo}

As caracteristicas demográficas e sociais dos participantes do estudo estão descritas na tabela 02.

Tabela 02 - Distribuição do número e porcentagem de casos e controles, segundo características sociais e demográficas, São Paulo, 1998-2002.

\begin{tabular}{|c|c|c|c|c|c|}
\hline \multirow[t]{2}{*}{ Variável } & \multicolumn{2}{|c|}{ Casos $(n=366)$} & \multicolumn{2}{|c|}{ Controles $(n=484)$} & \multirow{2}{*}{$\begin{array}{c}\text { Valor } \\
\text { p } \\
\left(\chi^{2}\right)\end{array}$} \\
\hline & $N^{\circ}$ & $\%$ & $N^{\circ}$ & $\%$ & \\
\hline \multicolumn{6}{|l|}{ Sexo } \\
\hline Homem & 310 & 84,7 & 370 & 78,9 & * \\
\hline Mulher & 56 & 15,3 & 99 & 21,1 & \\
\hline \multicolumn{6}{|l|}{ Idade (anos) } \\
\hline$<40$ & 19 & 5,2 & 40 & 8,5 & * \\
\hline $401-50$ & 93 & 25,4 & 102 & 21,7 & \\
\hline $501-60$ & 130 & 35,5 & 135 & 28,8 & \\
\hline $601-70$ & 84 & 23,0 & 118 & 25,2 & \\
\hline$\geq 70$ & 40 & 10,9 & 74 & 15,8 & \\
\hline \multicolumn{6}{|l|}{ Grau de Instrução ${ }^{\star \star}$} \\
\hline Analfabeto & 47 & 12,8 & 65 & 13,9 & 0,200 \\
\hline $\begin{array}{l}4 \text { primeiras séries do } 1^{\circ} \mathrm{Grau} \\
\text { (antigo primário) }\end{array}$ & 202 & 55,2 & 225 & 48,2 & \\
\hline $1^{\circ}$, Grau completo & 64 & 17,5 & 93 & 19,9 & \\
\hline $2^{\circ}, \mathrm{Grau}$ & 42 & 11,5 & 57 & 12,2 & \\
\hline Universitário & 11 & 3,0 & 27 & 5,8 & \\
\hline \multicolumn{6}{|l|}{ Região de nascimento*** } \\
\hline Norte & 1 & 0,3 & 1 & 0,3 & 0,21 \\
\hline Nordeste & 95 & 26,2 & 161 & 26,2 & \\
\hline Centro-oeste & 2 & 0,6 & 2 & 0,6 & \\
\hline Sudeste & 242 & 66,8 & 274 & 66,8 & \\
\hline Sul & 13 & 3,6 & 14 & 3,6 & \\
\hline Estrangeiro & 9 & 2,5 & 10 & 2,5 & \\
\hline
\end{tabular}

- variáveis de pareamento do estudo

* 3 individuos sem informação

*. 11 individuos sem informação 
A média de idade dos casos foi de $55,5(\mathrm{dp}=12,4)$ anos e a dos controles foi de $56.5(d p=10,9)$ anos, sem diferença estatistica $(p=0,247)$.

A média de anos em que os casos moravam na Grande São Paulo (34,2 $d p=17,4$ anos) não diferiu estatisticamente $(p=0,080)$ dos controles $(36,4$ $d p=17,3$ anos $)$

$\mathrm{Na}$ Tabela 03 , pode-se verificar a distribuição dos casos, em relação à localização do tumor, bem como o hospital de origem.

Tabela 03 -Distribuição do número e porcentagem dos casos segundo a localização do tumor e hospital de origem. São Paulo, 1998-2002.

\begin{tabular}{|c|c|c|c|c|c|c|c|c|}
\hline \multirow[t]{3}{*}{ Hospital } & \multicolumn{8}{|c|}{ Localização do Tumor } \\
\hline & \multicolumn{2}{|c|}{$\begin{array}{l}\text { Cavidade } \\
\text { oral }\end{array}$} & \multicolumn{2}{|c|}{ Orofaringe } & \multicolumn{2}{|c|}{ Hipofaringe } & \multicolumn{2}{|c|}{$\begin{array}{c}\text { Oral não } \\
\text { especificado }\end{array}$} \\
\hline & $n$ & $\%$ & $n$ & $\%$ & $n$ & $\%$ & $n$ & $\%$ \\
\hline H. Clinicas & 66 & 23,5 & 16 & 44,4 & 21 & 44,7 & 2 & 66,7 \\
\hline H. São Paulo & 20 & 7,1 & 3 & 8,3 & 5 & 10,6 & 0 & 0 \\
\hline ICAVC & 81 & 28,8 & 9 & 25,0 & 7 & 14,9 & 0 & 0 \\
\hline AC Camargo & 59 & 21,0 & 3 & 8,3 & 8 & 17,0 & 0 & 0 \\
\hline H. Heliopolis & 49 & 17,8 & 4 & 11,1 & 5 & 10,6 & 0 & 0 \\
\hline \multicolumn{9}{|l|}{ Irmandade } \\
\hline Santa Casa & 2 & 0,7 & 0 & 0 & 0 & 0 & 0 & 0 \\
\hline IAMSPE & 3 & 1,1 & 1 & 2,8 & 1 & 2,1 & 1 & 33,3 \\
\hline Total & 280 & 100,0 & 36 & 100,0 & 47 & 100,0 & 3 & 100,0 \\
\hline
\end{tabular}


A Tabela 4 apresenta a distribuição dos controles de acordo com o diagnóstico verificado.

Tabela-04 - Distribuição do número e porcentagem dos controles segundo diagnóstico, São Paulo, 1998-2002.

CID 10 - Código Internacional de Doenças - 10a . edição

\begin{tabular}{|c|c|c|c|c|}
\hline Capitulo & códigos & Descrição & $\bar{n}$ & $\%$ \\
\hline T & A00-B99 & Doenças infecciosas e parasitárias & 21 & 4,5 \\
\hline II & C00-D48 & Neoplasmas & 66 & 14,1 \\
\hline III & D50-D89 & $\begin{array}{l}\text { Doenças do sangue e órgão } \\
\text { formadores do sangue e doenças } \\
\text { imunitárias }\end{array}$ & 8 & 1,7 \\
\hline IV & E00-E90 & $\begin{array}{l}\text { Doenças endócrinas, metabólicas e } \\
\text { nutricionais. }\end{array}$ & 12 & 2,6 \\
\hline V & F00-F99 & Desordens mentais & 1 & 0,2 \\
\hline VI & G00-G99 & Doenças do sistema nervoso & 5 & 1,1 \\
\hline VII & $\mathrm{H} 00-\mathrm{H} 59$ & Desordens dos olhos e anexos & 3 & 0,6 \\
\hline VIII & $\mathrm{H} 60-\mathrm{H} 95$ & $\begin{array}{l}\text { Doenças das orelhas e processo } \\
\text { mastóide }\end{array}$ & 3 & 0,6 \\
\hline$X I X$ & $100-199$ & Doenças do sistema circulatório & 101 & 21,4 \\
\hline$x$ & J00-J99 & Doenças do sistema respiratório & 10 & 2,1 \\
\hline$X I$ & K00-K93 & Doenças do sistema digestivo & 114 & 24,4 \\
\hline XII & LOO-L99 & $\begin{array}{l}\text { Doenças da pele e dos tecidos } \\
\text { subcutâneos }\end{array}$ & 8 & 1,7 \\
\hline XII & M00-M99 & $\begin{array}{l}\text { Doenças do sistema músculo- } \\
\text { esquelético e tecido conectivo }\end{array}$ & 31 & 6,6 \\
\hline XIV & NOO-N99 & Doenças do sistema genito-urinário & 44 & 9,4 \\
\hline XV & Q00-Q99 & $\begin{array}{l}\text { anomalias congênitas, anomalias } \\
\text { cromossômicas e deformidades }\end{array}$ & 2 & 0,4 \\
\hline$X I X$ & SOO-T98 & $\begin{array}{l}\text { Injúria e envenenamento e outras } \\
\text { conseqüências de causas externas }\end{array}$ & 40 & 8,6 \\
\hline
\end{tabular}


A média, desvio padrão e os testes estatísticos para o peso relatado dois anos antes da entrevista por casos e controles, levando-se em conta o sexo pode ser observada no Quadro 06. Observou-se que, entre os homens, os casos apresentaram menor peso médio $(p<0,001)$. Entre as mulheres. não se observou diferença significativa estatisticamente entre casos e controles $(p=0,381)$.

Quadro 06 - Média, desvio padrão e valor do p para os testes estatísticos para a variável "peso dois anos anteriores à entrevista", relatada por casos e controles. São Paulo, 1998-2002.

\begin{tabular}{|ccccccccc|}
\hline Sexo & \multicolumn{3}{c}{ controles } & \multicolumn{5}{c|}{ casos } \\
& $\mathrm{n}$ & $\begin{array}{c}\text { média } \\
(\mathrm{kg})\end{array}$ & $\begin{array}{c}\mathrm{dp} \\
(\mathrm{kg})\end{array}$ & $\mathrm{n}$ & $\begin{array}{c}\text { média } \\
(\mathrm{kg})\end{array}$ & $\mathrm{dp}$ & $\mathrm{p}$ \\
& & $(\mathrm{kg})$ & \\
\hline homem & 361 & 72,1 & 14,64 & 298 & 66,2 & 11,9 & $<0,001^{*}$ \\
mulher & 94 & 63,0 & 15,28 & 53 & 60,4 & 11,9 & $0,286^{\star \star}$ \\
\hline
\end{tabular}

\subsection{Caracterização dos Fatores de Risco reconhecidos}

\subsubsection{Tabaco}

Na Tabela 04 apresenta-se a distribuição de casos e controles segundo as variáveis relacionadas ao consumo de tabaco. Observa-se que a proporção de individuos que relatam uso de charutos, cachimbos e maconha foi pequena na população de estudo. Há maior proporção de fumantes entre os casos em relação aos controles, como era esperado. Observou-se diferença estatisticamente significativa em relação ao período de tempo como fumante $r$ entre os casos que entre os controles $(p<0,001)$. 
Tabela 05 - Distribuição do número e porcentagem de casos e controles segundo as variáveis relacionadas ao consumo de tabaco. São Paulo, 19982002.

\begin{tabular}{|c|c|c|c|c|c|}
\hline \multirow[b]{2}{*}{ Variável } & \multicolumn{2}{|c|}{ Controles } & \multicolumn{2}{|c|}{ Casos } & \multirow[t]{2}{*}{ Valor $p^{*}$} \\
\hline & $\mathrm{n}$ & $\%$ & $\mathrm{n}$ & $\%$ & \\
\hline
\end{tabular}

\section{Cigarros}

Nunca fumou

Fumou no passado

Fumante

Charuto

Nunca fumou

Fuma ou fumou

Maconha

Nunca fumou

Fuma ou fumou

\section{Consumo de Tabaco} (maçoxano)

$$
\begin{aligned}
& 01-1 \\
& 11-25 \\
& 251-50 \\
& >=50
\end{aligned}
$$

\section{Periodo como fumante (anos)}

\begin{tabular}{lr}
$01-25$ & 219 \\
$25 I-35$ & \\
$>=35$ & 144 \\
\hline$\chi^{2}$
\end{tabular}

$\begin{array}{rrrrr}135 & 28,8 & 18 & 4,9 & <0,001 \\ 160 & 34,1 & 67 & 18,3 \\ 174 & 37,1 & 280 & 76,7\end{array}$

452

$\begin{array}{llll}97,4 & 348 & 95,3 & 0,107\end{array}$

$\begin{array}{llll}12 & 2,6 & 17 & 4,7\end{array}$

$\begin{array}{lrrrr}453 & 97,7 & 348 & 95,3 & 0,070 \\ 11 & 2,3 & 17 & 4,7 & \end{array}$

$\begin{array}{rrrrr}142 & 31,2 & 20 & 5,6 & <0,001 \\ 140 & 30,8 & 100 & 27,9 & \\ 118 & 25,9 & 142 & 39,7 & \\ 55 & 12,1 & 96 & 26,8 & \end{array}$

$\begin{array}{lllll}219 & 48,1 & 64 & 17,9 & <0,001 \\ 90 & 19,8 & 104 & 29,0 \\ 44 & 32,1 & 190 & 53,1\end{array}$

Bibiotacascir

FRCULDADE DE SALUOE PÚBLICA UNIVERSIDADE DE ST̃O PAUKO 


\subsubsection{Consumo de bebidas}

$\mathrm{Na}$ Tabela 05 pode-se observar como se distribuem os casos e controles em relação às variáveis relacionadas ao consumo de bebidas alcoólicas. Observa-se que tanto a proporção de indivíduos que relatam consumir bebidas alcoólicas correntemente quanto o consumo médio de álcool por dia é significativamente maior entre casos que entre controles.

Tabela 06 - Distribuição de casos e controles segundo as variáveis relacionadas ao consumo de bebida alcoólica. São Paulo, 1998-2002.

\begin{tabular}{|c|c|c|c|c|c|}
\hline \multirow[b]{2}{*}{ Variável } & \multicolumn{2}{|c|}{ Controles } & \multicolumn{2}{|c|}{ Casos } & \multirow{2}{*}{$\begin{array}{c}\text { Valor } \\
p^{*}\end{array}$} \\
\hline & $\mathrm{N}^{0}$ & $\%$ & $\overline{N^{0}}$ & $\%$ & \\
\hline \multicolumn{6}{|l|}{ Bebida alcoólica } \\
\hline Nunca bebeu & 142 & 30,3 & 26 & 7,1 & $<0,001$ \\
\hline Bebeu no passado & 180 & 38.5 & 151 & 41,0 & \\
\hline Bebe correntemente & 146 & 31,2 & 190 & 51,9 & \\
\hline \multicolumn{6}{|l|}{$\begin{array}{l}\text { Consumo alcoólico } \\
\text { médio(g/d) }\end{array}$} \\
\hline Não bebe & 142 & 30.9 & 26 & 7,1 & $<0,001$ \\
\hline $0,011-40$ & 174 & 37,9 & 112 & 30,8 & \\
\hline $401-80$ & 62 & 13,5 & 70 & 19,2 & \\
\hline $801-120$ & 27 & 5,9 & 46 & 12,7 & \\
\hline$\geq 120$ & 54 & 11,7 & 110 & 30,2 & \\
\hline
\end{tabular}

O consumo de chimarrão, fator reconhecido como de risco para o câncer oral, foi pequeno na população estudada e não diferiu estatisticamente entre casos e controles (Tabela 06). 
Tabela 07- Distribuição do número e porcentagem de casos e controles segundo consumo de chimarrão. São Paulo, 1998-2002.

\begin{tabular}{|c|c|c|c|c|c|}
\hline \multirow[t]{2}{*}{ Chimarrão } & \multicolumn{2}{|c|}{ Controles } & \multicolumn{2}{|c|}{ Casos } & \multirow{2}{*}{$\begin{array}{c}\text { Valor } \\
p^{\star}\end{array}$} \\
\hline & $N^{\circ}$ & $\%$ & $N^{\circ}$ & $\%$ & \\
\hline Nunca & 436 & 93,6 & 328 & 90,9 & 0,208 \\
\hline Só no passado & 22 & 4,7 & 27 & 7,5 & \\
\hline Bebe correntemente & 8 & 1,7 & 6 & 1,6 & \\
\hline
\end{tabular}

\subsection{Caracterização das variáveis de consumo alimentar}

Na Tabela 07 estão descritas as freqüências médias de consumo dos itens alimentares que foram questionados, bem como o teste estatístico não paramétrico para comparação das mesmas.

Observou-se que os alimentos com maior freqüência média de consumo, tanto entre casos quanto entre controles, foram o arroz e massas e as leguminosas. Em contrapartida, peixes e pratos à base de milho apresentam 0 menor consumo médio.

Os casos diferiram estatisticamente dos controles em relação ao consumo de manteiga, pão, carne suina, ovos, batatas, vegetais crus, leguminosas, suco de frutas, frutas citricas e maçãs (Tabela 07). 
Tabela 08- Caracterização da freqüência de consumo de alimentos entre casos e controles. São Paulo, 1998-2002.

\begin{tabular}{|c|c|c|c|c|c|c|}
\hline \multirow{2}{*}{ Alimentos } & & \multicolumn{3}{|c|}{ Controles } & Casos & \multirow[t]{2}{*}{$p^{*}$} \\
\hline & & $n^{\circ}$ & $\begin{array}{c}\text { Média (dp) } \\
\text { porçōes/sem }\end{array}$ & $\pi^{\circ}$ & $\begin{array}{l}\text { Média (dp) } \\
\text { porçōes/sem }\end{array}$ & \\
\hline Leite & 1 copo & 482 & $6,9(6,3)$ & 366 & $7,0(9,2)$ & 0.060 \\
\hline logurte & 1 pote & 481 & $0,59(0,02)$ & 366 & $0,43(0.02)$ & $<0.001$ \\
\hline Manteiga & 1 colher chá & 482 & $6,0(6,2)$ & 366 & $4,9(5,5)$ & $<0,001$ \\
\hline Pão & 1 unidade $50 \mathrm{~g}$ & 482 & $7,9(5,6)$ & 365 & $7,4(6,2)$ & 0,013 \\
\hline Arroz e massas & 4 colneres & 482 & $12,5(5,8)$ & 365 & $12,7(6,6)$ & 0,982 \\
\hline Pratos e milho & 1 prato fundo & 481 & $0,98(1,3)$ & 364 & $1,2(1,8)$ & 0.691 \\
\hline Mandioca & 1 pedaço médio & 476 & $2,4(4,1)$ & 363 & $2,4(4,2)$ & 0,235 \\
\hline Carne bovina & 1 pedaço médio & 482 & $4,4(3,4)$ & 364 & $4,5(3,4)$ & 0,745 \\
\hline Carne suina & 1 pedaço médio & 482 & $0,6(1,0)$ & 365 & $0,7(1,5)$ & 0,031 \\
\hline Frango & 1 pedaço médio & 482 & $2.8(2,3)$ & 365 & $2,6(2,3)$ & 0,105 \\
\hline Peixe & 1 pedaço médio & 481 & $0,9(0,9)$ & 365 & $0,8(0,9)$ & 0,234 \\
\hline Embutidos & 2 fatias & 481 & $1,2(1,7)$ & 365 & $1,4(2,0)$ & 0,401 \\
\hline Ovos & 1 unidade & 482 & $2,1(2,5)$ & 364 & $2,7(2,8)$ & $<0,001$ \\
\hline Queijo & 2 fatias & 482 & $2,0(2,4)$ & 366 & $2,0(2,9)$ & 0,167 \\
\hline Batata & 1 unidade & 482 & $2,3(1,9)$ & 366 & $2,9(2,5)$ & $<0,001$ \\
\hline Vegetais crus & $\begin{array}{c}1 \text { prato } \\
\text { sobremesa }\end{array}$ & 482 & $5,6(4,1)$ & 365 & $4,4(3,6)$ & $<0,001$ \\
\hline Cruciferas & $\begin{array}{c}1 \text { prato } \\
\text { sobremesa }\end{array}$ & 481 & $1,7(2,2)$ & 365 & $2,0(2,4)$ & 0,159 \\
\hline Cenoura & 1 unidade média & 482 & $1,9(2,3)$ & 364 & $1,8(2,2)$ & 0,057 \\
\hline Tomate & 1 pequeno & 482 & $3,1(2,9)$ & 366 & $2,9(3,0)$ & 0,382 \\
\hline Feijão & 4 colheres & 482 & $10,9(5,9)$ & 364 & $9,9(4,9)$ & 0,013 \\
\hline Suco de frutas & 1 copo & 482 & $3,7(3,9)$ & 366 & $3,4(4,4)$ & 0,005 \\
\hline Maçãs & 1 média & 482 & $1,7(2,3)$ & 365 & $1,4(2,1)$ & $<0,001$ \\
\hline Frutas citricas & 1 média & 482 & $5,3(7,1)$ & 364 & $4,1(6,2)$ & 0,001 \\
\hline Banana & 1 unidade média & 482 & $4,2(4,6)$ & 364 & $4,1(5,8)$ & 0,117 \\
\hline Doces e bolos & 1 fatia ou taça & 482 & $2,1(2,7)$ & 365 & $2,1(2,9)$ & 0,051 \\
\hline
\end{tabular}




\subsection{Associação entre fatores dietéticos e câncer oral}

A seguir são apresentados os resultados das análises brutas e múltiplas para os fatores dietéticos e o câncer oral, primeiramente para os alimentos, como se apresentam no questionário, e, a seguir, agrupados em categorias definidas a priorie a posteriori.

\subsubsection{Alimentos}

O consumo de leite, iogurte e manteiga (Tabela 9) foram fatores protetores na análise univariada. Após o ajuste pelos fatores de risco reconhecidos ou fatores de confusão potenciais, o consumo de manteiga se manteve como fator de proteção, porém, observou-se que o mais alto tercil de consumo de leite, correspondente à mais que 7 porções semanais, associou-se positivamente ao câncer oral. Inesperadamente (Tabela 09).

$\mathrm{Na}$ análise dos alimentos que são fontes de carboidratos simples e complexos (Tabela 10), verificou-se que, independente dos fatores de risco reconhecidos ou fatores de confusão potenciais, o consumo no segundo tercil (14 porções por semana) de arroz e massas mostrou-se como fator de proteção, enquanto o consumo de batatas associou-se positivamente com 0 câncer oral, além deste alimento também apresentar tendência significativa para aumento de risco de acordo com o aumento do consumo.

Não se observou associação entre o consumo de carne, quer bovina ou de outro animal, e o câncer oral (Tabela 11). No entanto, o consumo de ovos apresentou-se como fator de risco, mesmo após o ajuste da estimativa pelos 
fatores de controle, apresentando ainda tendência de aumento de risco com o aumento dos niveis de exposição significativa estatisticamente.

O consumo de feijão, bem como o consumo de vegetais crus, associaram-se negativamente e apresentaram tendência significativa para maior proteção quanto maior o consumo (Tabela 12). 


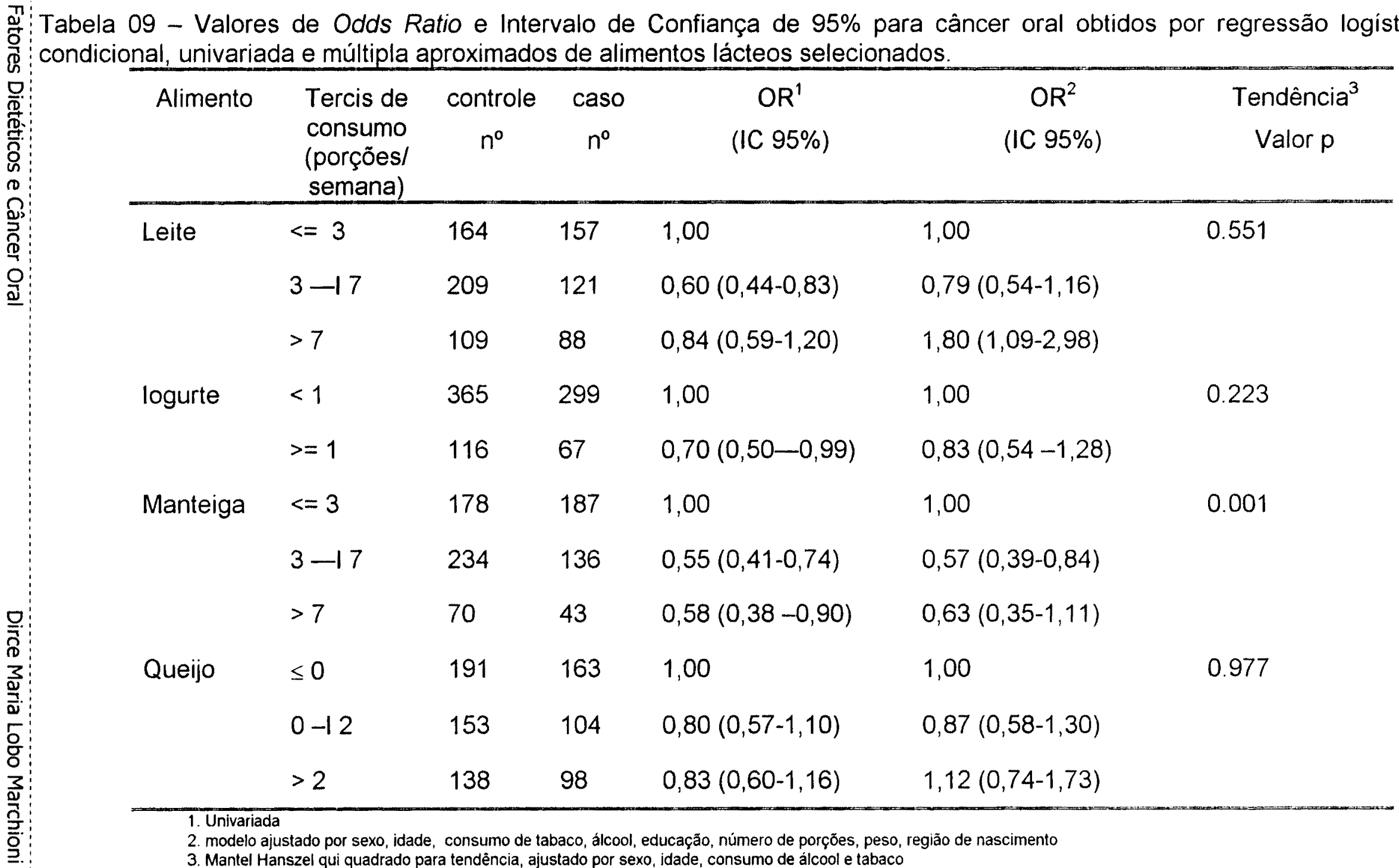




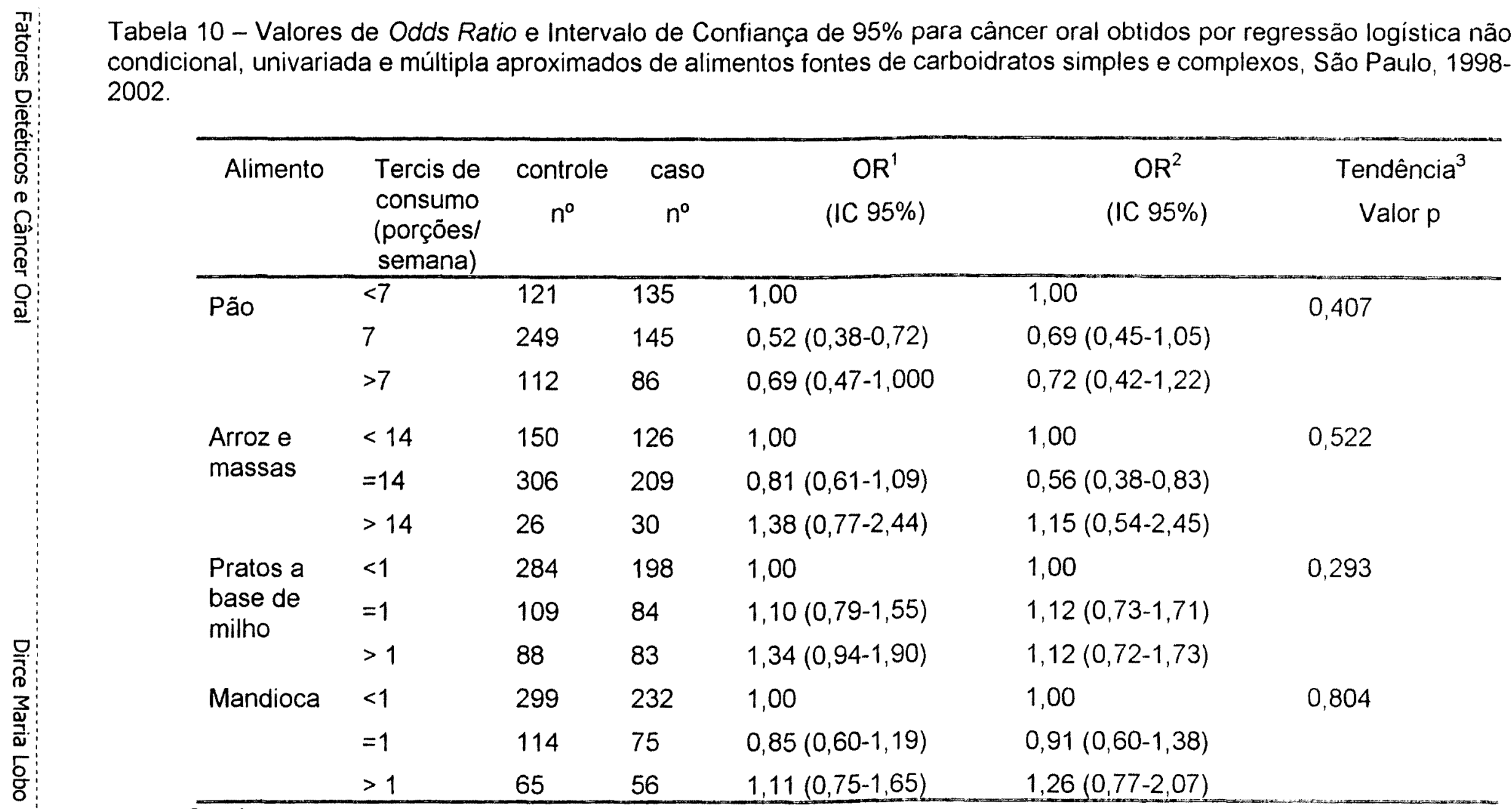


Tabela 10 - Valores de Odds Ratio e Intervalo de Confiança de 95\% para câncer oral obtidos por regressão logística não condicional, univariada e múltipla aproximados de alimentos fontes de carboidratos simples e complexos, São Paulo, 1998-2002 (continuação)

\begin{tabular}{|c|c|c|c|c|c|c|}
\hline Alimento & $\begin{array}{l}\text { Tercis de } \\
\text { consumo } \\
\text { (porções/ } \\
\text { semana) }\end{array}$ & $\begin{array}{c}\text { controle } \\
n^{\circ}\end{array}$ & $\begin{array}{c}\text { caso } \\
n^{\circ}\end{array}$ & $\begin{array}{c}\text { OR }^{1} \\
\text { (IC 95\%) }\end{array}$ & $\begin{array}{c}\mathrm{OR}^{2} \\
(\mathrm{IC} 95 \%)\end{array}$ & $\begin{array}{c}\text { Tendência } \\
\text { Valor } p\end{array}$ \\
\hline \multirow{3}{*}{$\begin{array}{l}\text { Farinha de } \\
\text { mandioca }\end{array}$} & $<1$ & 265 & 203 & 1,00 & 1,00 & \multirow[t]{3}{*}{0,805} \\
\hline & $=1$ & 81 & 52 & $0,84(0,56-1,24)$ & $0,82(0,50-1,36)$ & \\
\hline & $>1$ & 130 & 108 & $1,08(0,79-1,48)$ & $1,01(0,67-1,52)$ & \\
\hline \multirow[t]{3}{*}{ Batata } & $\leq 1$ & 200 & 99 & 1,00 & 1,00 & \multirow[t]{3}{*}{$<0,001$} \\
\hline & $1-13$ & 195 & 170 & $1,76(1,28-2,41)$ & $1,91(1,30-2,81)$ & \\
\hline & $>3$ & 87 & 96 & $2,22(1,53-3,25)$ & $2,46(1,53-3,95)$ & \\
\hline \multirow{3}{*}{$\begin{array}{l}\text { Doces ou } \\
\text { bolos }\end{array}$} & $\leq 0$ & 184 & 157 & 1,00 & 1,00 & \multirow[t]{3}{*}{0,602} \\
\hline & $0-12$ & 61 & 45 & $0,86(0,56-1,34)$ & $1,05(0,61-1,85)$ & \\
\hline & $>2$ & 136 & 94 & $0,81(0,57-1,13)$ & $0,94(0,61-1,43)$ & \\
\hline
\end{tabular}




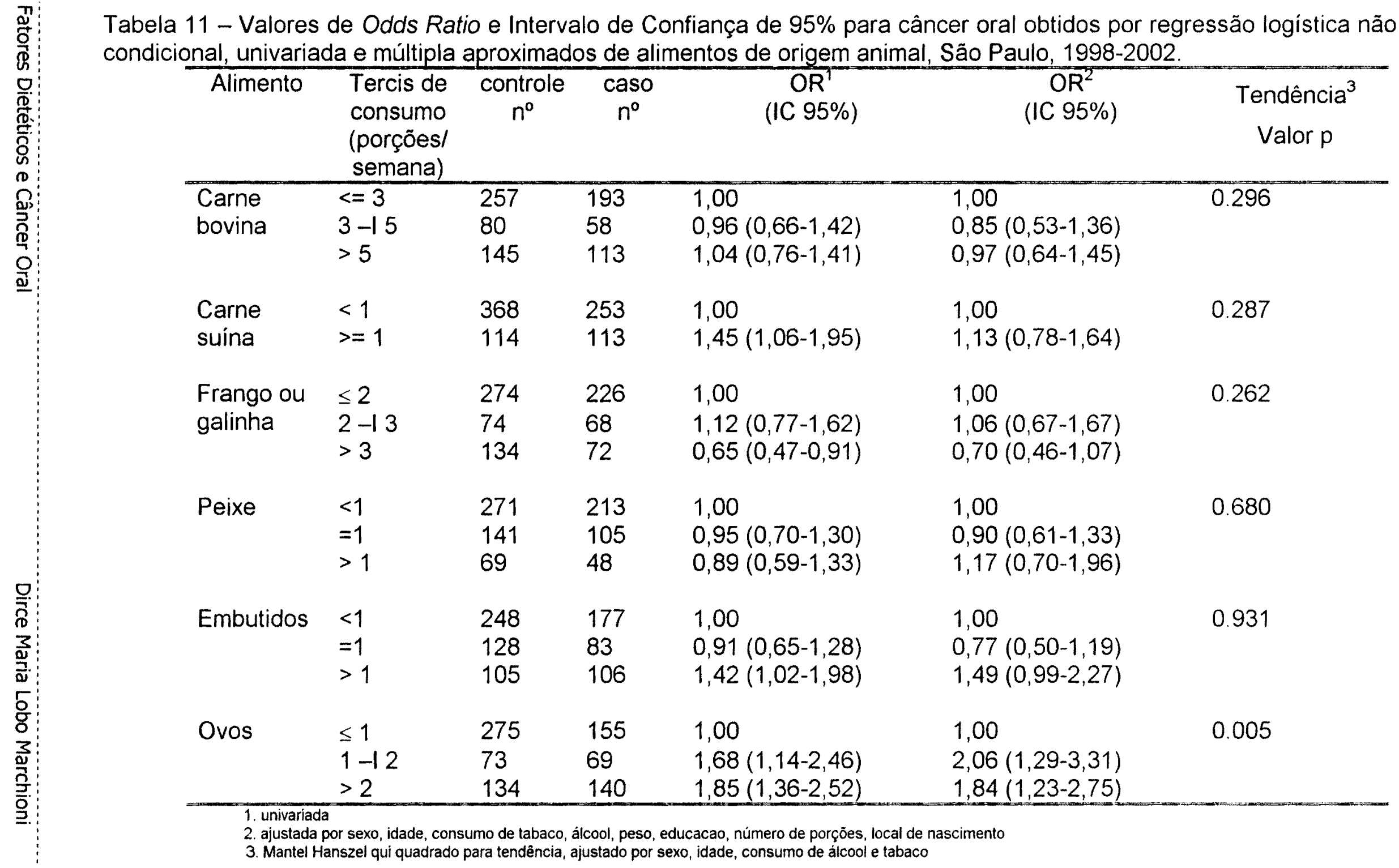




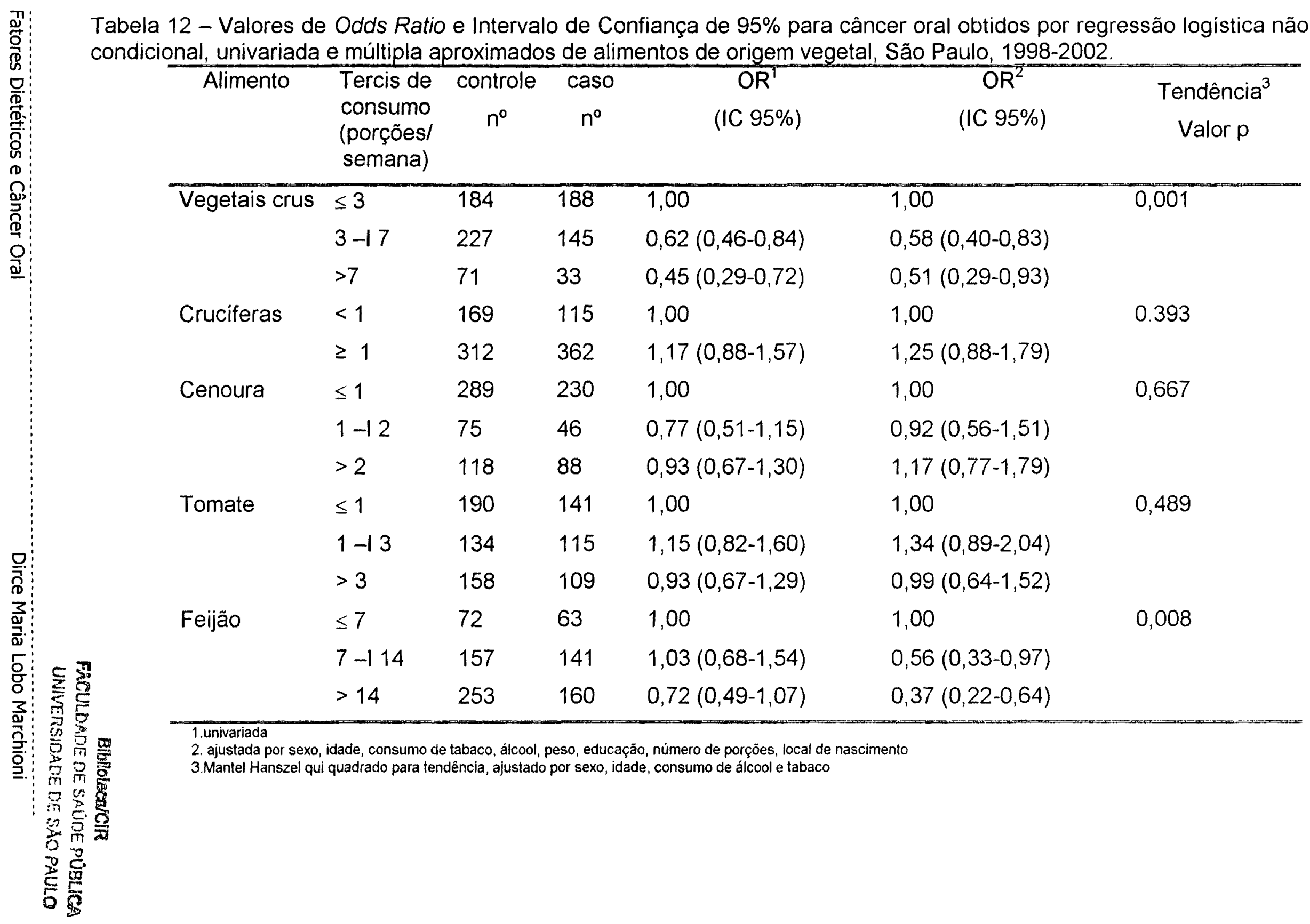




\begin{tabular}{|c|c|c|c|c|c|c|}
\hline Alimento & $\begin{array}{l}\text { Tercis de } \\
\text { consumo } \\
\text { (porções/ } \\
\text { semana) } \\
\end{array}$ & $\begin{array}{c}\text { controle } \\
n^{\circ}\end{array}$ & $\begin{array}{l}\text { caso } \\
n^{0}\end{array}$ & $\begin{array}{c}\text { OR }^{1} \\
\text { (IC 95\%) }\end{array}$ & $\begin{array}{c}O^{2} \\
(I C 95 \%)\end{array}$ & $\begin{array}{c}\text { Tendência } \\
\text { Valor } p\end{array}$ \\
\hline \multirow{3}{*}{$\begin{array}{l}\text { Suco de } \\
\text { Frutas }\end{array}$} & $<1$ & 178 & 167 & 1,00 & 1,00 & \multirow[t]{3}{*}{0,371} \\
\hline & $1-15$ & 177 & 114 & $0,69(0,50-0,95)$ & $0,84(0,57-1,24)$ & \\
\hline & $>5$ & 127 & 84 & $0,70(0,50-1,00)$ & $1,07(0,68-1,70)$ & \\
\hline \multirow[t]{3}{*}{ Maçãs } & $\leq 0$ & 213 & 199 & 1,00 & 1,00 & \multirow[t]{3}{*}{0,089} \\
\hline & $0-11$ & 117 & 67 & $0,61(0,43-0,87)$ & $0,86(0,55-1,34)$ & \\
\hline & $>1$ & 152 & 98 & $0,69(0,50-0,95)$ & $1,17(0,78-1,77)$ & \\
\hline \multirow{3}{*}{$\begin{array}{l}\text { Frutas } \\
\text { citricas }\end{array}$} & $\leq 2$ & 214 & 190 & 1,00 & 1,00 & \multirow[t]{3}{*}{0,182} \\
\hline & $2-15$ & 109 & 73 & $0,75(0,53-1,07)$ & $0,88(0,56-1,39)$ & \\
\hline & $>5$ & 159 & 101 & $0,71(0,52-0,98)$ & $0,85(0,55-1,32)$ & \\
\hline \multirow[t]{3}{*}{ Bananas } & $\leq 2$ & 225 & 183 & 1,00 & 1,00 & \multirow[t]{3}{*}{0,412} \\
\hline & $2-15$ & 114 & 93 & $1,00(0,71-1,40)$ & $1,15(0,75-1,76)$ & \\
\hline & $>5$ & 143 & 88 & $0,76(0,54-1,05)$ & $0,96(0,62-1,47)$ & \\
\hline
\end{tabular}




\subsubsection{Grupos de alimentos definidos a priori}

Observou-se que o consumo médio entre 17 a 22 porções por semana de cereais mostrou uma associação negativa, estatisticamente significativa, para o câncer oral (Tabela 13).

Para o consumo de laticínios, verificou-se efeito protetor para o consumo no tercil intermediário, ou seja, de 7 a 11 porções semanais. Porém, o consumo mais elevado, maior que 11 porções/semana, passa a ter o efeito inverso. No entanto, estas associações não apresentaram significado estatístico (Tabela 14). Para o consumo de carnes (Tabela 14), quer carne vermelha, branca ou para a somatório de consumo de todos os tipos, não se observou associação estatisticamente significativa.

Verificou-se diminuição do risco o maior consumo de vegetais, frutas e o de ambos agrupado, porém não significativo estatisticamente. No entanto, observou-se tendência significativa para diminuição do risco de câncer oral para o maior consumo de vegetais e frutas (Tabela 15).

Quando se agrupam os alimentos de origem vegetal, bem como os alimentos básicos, verificou-se igualmente diminuição do risco, porém sem significado estatístico (Tabelas 16). 
Tabela 13 - Valores de Odds Ratio e Intervalo de Confiança de 95\% para câncer oral obtidos por regressão logística não condicional múltipla, aproximados de grupos de alimentos, São Paulo, 1998-2002.

\begin{tabular}{|c|c|c|c|c|c|c|}
\hline $\begin{array}{l}\text { Grupo de } \\
\text { alimentos }\end{array}$ & $\begin{array}{l}\text { Tercis de } \\
\text { consumo } \\
\text { (porções/ } \\
\text { semana) }\end{array}$ & $\begin{array}{c}\text { controle } \\
n^{\circ}\end{array}$ & $\begin{array}{c}\text { caso } \\
n^{\circ}\end{array}$ & $\begin{array}{c}\mathrm{OR}^{1} \\
(\mathrm{IC} 95 \%)\end{array}$ & $\begin{array}{c}\mathrm{OR}^{2} \\
(\mathrm{IC} 95 \%)\end{array}$ & $\begin{array}{c}\text { Tendência }{ }^{3} \\
\text { (valor } p \text { ) }\end{array}$ \\
\hline \multirow[t]{3}{*}{ Cereais } & $\leq 17$ & 160 & 147 & 1,00 & 1,00 & 0,227 \\
\hline & $17-122$ & 181 & 104 & $0,62(0,44-0,86)$ & $0,57(0,37-0,87)$ & \\
\hline & $>22$ & 140 & 114 & $0,88(0,63-1,24)$ & $0,76(0,47-1,23)$ & \\
\hline Raízes e & $\leq 3$ & 212 & 141 & 1,00 & 1,00 & 0,460 \\
\hline \multirow[t]{2}{*}{ tubérculos } & $3-16$ & 124 & 98 & $1,17(0,84-1,65)$ & $1,18(0,77-1,79)$ & \\
\hline & $>6$ & 138 & 123 & $1,34(0,95-1,85)$ & $1,23(0,81-1,87)$ & \\
\hline Alimentos & $\leq 21$ & 206 & 168 & 1,00 & 1,00 & 0,307 \\
\hline \multirow[t]{2}{*}{ amiláceos } & $211-26$ & 110 & 74 & $0,82(0,58-1,18)$ & $0,71(0,45-1,12)$ & \\
\hline & $\geq 26$ & 157 & 118 & $0,92(0,67-1,26)$ & $1,00(0,63-1,59)$ & \\
\hline
\end{tabular}




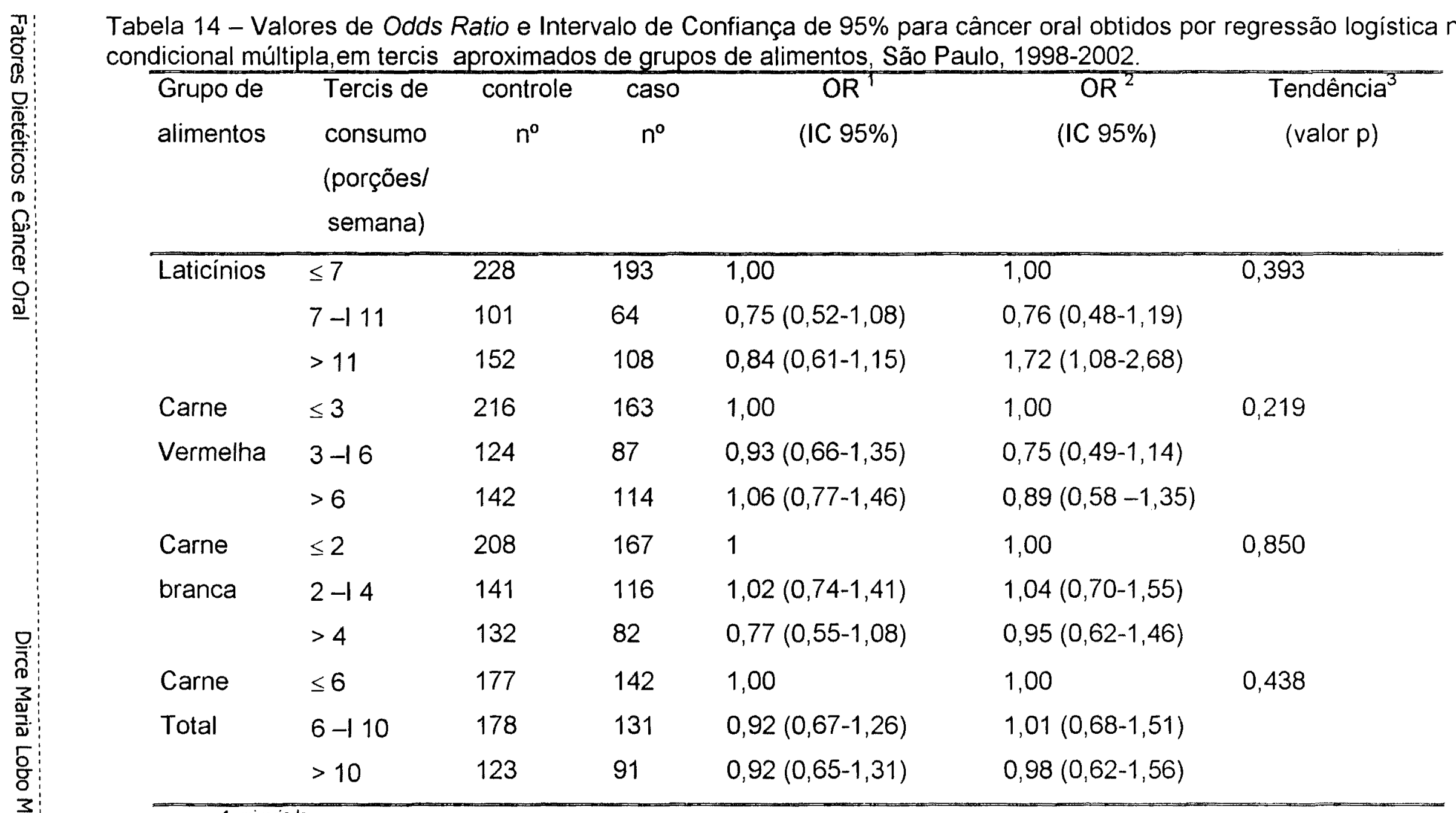

1.univariada

2. ajustada por sexo, idade, consumo de tabaco, álcool, peso, educaçăo, número de porções, local de nascimento

3.Mantel Hanszel qui quadrado para tendência, ajustado por sexo, idade, consumo de álcool e tabaco 
Tabela 15- Valores de Odds Ratio e Intervalo de Confiança de 95\% para câncer oral obtidos por regressão logística não condicional múltipla, em tercis aproximados de grupos de alimento, São Paulo, 1998-2002.

\begin{tabular}{|c|c|c|c|c|c|c|}
\hline $\begin{array}{l}\text { Grupo de } \\
\text { alimentos }\end{array}$ & $\begin{array}{l}\text { Tercis de } \\
\text { consumo } \\
\text { (porções/ } \\
\text { semana) }\end{array}$ & $\begin{array}{c}\text { controle } \\
n^{0}\end{array}$ & $\begin{array}{l}\text { caso } \\
n^{\circ}\end{array}$ & $\begin{array}{c}\text { OR } \\
\text { (IC 95\%) }\end{array}$ & $\begin{array}{c}\mathrm{OR}^{2} \\
(\mathrm{IC} 95 \%)\end{array}$ & $\begin{array}{c}\text { Tendência } \\
\text { (valor } p \text { ) }\end{array}$ \\
\hline \multirow[t]{3}{*}{ Vegetais } & $\leq 8$ & 189 & 172 & 1,00 & 1,00 & 0,043 \\
\hline & $8-115$ & 148 & 114 & $0,85(0,61-1,15)$ & $1,09(0,73-1,66)$ & \\
\hline & $>15$ & 144 & 78 & $0,59(0,42-0,84)$ & $0,73(0,46-1,16)$ & \\
\hline \multirow[t]{3}{*}{ Frutas } & $\leq 7$ & 160 & 148 & 1,00 & 1,00 & 0,089 \\
\hline & $7-116$ & 163 & 123 & $0,83(0,59-1,13)$ & $1,08(0,71-1,65)$ & \\
\hline & $>16$ & 159 & 93 & $0,63(0,45-0,89)$ & $0,89(0,54-1,47)$ & \\
\hline Vegetais e & $\leq 18$ & 175 & 172 & 1,00 & 1,00 & 0,010 \\
\hline \multirow[t]{2}{*}{ frutas } & $18-132$ & 154 & 110 & $0,73(0,53-1,00)$ & $0,84(0,55-1,29)$ & \\
\hline & $>32$ & 152 & 81 & $0,54(0,38-0,76)$ & $0,73(0,43-1,26)$ & \\
\hline
\end{tabular}

1.univariada

2. ajustada por sexo, idade, consumo de tabaco, álcool, peso, educação, número de porções, local de nascimento

3. Mantel Hanszel qui quadrado para tendência, ajustado por sexo, idade, consumo de álcool e tabaco 


Tabela 16 - Valores de Odds Ratio e Intervalo de Confiança de 95\% para câncer oral obtidos por regressão logistica não
condicional mültipla, em tercis aproximados de grupos de alimentos, São Paulo, 1998-2002.

1. univariada

2. ajustada por sexo, idade, consumo de tabaco, álcool, peso, educação, número de porções, local de nascimento

3. Mantel Hanszel qui quadrado para tendẻncia, ajustado por sexo, idade, consumo de álcool e tabaco 


\subsubsection{Grupos de alimentos definidos a posteriori}

Na Tabela 17, observam-se os resultados da associação dos grupos de alimentos identificados por análise fatorial, e o câncer oral.

O consumo no tercil mais elevado do padrão "tradicional" mostrou-se protetor para o câncer oral, independente do consumo de álcool, tabagismo, e das demais variáveis de controle, porém sem significado estatistico.

Por outro lado, o consumo no tercil mais elevado do quarto padrão, nomeado como "monótono", mostrou-se como fator de risco, mesmo depois de ajustado, com tendência significativa.

Os padrōes "prudente" e "lanches" não apresentaram associação estatisticamente significativa com o câncer oral. 
Tabela 17 - Valores de Odds Ratio e Intervalo de Confiança de 95\% para câncer oral obtidos por regressão logística não condicional múltipla, em tercis aproximados de grupos de alimentos definidos "a posteriori" por análise fatorial, São Paulo, 1998-2002.

\begin{tabular}{|c|c|c|c|c|c|}
\hline Fatores & $\begin{array}{c}\text { Tercis } \\
\text { dos } \\
\text { escores }\end{array}$ & $\begin{array}{l}\text { casos: } \\
\text { controles }\end{array}$ & $\begin{array}{c}\mathrm{OR}^{1} \\
\left(\mathrm{I} \mathrm{C}_{95 \%}\right)\end{array}$ & $\begin{array}{c}\mathrm{OR}^{2} \\
\text { (IC } 95 \%)\end{array}$ & $\begin{array}{c}\text { Tendên- } \\
\text { cia }\end{array}$ \\
\hline \multirow[t]{3}{*}{ Prudente } & $1^{\circ}$ & $155: 137$ & 1,00 & 1,00 & 0,971 \\
\hline & $2^{\circ}$ & $155: 112$ & $0,83(0,63-1,44)$ & $0,95(0,63-1,44)$ & \\
\hline & $3^{\circ}$ & $155: 112$ & $0,82(0,59-1,14)$ & $1,05(0,63-1,64)$ & \\
\hline \multirow[t]{3}{*}{ Tradicional } & $1^{\circ}$ & $155: 124$ & 1,00 & 1,00 & 0,140 \\
\hline & $2^{\circ}$ & $155: 126$ & $1.01(0,731-1,41)$ & $0,76(0,50-1,17)$ & \\
\hline & $3^{\circ}$ & $155: 111$ & $0,90(0,64-1,26)$ & $0,51(0,32-0,81)$ & \\
\hline \multirow[t]{3}{*}{ Lanches } & $1^{\circ}$ & $155: 139$ & 1,00 & 1,00 & 0,366 \\
\hline & $2^{\circ}$ & $155: 94$ & $0,67(0,47-0,95)$ & $0,83(0,54-1,28)$ & \\
\hline & $3^{\circ}$ & $155: 128$ & $0,92(0,66-1,28)$ & $1,03(0,64-1,64)$ & \\
\hline \multirow[t]{3}{*}{ Monótono } & $1^{\circ}$ & $155: 69$ & 1,00 & 1,00 & $<0,001$ \\
\hline & $2^{\circ}$ & $155: 110$ & $1,60(1,09-2,31)$ & $1,48(0,93-2,34)$ & \\
\hline & $3^{\circ}$ & $155: 180$ & $2,63(1,84-3,76)$ & $1,78(1,12-2,85)$ & \\
\hline
\end{tabular}

1. univariada

2. ajustada por sexo, idade, consumo de tabaco, álcool, peso, educação, número de porções, local de nascimento

3. $\chi^{2}$ Mantel Hanszel para tendência, ajustado por sexo, idade, consumo de tabaco, álcool 
discussão 


\section{DISCUSSÃO}

Este estudo, do tipo caso controle de base hospitalar, baseado em dados obtidos no município de São Paulo, buscou verificar as associações entre alimentos e grupos de alimentos, definidos a priori e a posteriori e o câncer oral.

Foi possivel verificar o consumo habitual de determinados alimentos. A freqüência média de consumo de pão e leite foi aproximadamente diária. Arroz e feijão foram consumidos em média duas vezes por dia. Quanto às carnes, a bovina foi consumida em média 4 vezes na semana, seguida das aves, aproximadamente 3 vezes por semana. Estes dados são consistentes com os relatados por PONTES, 2000, tendo por base a POF - Pesquisa de Orçamento Familiar 1995-1996, pois o arroz, o feijão e a carne bovina foram os alimentos que apresentaram os maiores consumos per capita, em kg por ano. Neste estudo, o autor considera o arroz e feijão "campeões de democracia", devido as quantidades consumidas por pobres e ricos apresentarem valores muito semelhantes. No Estudo Multicêntrico de Consumo Alimentar em Familias e Individuos, conduzido no periodo de 1996 a 1997, o arroz, o pão francês e o leite foram alguns dos alimentos mais consumidos nas cinco cidades pesquisadas: Campinas, Goiânia, Ouro Preto, Rio de Janeiro e Curitiba (SILVA 1998).

Em contrapartida, neste estudo, certos alimentos mostraram um consumo bastante baixo, tanto por casos quanto por controles: iogurte, pratos a base de milho, peixes e carne suina. 


\subsection{Alimentos}

A interpretação das fracas associações observadas é dificultada pelo pequeno número de itens alimentares do questionário, o mesmo para todos os centros participantes do estudo. O mesmo questionário já havia sido utilizado pelo Estudo Internacional em HPV e câncer oral (TALAMINI et al. 2000), também coordenado pelo IARC.

Foi possivel observar que casos de câncer oral diferiram dos controles em determinados aspectos do seu comportamento alimentar: no menor consumo de arroz e massas, feijão e vegetais crus e saladas. Estes achados foram independentes do consumo de álcool, tabagismo e demais variáveis de controle.

Neste estudo, o feijão apresentou-se como fator protetor para o câncer oral, com tendência significativa para diminuição do risco com o aumento do consumo. Os grãos têm recebido destaque na literatura científica recentemente. Atualmente seu consumo vem sendo recomendado por Organizações de Saúde, pois aparentemente colabora para a redução de riscos das doenças crônicas não transmissiveis (LETERME 2002). Os grãos são uma fonte de fibras dietéticas, amido-resistente, oligossacarideos e carboidratos fermentáveis. São também ricos em antioxidantes, incluindo minerais traços, compostos fenólicos, além de ácido fítico. São ainda fontes de fitoestrógenos. Os grãos têm uma digestão e absorção mais lenta do que, por exemplo, alimentos refinados, e diminuem a resposta glicêmica sanguínea pós-prandial. Estes mecanismos, isoladamente ou em conjunto, 
poderiam explicar o efeito protetor atribuido a este alimento, nas várias fases do processo carcinogênico (SLAVIN, 2000, MARQUART et al, 2000).

No entanto, os resultados dos estudos epidemiológicos são inconsistentes, e a avaliação da possivel contribuição quantitativa para a diminuição do risco permanece incerta (MATHERS 2002). Nos estudos de GRIDLEY et al., 1990, KJAERHEIM et al. 1998, FRANCESCHI et al. 1991, FRANCESCHI 1999 e GARROTE et al. 2001, os grãos associaram-se positivamente ao câncer, enquanto PETRIDOU et al. 2002, na Grécia, observaram associação negativa.

Nos estudos de FRANCESCHI et al. 1991 e CHYOU et al. 1995, GARROTE et al. 2001, o consumo mais freqüente de arroz associou-se com aumento do risco para o câncer oral. Porém FRANCESCHI et al. 1999, em um dos maiores estudos conduzidos na Europa não observou associação direta, como no estudo prévio. ZHENG et al. 1993 e, recentemente, PETRIDOU et al. 2002 observaram associação inversa, como ocorreu neste estudo.

Consistente com os estudos de MCLAUGHLIN et al., 1988, FRANCO et al., 1989, LEVI et al. 1998, GARROTE et al. 2001, TAVANI et al. 2001, USCUDUN et al. 2002, a categoria de consumo mais elevada para os vegetais crus apresentou aproximadamente metade do risco para o câncer oral. Aparentemente, os vegetais crus parecem ter efeito protetor mais pronunciado que vegetais consumidos cozidos. Estes achados podem ser devidos a um efeito mecânico na cavidade oral ou ao efeito de alguma substância que seja sensivel ao calor (FRANCESCHI et al. 1999). 
Além dos vegetais crus, as evidências para o efeito protetor dos vegetais são consistentes para cenoura, vegetais verdes e amarelos e tomates (FRANCO et al. 1989, GRIDLEY et al. 1990, FRANCESCHI 1991, 1992, ZHENG 1993, FIORETTI et al. 1999 GARROTE et al. 2001, TAVANI et al. 2001), mas fraca para crucíferas, para as quais efeitos nulos ou de risco foram descritos (McLAUGHLIN et al. 1988, ZHENG et al. 1992, GARROTE et al. 2001). Neste estudo, os resultados verificados para o consumo de cenouras, cruciferas e tomates não evidenciaram diferenças de consumo entre casos e controles.

As crucíferas, como brócoli, couve-flor, repolho, couve, plantas do gênero Brassica, são vegetais consumidos com bastante freqüência na Europa e Ásia. Estes vegetais têm suscitado interesse crescente nos últimos anos, pois lhe são imputados atividades anticarcinogênicas. Glucosinolatos, ou, mais acuradamente, indoles e isotiocianatos formados pela hidrólise enzimática parecem ser responsáveis por estas atividades. Estes são compostos organosulfurados que têm sido implicados na detoxificação de carcinógenos e outros compostos estranhos (ZHANG et al., 1992; SHAPIRO 1998, VERHOEIN 1997, KRISTAL e LAMPE, 2002). Neste estudo, não foram verificados efeitos associados ao consumo destes alimentos. No entanto, ressalta-se o baixo consumo destes alimentos nesta população: tanto entre casos quanto entre controles.

Vegetais e frutas alaranjadas como as cenouras, mamão e manga, são fontes relativamente ricas de beta-caroteno e alfa-caroteno, que, ao lado 
de suas propriedade antioxidantes, tem atividade de vitamina A, que, por sua vez, tem um papel fundamental na diferenciação das células epiteliais (PAIVA e RUSSELL 1999). No entanto, não se observou, neste estudo, efeito protetor para este alimento em relação ao câncer oral.

Também têm sido evidenciadas as propriedades benéficas do consumo de tomates e de seus derivados. A capacidade antioxidante do licopeno, um carotenóide sem atividade de vitamina $A$, presente em frutas e vegetais, mas principalmente em tomates, podem ser responsáveis por estes efeitos (RAO e AGARWAL 2000). Os antioxidantes podem prevenir os danos ao DNA causados pelos radicais livres (GAREWAL 1995). Neste estudo, estes alimentos não se mostraram associados ao câncer oral.

Os resultados nulos verificados neste estudo para o consumo de cenoura, crucíferas e tomates podem ser devidos à vieses como os erros de classificação (misclassification) ou falta de heterogeneidade na população estudada (KOPEC e ESDAILE 1990, POTTER e STEINMETZ 1996).

Observou-se ainda que o consumo aumentado de ovos associou-se diretamente com o câncer oral. Apesar deste alimento ter sido investigado em vários estudos, os resultados são inconsistentes. FRANCESCHI et al., 1991, 1999 e LEVI et al, 1998, observaram associação positiva, estatisticamente significativa entre ovos e câncer oral, além de tendência significativa para aumento de risco com aumento de consumo. ZHENG et al, 1993, observaram uma associação negativa, enquanto TAKEZAKI et al, 1996, KJAERHEIM et al 1998, e DE STEFANI et al 1999, observaram 
associações positiva, porém todas não significativas estatisticamente. $\dot{E}$ possivel que este efeito seja devido à gordura saturada e colesterol (LEVI et al, 1998).

Observou-se ainda que o consumo aumentado de batatas associou-se positivamente. Um número menor de estudos relataram resultados para este alimento. LEVI et al 1998 e DE STEFANI et al, 1999, verificaram associações positivas, porém não significativas, enquanto FRANCESCHI et al, 1999, e GARROTE et al, 2001, relataram efeitos nulos. É possivel que este feito seja devido ao consumo de uma dieta menos variada, portanto com menor fornecimento de nutrientes, pois o câncer oral parece estar relacionado com este tipo de dieta (FRANCESCHI et al, 1990, LEVI et al 1998). De fato, na análise dos padrões da dieta, a batata foi considerada um dos alimentos com contribuição significativa para o fator monótono, enquanto que os vegetais e frutas correlacionaram-se negativamente com este fator

GARROTE et al. 2001, relatando os resultados obtidos em Cuba, como parte de um estudo internacional conduzido sob a coordenação da IARC que utilizou questionário semelhante ao utilizado neste estudo, verificou riscos aumentados, estatisticamente significativos, para o consumo de carnes e embutidos. Apesar das quantidades nos tercis de consumo terem sido semelhantes, este mesmo efeito não foi observado em São Paulo, onde foram observadas associações inversas, porém não significativas estatisticamente. Tais achados parecem reforçar a tese que, mais que os 
alimentos em si, a combinação dos mesmos, associados ao estilo de vida podem ser fatores determinantes na etiologia do câncer oral.

\subsection{Grupos de alimentos}

Entre os achados mais consistentes dos estudos epidemiológicos que investigaram o câncer oral e a dieta, estão os efeitos protetores das frutas e vegetais: praticamente todos os estudos relataram associações inversas (NOTANI e JAYANT 1987, OREGGIA et al. 1991, FRANCESCHI et al. 1991, 1992, GRIDLEY et al. 1990, LEVI et al. 1998, DE STEFANI et al.1999, FRANCESCHI et al. 1999, GARROTE et al. 2001). A mais alta categoria de freqüência de consumo mostra aproximadamente metade do risco. Neste estudo também evidenciou-se associação direta, porém não significativa estatisticamente.

O consumo de frutas é especialmente consistente, com aproximadamente o dobro do risco para o câncer oral para quem consome menos em comparação com as maiores categorias de consumo de frutas (POTTER e STEINMETZ 1996, WCRF 1997). As evidências de um efeito independente do consumo de frutas são várias, pois, nos estudos onde as estimativas são ajustadas pelo consumo de álcool e fumo, associações significativas ainda são encontradas.

Os possiveis efeitos anticarcinogênicos de frutas e vegetais podem ser devido às substâncias como carotenóides, ascorbatos, tocoferóis, selênio, fibra dietética, indoles, fenóis, ácido fólico e outras substâncias que têm sido 
chamadas fitoquímicos ou compostos bioativos (POTTER e STEINMETZ 1996, MATHERLY 2001, AMES e WAKIMOTO 2002)

Os únicos resultados significativos foram verificados para o consumo de cereais, com diminuição de $40 \%$ no risco para consumo no tercil intermediário e laticinios, aumento de $70 \%$ no risco para consumo maior que 11 porções semanais.

GARROTE et al. 2001, verificaram aumento do risco, porém não significativo, com o aumento do consumo de alimentos de origem animal e alimentos básicos (cereais e leguminosas). Nossos achados, apesar de, da mesma forma, não terem alcançado significado estatistico, estão em concordância com relação à associação positiva no grupo de alimentos de origem animal, porém estão em desacordo com relação ao consumo de alimentos básicos.

\subsection{Padrões alimentares}

No estudo da dieta, deve-se levar em conta que os indivíduos ingerem os nutrientes necessários a partir da escolha dos alimentos, que é influenciada por inúmeros fatores: culturais, sociais e demográficos. Assim, a abordagem da dieta em termos de alimentos, mais que nutrientes, é particularmente valiosa. Além disso, os alimentos são misturas complexas de compostos químicos que podem ser antagônicos, competir ou alterar a biodisponibilidade de outros compostos quimicos ou nutrientes (WILLETT 1998). A identificação de padrões permite o exame do efeito da dieta como um todo, podendo descrever associaçōes com doenças para além das 
descritas por nutrientes ou alimentos singulares (SLATTERY et al., 1998; Hu et al., 1999, SCHULZE et al., 2001).

Além dos estudos em dieta e câncer oral serem relativamente escassos, um número ainda menor analisou os padrões de consumo e pouco se sabe sobre os padrões dietéticos associados com risco elevado (WCRF 1997). Este estudo buscou identificar os padrões dietéticos do grupo de individuos participantes, utilizando análise fatorial, e verificar sua associação com o câncer oral.

Apesar das evidências convincentes da redução do risco para o desenvolvimento do câncer oral devido ao consumo de frutas e verduras, não se observou este efeito para o consumo mais elevado do padrão prudente, caracterizado por estes alimentos. O segundo fator, caracterizado pela presença de arroz e massas, carnes e feijão, mostrou-se protetor para o câncer oral. Este fato pode denotar que a prática de fazer refeições regulares, que no nosso meio é caracterizada pelo consumo da mistura arroz e feijão, pode ser um fator que colabora para a redução do desenvolvimento do câncer oral, independente de outros fatores de risco não dietéticos. Também SICHIERI, 2002, em estudo conduzido no Rio de Janeiro, observou um padrão caracterizado por arroz e feijão.

O terceiro padrão, por sua vez, caracterizou-se pela presença de alimentos que têm sido associados com aumento de risco para o desenvolvimento de doenças crônicas não transmissíveis, como por exemplo, carnes processadas, que têm elevado conteúdo de sódio e gordura 
saturada, e doces, que contém carboidratos com elevado índice glicêmico. Porém, não se observou aumento de risco para o consumo mais elevado deste padrão.

Verificou-se, no entanto, que individuos com escores no tercil mais elevado do padrão monótono, caracterizado por uma associação negativa com frutas e vegetais, estavam mais sujeitos à terem câncer oral, segundo a estimativa ajustada de risco, em comparação com indivíduos nos escores mais baixos. FRANCESCHI et al. 1999, analisando a diversidade de consumo de frutas e vegetais, verificaram que o consumo de vários tipos de frutas e vegetais parecia exercer proteção significativa contra o câncer oral.

Os padrōes extraidos neste estudo foram diferentes dos retidos em estudos anteriores em populações adultas: RANDALL et al, 1990, GALLAGHER et al. 1990, SLATTERY et al. 1998, HU et al. 1999, FUNG et al., 2001, PALLI et al., 2001, SCHULZE et al. 2001. Ressalta-se que padrões são julgados comparáveis somente se os grupos de alimentos forem similares e se os factor loadings forem igualmente semelhantes em sua magnitude. De fato, como os padrões são extraídos a partir dos dados obtidos na população de estudo, não é de se estranhar que não se reproduzam resultados em populações com hábitos de alimentação diferentes. No entanto, esta caracteristica do método pode acarretar dificuldades em reproduzir estimativas de risco em populações de estudo diferenciadas. 
Apesar disso, uma vantagem desta abordagem é que a descrição de padrões dietéticos permite que a promoção de mudanças seja focalizada no consumo de alimentos que são reconhecidos prontamente pelo grupo-alvo (GALLAGHER et al. 1993). Ressalta-se que, atualmente, as guias para alimentação têm sido lançadas com ênfase em alimentos e no padrão global de alimentação (KRAUSS et al., 2001).

\subsection{Considerações Metodológicas}

Estudos tipo caso-controle são em geral criticados por serem suscetiveis a vieses de seleção e informação. A estes problemas metodológicos adicionam-se outras dificuldades quando se investigam as relações entre câncer e dieta. Inicialmente, a inabilidade de se estimar com precisão e acurácia o consumo dietético. Há ainda as dificuldades para estabelecer ou recordar a verdadeira exposição. Outro problema é que as diferenças na ingestão de alimentos tendem a ser pequenas nos estudos em que os indivíduos são as unidades de medida. A magnitude da associação que pode ser observada é, portanto, muito menor e o poder para detectar as relações entre câncer e dieta são reduzidas, independente do método de avaliação da dieta (HERBERT e MILLER 1988, WILLET 1996, DAY e FERRARI 2002).

A ingestão de determinado alimento pode estar altamente correlacionada com a ingestão de outros, além de refletir a escolha individual por um estilo de vida. Teoricamente, pode-se modelar estatisticamente, ajustando pelas variáveis de confusão, porém, é sempre difícil julgar a 
adequação destes ajustes (PINTOS et al.. 1994). Nesse sentido, a opção pela análise dos alimentos em função da forma que eles se combinam, pode ser considerada um dos pontos fortes deste trabalho.

O problema do erro de medida é uma das grandes preocupações em Epidemiologia Nutricional. Erros na medida da exposição à dieta podem levar a estimativas distorcidas do efeito e reduzir o poder dos testes estatísticos, ou a testes enviesados. Os estudos caso-controle, que coletam os dados retrospectivamente, são particularmente vulneráveis a este problema. Além disso, quando estudando efeitos fracos com instrumentos imprecisos, problemas típicos de estudos retrospectivos, os vieses de recordação podem ser exacerbados e gerar relações espúrias (GIOVANNUCCI et al. 1993, DAY e FERRARI 2002).

Vários métodos foram desenvolvidos nas últimas décadas na tentativa de minimizar estes efeitos nas estimativas do risco. Uma abordagem comum é fazer um estudo de validação, por meio da coleta de dados por um método mais acurado em uma amostra da população de estudo e corrigir as estimativas de risco com a estimativa do erro de medida. No entanto, O QFA, o principal instrumento de medida da dieta utilizado em estudos epidemiológicos, em geral é validado utilizando-se instrumentos que podem ter erros correlacionados. Este fato pode levar a uma subestimação da variància do erro, produzindo o viés de atenuação (ARMSTRONG et al. 1992). Para evitar este viés, uma medida independente da dieta precisa ser 
tomada, tal como um marcador biológico do consumo, e, após, a aplicação de um método para corrigir o erro seja aplicado aos dados.

Outra preocupação é o consumo calórico. É muito difícil estabelecer o papel do consumo calórico sobre a carcinogênese, já que, ao aumentar ou diminuir o mesmo, aumentam ou diminuem os outros constituintes da dieta que podem ser promotores ou protetores dos tumores (SERRA MAJEM e ARANCETA 1995). Uma das abordagens mais utilizadas é fazer o ajuste pelas calorias pelo método proposto por WILLETT e STAMPFER, 1986. No entanto, esta abordagem tem sido questionada, pois estudos recentes têm demonstrado que o peso dos individuos está mais relacionado com o dispêndio energético que as estimativas de ingestão energética. Dessa forma, DAY e FERRARI, 2002, sugerem que se o objetivo é ajustar pelo consumo energético, então usar o peso como substituto pode ser melhor que ajustar pela energia per se. Neste estudo, utilizamos como opção ao ajuste pelas calorias o ajuste simultâneo pelo peso relatado do individuo antes do início dos sintomas, e pelo número de porções consumidas.

Neste estudo, para a identificação de grupos de alimentos a partir dos dados levantados, utilizou-se a análise fatorial. Neste método, como em outros métodos estatísticos, certas decisões são tomadas arbitrariamente. Estas incluem: quais variáveis devem ser incluidas no modelo e qual número de fatores devem ser retidos e como nomeá-los. Foram incluidas neste estudo todas as variáveis praticamente todas as variáveis dietéticas constantes no QFA. A seguir, estas variáveis foram agrupadas em fatores. 
que são combinações lineares dos dados. Os fatores retidos não representam todos os possiveis padrões, como indica a proporção da variabilidade explicada da dieta que estes fatores representam. No entanto foi possivel identificar padrões plausiveis e interpretáveis.

\subsection{Vies de confundimento}

O viés de confundimento é outro tópico de destaque no estudo da relação entre a exposição e a doença. Pode ocorrer que a associação verificada possa estar sendo causada por um fator ainda desconhecido e que não foi levado em consideração nem no planejamento do estudo nem na fase de análise.

Os hábitos alimentares, tais como a inclusão de frutas e verduras na dieta, podem refletir a posição socioeconômica e nível educacional. As classes sociais inferiores tendem a ter uma dieta menos saudável (JAMES et al. 1997). GISKES et al., 2002, baseados em inquérito populacional, relataram que adultos de menor renda consumiam uma menor variedade de frutas e vegetais que os de renda mais elevada. No Brasil, PONTES 2000 relata maior consumo de leite e carnes nas familias de classe de renda mais elevada. Por outro lado, educação e renda estão positivamente relacionadas. PARMENTER et al., 2000, relataram diferenças significativas em conhecimentos entre os grupos sócio-demográficos, com homens tendo menor conhecimento que mulheres e o conhecimento declinando com menor nível educativo e socioeconômico. A instrução é provavelmente o critério mais utilizado no Brasil para separar as pessoas por nivel socioeconômico 
(PEREIRA 2001). Neste estudo, o grau de instrução foi utilizado no modelo estatístico como variável de controle, para ajustar por estes possiveis efeitos de confusão.

Outras importantes variáveis são os hábitos de consumo de tabaco e álcool, os dois mais importantes e reconhecidos fatores de risco para o câncer oral.

DALLONGEVILLE et al., 1998, conduziram uma metanálise sobre a ingestão de nutrientes associados com tabagismo e verificaram que fumantes tinham ingestão mais baixa de fibra, vitamina $C$, vitamina $E$ e betacaroteno, nutrientes correlacionados com ingestão de frutas e vegetais, ao lado de maior consumo de álcool e energia.

O alcoolismo crônico interfere com o estado nutricional e induz a depleção de vitaminas e minerais, e pode ser capaz de modificar a resposta imunológica do indivíduo (KATO e NOMURA 1994, TUYNS 1996).

O questionário utilizado na pesquisa permitiu um conhecimento detalhado da exposição ao tabaco e álcool, tanto em termos de período, duração e intensidade da exposição, sendo que as variáveis incorporadas no ajuste do modelo estatístico permitiram levar em conta os consumos médios apresentados pelos indivíduos participantes durante a vida.

\subsection{Limitações}

Os estudos epidemiológicos observacionais procuram mimetizar a lógica dos experimentos, comparando dois grupos, teoricamente da mesma 
população. Nos estudos caso-controle, estes grupos seriam diferentes em relação ao efeito a ser estudado. Buscam-se então, explicações para este efeito, pela presença ou ausência da exposição no passado. Se a população é tão homogênea, que a magnitude das diferenças observadas quanto à exposição é pequena, torna-se dificil detectar os riscos associados à esta exposição. Esta é uma possivel explicação para os resultados deste estudo. São individuos semelhantes em relação ao grau de instrução, tempo de moradia em São Paulo, e com relação ao consumo da maioria dos alimentos pesquisados. Este fato, aliado a um instrumento cuja acurácia é desconhecida, pode ter causado a classificação equivocada dos individuos, reduzindo a possibilidade do estudo de detectar o efeito.

Ainda assim, foi possivel observar uma forte associação com o consumo de feijão. O consumo de cereais, basicamente arroz e pão, em quantidades que corresponderiam a aproximadamente 3 porções diárias (provavelmente duas porções de arroz e uma de pão), também mostraram diminuir o risco. Quando se agrupam os alimentos, os alimentos básicos mostraram-se também protetores. Utilizando a abordagem estatistica para agrupamento das variáveis dietéticas, obteve-se uma agregação dos alimentos arroz e feijão, consistente com a dieta tradicional do brasileiro, que igualmente se mostrou protetora. Utilizando diferentes abordagens, foi possivel obter resultados que apontam na mesma direção. As análises sugerem que o consumo regular, praticamente diário, do prato brasileiro de ricos e pobres: arroz e feijão, pode diminuir os riscos associados com o 
câncer oral, independente do consumo de álcool, tabaco, do grau de instrução e do local de nascimento.

Esta mistura tradicional fornece proteina de bom valor biológico, com a vantagem de aportar fibras dietéticas, carboidratos complexos, ser baixa em gorduras saturadas e não possuir colesterol. Qual seria o exato mecanismo que pode responder ao efeito observado de proteção ao câncer oral, não é possivel identificar a partir de um estudo com este delineamento. Não se pode deixar de aventar a possibilidade da ocorrência de uma associação espúria, por um fator ainda desconhecido, já que os considerados importantes foram controlados no desenho do estudo e na modelagem estatística.

Têm-se relatado na literatura, tendência ao menor consumo dos alimentos básicos, arroz e especialmente feijão, com queda de consumo verificadas entre as POFs de 87 e 96 respectivamente de 16\% e 32\%, Em compensação, houve substancial aumento do consumo de proteínas, representadas pela carne bovina e de frango, em consonância com a transição nutricional. (PONTES 2000, MONTEIRO et al. 1995, MONTEIRO et al. 2000). De fato, neste estudo, não foi o padrão tradicional que explicou a maior variância no consumo dietético.

Se este padrão é realmente favorável para a prevenção do câncer oral, é mais uma motivação para a reversão da tendência da adoção dos padrões dietéticos de sociedades afluentes, cujas conseqüências já reconhecidas são o aumento das doenças crônicas não transmissiveis. 
A maioria dos estudos conduzidos para investigar a relação da dieta com o câncer oral foram relativamente pequenos e baseados em questionários simplificados que não permitiam estimativas acuradas do consumo, nem ajuste por energia. Exceções são os estudos conduzidos por FRANCESCHI et al. 1999 e PETRIDOU et al., 2002.

O estudo do qual foram retirados os dados deste trabalho é um dos maiores estudos já realizados no Brasil até o momento, envolvendo cinco centros, mobilizando grande número de pessoas na operacionalização, coleta, crítica e análise de dados. O delineamento é cuidadoso, e o questionário utilizado bastante abrangente e igual para todos os centros participantes. No entanto, o estudo não foi delineado especialmente para o estudo dos fatores dietéticos, sendo que o número de itens alimentares que faziam parte do QFA era limitado, e não permitindo estimar o consumo de energia e nutrientes. Apesar disso, cumpre ressaltar que, devido às dificuldades operacionais e logísticas, bem como os custos financeiros para a condução de trabalhos do porte deste estudo-base, especialmente em paises em desenvolvimento, acreditamos que, mesmo com as deficiências metodológicas para o levantamento de fatores nutricionais, este estudo pode contribuir de forma relevante para a compreensão dos fatores dietéticos que possam estar envolvidos na etiologia do câncer oral. Acreditamos ainda ter sido possivel levantar questões que podem ser investigadas em estudos subseqüentes. 
conclusões 


\section{CONCLUSÕES}

- Foram observadas associações inversas, estatisticamente significativas, para a mais elevada categoria de consumo de feijão e vegetais crus;

- Observou-se diminuição do risco, estatisticamente significativo, para o consumo de 14 porções semanais de arroz e massas;

- Foram observadas associações positivas, estatisticamente significativas, para o consumo de ovos e batatas, e para o consumo de mais que 7 porções semanais de leite;

- Emergiram associações inversas, porém não significativas, para o consumo de cenouras, banana e frutas citricas;

- Na análise dos grupos de alimentos definidos a priori, somente os cereais associaram-se de forma significativa, inversamente com 0 câncer oral;

- O padrão identificado como tradicional, caracterizado pelo consumo de arroz, carne e feijão, associou-se de forma inversa e independente com o câncer oral, fornecendo evidências para o efeito protetor de alimentos básicos, típicos da dieta brasileira.

- A categoria mais elevada de consumo do padrão monótono, caracterizado pelo baixo consumo de frutas e vegetais, associou-se 
positivamente com o câncer oral, independente dos fatores de risco reconhecidos para este câncer: álcool e fumo.

- Observou-se efeito dose-resposta significativo, com diminuição de risco de acordo com o aumento do consumo, para vegetais crus e feijão;

- Observou-se efeito dose-resposta significativo, com aumento do risco segundo o aumento do consumo de batata e ovos;

- Com relação aos grupos de alimentos, verificou-se diminuição de risco segundo maior consumo de vegetais e frutas, e aumento de risco segundo maior consumo de alimentos de origem animal e para o padrão monótono 


\section{referências}




\section{REFERÊNCIAS}

Ames BN, Wakimoto P. Are vitamin and mineral deficiencies a major cancer risk? Nat Rev Cancer 2002;2(9):694-704.

Armstrong BK, White E, Saracci, R. Principles of exposure measurement in Epidemiology. Oxford, Oxford University Press; 1992.

Azevedo G, Mendonça S. Cancer no Brasil: um risco crescente. Rev Bras Cancer 1992; 38(4): 167-76.

Baron JA Rohan TE Tobacco. In: Schottenfeld D Fraumeni JF Jr (eds) Cancer epidemiology and prevention. $2^{\text {nd }}$ ed New York: Oxford University Press; 1996 Blot WJ, McLaughlin JK, Devesa SS, Fraumeni JF. Cancers of the oral cavity and pharynx. In: Schottenfeld D, Fraumeni JF. Cancer epidemiology and prevention. $2^{\text {nd }}$ ed. New York: Oxford University; 1996

Blot WJ, McLaughlin JK, Winn DM, Austin DF, Greenberg RS, Preston-Martin S, Bernstein L, Schoenberg JB, Stemhagen A, Fraumeni JF Jr. Smoking and drinking in relation to oral and pharyngeal cancer. Cancer Res 1988; $48(11): 3282-7$

Blot WJ, Winn DM, Fraumeni JF Jr. Oral cancer and mouthwash. J Natl Cancer Inst. $1983 ; 70(2): 251-3$

Bofetta $\mathrm{P}$, Brennan $\mathrm{P}$, Herrero R. International study on environment, viruses and cancer of oral cavity na the larynx: study protocol. International Agency for Research on Cancer (IARC); 1998. 
Boffetta P, Mashberg A, Winkelmann R, Garfinkel L Carcinogenic effect of tobacco smoking and alcohol drinking on anatomicsites of the oral cavity and oropharynx. Int J Cancer 1992; 52(4):530-3.

Bosetti C, Negri E, Franceschi S, Conti E, Levi F, Tomei F, La Vechia C. Risk factors for oral and pharyngeal cancer in women: a study from Italy and Switzerland. British Journal of Cancer 2000, 82(1): 204-207.

Boyle P, Macfarlane G Blot WJ et al. Oral carcinogenesis in Europe. Oral Oncol Eur J Cancer 1995; 31B:1-11

Breslow NE, Day NE. Statistical methods in cancer research: the analysis of case-controls studies. Lyon: IARC; 1980. IARC Scientific Publications no. 32.

Carlini EA, Galduroz JCF, Noto AR, Nappo AS. I Levantamento domiciliar sobre o uso de drogras psicotrópicas no Brasil: estudo envolvendo as 107 maiores cidades do país. São Paulo: SENAD; 2002.

Choi SY, Kahyo $\mathrm{H}$. Effect of cigarette smoking and alcohol consumption in the aetiology of cancer of the oral cavity, pharynx and larynx. Int J Epidemiol 1991; 20(4): $878-85$

Chyou PH, Nomura AMY, Stemmermann GN. Diet, alcohol, smoking and cancer of the upper aerodigestive tract: a prospective study among hawaii japanese men. Int J Caner 1995; 60: 616-25. 
Cohen LA. Diet and cancer. Sci Am 1987; 257: 42-50.

Coleman MP, Esteve J, Damiecki $P$ et al (eds) Trend in cancer incidence and mortality. Lyon, IARC Press;1993. IARC Scientific Publication no. 121.

Costa e Silva VL, Koifman S. Smoking in Latin America: a major public health problem. Cad Saúde Pública 1998;14 (Sup. 3): 99-108.

Dallongeville J, Marecaux N, Fruchart JC, Amouye P. Cigarrette smoking is associated with unhealthy patterns of nutrient intake: a meta-analysis. $J$ Nutrition 1998;128: 1450-1457.

Day NE, Ferrari P. Some methodological issues in nutritional epidemiology. In: Riboli E, Lamber R. Nutrition and lifestyle: opportunities for cancer prevention. Lyon: IARC Press; 2002. IARC Scientific Publications no. 156.

De Stefani E Boffetta P Oreggia F Medilaharsu M Deneo Pellegrini H. Smoking patterns and cancer of the oral cavity and pharynx a case control study in Uruguay. Oral Oncoloy 1998; 3440-6

De Stefani E, Boffetta P, Oreggia F, Fierro L, Mendilaharsu M. Hard liquor drinking is associated with higher risk of cancer of the oral cavity and pharynx than wine drinking. A case-control study in Uruguay. Oral Oncol 1999; 34(2):99-104.

De Stefani E, Deneo-Pellegrini H, Mendilaharsu M, Ronco A. Diet and risk of cancer of the upper aerodigestive tract--I. Foods. Oral Oncol 1999, 35(1):17-21. 
Elmore JG, Horwitz RI. Oral cancer and mouthwash use: evaluation of the epidemiologic evidence. Otolaryngol Head Neck Surg 1995;113(3):253-61.

Esteve J, Riboli E, Pequignot G, Terracini B, Merletti F, Crosigniani P et al. Diet cancers of larynx and hypopharynx: the IARC multi center study in southwestern Europe. Cancer Causes Control 1996; 7(2):240-52.

Ferlay J, Bray F, Pisani P, Parkin DM. GLOBOCAN 2000: Cancer incidence, mortality and prevalence worldwide, Version 1.0. IARC CancerBase No. 5. Lyon, IARCPress; 2001.

Fioretti F, Bosetti C, Tavani A, Franceschi S, La Vecchia C. Risk factors for oral and pharyngeal cancer in never smokers. Oral Oncology 1999; 35: 375-78.

Fonseca LAM. Mortalidade por câncer no Estado de São Paulo: perfil atual, distribuiçào geográfica e tendências temporais. São Paulo, 1996 [Tese de doutorado - Faculdade de Saúde Pública da USP].

[FOSP] BOLETIM DO REGISTRO HOSPITALAR DE CÀNCER, 2(11), 2002. arquivo disponivel na URL:http://www.fosp.saude.sp.gov.br. [10/dezembro/ 2002].

Franceschi S, Barra S, La Vecchia C, Bidoli E, Negri E, Talamini R. Risk factors for cancer of the tongue and the mouth. A case-control study from northern Italy. Cancer. 1992,70(9):2227-33. 
Franceschi S, Bidoli E, Baron AE,Barra S, Talamini R, Serraino D, La Vecchia

C. Nutrition na cancer of the oral cavity and pharynx in north east Italy. Int $J$ Cancer $1991 ; 47: 20-5$.

Franceschi S, Bidoli E, Herrero, R Munoz N. comparison of cancers of the oral cavity and pharynx worldwide. Oral Oncoloy 2000, 36:106-115.

Franceschi S, Bidoli E, Negri E, Barbone F, La Vecchia C. Alcohol and cancers of the upper aerodigestive tract in men and women Cancer Epidemiol Biomarkers Prev 1994 Jun;3(4):299-304.

Franceschi S, Favero A., Conti E, Talamini R, Volpe R, Negri E, Barzan L, La Vecchia C. Food groups, oils and butter and cancer of the oral cavity and pharynx. British Journal of Cancer, 1999, 80(3/4): 614-20.

Franco EL, Dib LL, Pinto DS, Lombardo V, Contesini H.Race and gender influences on the survival of patients with mouth cancer. J Clin Epidemiol 1993 Jan; $46(1): 37-46$

Franco EL, Kowalki LP, Oliveira BV, Curado MP, Pereira RN, Silva ME, Fava AS, Torloni $H$. Risk factors for oral cancer in Brazil: a case-control study. Int J Cancer $1989 ; 43(6): 992-1000$.

Fung TT, Willet WC Stampfer MJ, Manson JE; Hu FB. Dietary patterns and the risk of coronary heart disease in women. Arch. Intern. Med 2001; 161: 18571862. 
Gallagher ML, Farrior E, Broadhead L, Gillette LS, Rowe ML, Somes G, West P, Kolasa KM. Developing and testing of a food frequency recall instrument for describing dietary patterns in adults and teenagers. Nutr. Res 1993; 13:177188.

Garewal H. Antioxidants in oral cancer prevention. Am J Clin Nutr 1995; 62(S): $1410 S-6 S$.

Garrote LF, Herrero R, Reyes RM, Vaccarella S, Anta JL, Ferbeye L, Munoz N, Franceschi S. Risk factors for cancer of the oral cavity and oro-pharynx in Cuba. Br J Cancer 2001;85(1):46-54.

Giovannuccini E, Stamper MJ, Coldtiz Ga Manson JE, Rosner BA, Longnecker M, Speizer FE, Willett WC. A comparison of prospective and retrospective assessment of the diet in the study of breast cancer. Am J Epidemiol 1993; 137: $502-511$.

Giskes K, Turrell G, Patterson C, Newman B. Socio-economic differences in fruit and vegetable consumption among Australian adolescents and adults. Public Health Nutr 2002; 5(5):663-9.

Gordon T, Fisher M, Rifkind BM. Some difficulties inherent in the interpretation of dietary data from free-living populations. Am J Clin Nutr 1984; 39: 152-56.

Graham S, Dayal H, Rohere T, Swanson M,. Sultz H, Shedd D, Fischman S. Dentition, diet, and alcohol in the epidemiology of oral cancer. J Natl Cancer Inst $1977,59(6):$ : 1611-1618. 
Gridley G, McLaughlin, Block G, Blot WJ, Winn DM, Greenberg RS, Schoenberg JB, Preston-Martin S, Austin DF, Fraumeni JF. Diet and oral and pharyngeal cancer among blacks. Nutrition and cancer 1990, 14(3/4): 219-224.

Haines PS, Siega-Riz AM, Popkin BM. The Diet Quality Index revised: a measurement instrument for populations. J Am Diet Assoc 1999; 99(6), 697704.

Hair JF; Anderson RE Tatham RL; Black WC. Mutivariate data analysis with readings. 4.ed. New Jersey: Prentice Hall;1995.

Harris PJ, Ferguson LR. Dietary fibres may protect or enhance carcinogenesis. Mutat Res 1999; 443(1-2): 95-110.

Hebert JR, Miller DR. Methodologic considerations for investigating the dietcancer link. Am J Clin Nutr 1988; 47(6): 1068-77.

Hindle L, Downer, MC, Speight P. The epidemiology of oral cancer. Br J Oral Maxillofacn Surg 1996; 34: 471-6.

Horta BL, Calheiros P, Pinheiro RT, Tomasi E, Amaral KC. Tabagismo em adolescentes de área urbana na região Sul do Brasil. Rev. Saúde Pública, $200135: 159-164$

Hosmer DW, Lemeshoe S. Applied logistic regression. New York: Johun Wiley; 1989. 
Hu FB, Rimm E, Smith-Warner SA; Feskanich D, Stampfer MJ; Ascherio A, Sampson L; Willet WC. Reproducibility and valitidy of dietary patterns assessed with a food frequency questionnaire. Am J Clin Nutr 1999; 69: 243-9.

IARC - Tobacco smoking. Monographs on the carcinogenic risk of chemical to humans. Lyon: IARC Press, 1986.

IARC. Alcohol drinking. IARC Monographs on the evaluation carcinogenic risk in humans. Lyon: IARC Press; 1988.

INCA INSTITUTO NACIONAL DO CÂNCER. Estimativas da incidência e mortalidade de câncer no Brasil: 2000. Brasilia (DF), 2000.

INCA. INSTITUTO NACIONAL DO CÂNCER. Estimativa da incidência e mortalidade por câncer no Brasil 2002. Disponivel em URL: http//wnw. inca.org.br/cancer/epidemiologia/estimativa2002.[novembro 2002].

James WP Nelson M. Ralph A, Leather S. Socio-economic determinants of health. The contribution of nutrition to inequalities in health. BMJ 1997; 314: 1545-1549.

Johnson NW, Warnakulariya KA. Epidemiology and aetiology of oral cancer in the United Kingdon. Community Dental Helth 1993; 10: 13-29

Kabat GC, Hebert JR, Wynder EL Risk factors for oral cancer in women. Cancer Res $1989 ; 49(10): 2803-6$ 
Kjaerheim K, Gaar M. Anderse A. The role of alcohol, tobacco and dietary factors in upper aerogastric tract cancer: a prospective study of 10.900 Norwegian men. Cancer Cause Control 1998; 9(1): 99-108.

Kamat AM, Lamm DL. Chemoprevention of urological cancer. J Urol 1999 161(16): $1748-60$.

Kant AK. Indexes of overall diet quality: a review. J Am Diet Assoc 1996; 96: $785-91$

Kato 1, Nomura AMY. Alcohol in the aetiology of upper aerodigestive tract cancer. Eur J Cancer B Oral Oncol 1994; 30B(2):75-81.

Key TJ Allen NE Spencer EA Travis RC. The effect of diet on risk of cancer. Lancet 2002; 360: 861-68

Kim J-O, Mueller CW. Factor analysis: statistical methods and practical issues. Thousand Oaks, CA: Sage Publications; 1978.

Kleinbaum DG, Kupper LL, Muller KE, Nizam A. Applied regression analysis and other multivariable methods. $3^{\text {rd }}$ ed. Pacific Grove, CA: Duxbury; 1998.

Kopec JA, Esdaile JM. Bias in case-control studies. A review. J Epidemiol Community Health $1990 ; 44(3): 179-86$. 
Krauss RM, Eckel RH, Howarsd B, Appel LJ, Daniels SR, Deckelbaum RJ; Erdman JW, Etherton PK et al Revision 2000: a statement for healthcare professionals from the nutrition committee of the American Heart Association. J.Nutr 2001; 131: 132-146.

Kristal AR, Lampe, JW. Brassica vegetables and prostate cancer risk: a review of epidemiological evidence. Nutrition and Cancer 2002; 42(1): 1-9.

Kuper H, Boffetta P, Adami HO. Tobacco use and cancer causation: association by tumor type. J. Internal Medicine 2002; 252:206-22

La Vechia C, Tavani A, Franceschi S, Levi F, Corrao G, Negri E. Epidemiology and prevention of oral cancer. Oral Oncol 1997; 33(5):302-12.

Laranjeira R, Hinkly D. Evaluation of alcohol outlet density and its relation with violence. Rev Saúde Pública 2002; 36(4): 455-461.

Leite ISG, koifman S. Revisão dos fatores de risco para o câncer de boca e faringe. Rev Bras Cancerol 1998; 44(4): 317-25.

Leterme P. Recommendations by health organizations for pulse consumption. Br J Nutr 2002; 99(3S): S279-42.

Levi F, Pasche C, La Vechia C, Lucchini F, Franceschi S, Monnier P. Food groups and risk of oral and pharyngeal cancer. Inter J Cancer 1998; 77(5): 7059. 
Macfarlane GJ, Zheng T, Marshall P, Boffetta P, Niu S, Brasure J, Merlett F, Boyle P. Alcohol, tobacco, diet and risk of oral cancer: a pooled analysis of three case-control studies. Oral Onc Eur J Cancer 1995; 31B (3): 181-7.

Marquart L, Jacobs DR Jr, Slavin JL. Whole grains and health: an overview. J Am Coll Nutr. $2000 ; 19$ (3 Suppl): 289S-290S.

Marshal J R, Graham S, Haughey B, Shedd D, O'Shea R, Brasure J, Wilkinson GS, West D. Smoking, alcohol, dentition and diet in the epidemiology of oral cancer. Oral Oncol Eur J Cancer, 1992, 28B(1)9-15.

Marshall JR; Boyle, P. Nutrition and oral cancer. Cancer Causes Control 1996; $7: 101-11$

Martinez ME; Marsahll JR; Schrest L. Invited commentary: factor analysis and the search objectivity. Am J Epidemiol 1998; 148(1): 17-19.

Mashberg A, Barsa P, Grossman ML. A study of the relationship between mouthwash use and oral and pharyngeal cancerJ Am Dent Assoc. 1985 , $110(5): 731-4$

Mashberg A, Boffetta P, Winkelman R, Garfinkel L.Tobacco smoking, alcohol drinking, and cancer of the oral cavity and oropharynx among U.S. veterans. Cancer $1993 ; 72(4): 1369-75$.

Matherly LH. Molecular and cellular biology of the human reduced folate carrier. Prog Nucleic Acid Res Mol Biol 2001; 67:131-62 
Mathers JC. Pulses and carcinogenesis: potential for the prevention of colon, breast and other cancers. Br J Nutr 2002; 99(3S): S273-9.

McLaughlin JK, Gridley, G, Block, G, Winn DM, Preston-Martin S; Schoenber JB; Greenberg RS, Stemhagem A, Austin DF, Ershow AG; Blot WJ, Fraumeni JF. Dietary factor in oral and pharyngeal cancer J Natl Cancer Inst 1988 , $80(15): 1237-1243$

Merletti F, Boffetta P, Ciccone G, Mashberg A, Terracini B.Role of tobacco and alcoholic beverages in the etiology of cancer of the oral cavity/oropharynx in Torino, Italy. Cancer Res 1989;49(17):4919-24.

Mirra, A P Incidência de câncer no municipio de São Paulo, Brasii 1983 - 1988 1993; tendência no periodo 1969-1993.- São Paulo: MS/USP/FSP; 1999

Mirra, A P; Latorre, MRDO; Veneziano, DB. Incidência de câncer no municipio de São Paulo, Brasil - 1997-1998: mortalidade de câncer no municipio de São Paulo, Brasil: tendência no período 1969-1998. São Paulo: MS/USP. FSP; 2001 Monteiro CA, Mondini, L, Costa, RBL. Mudanças na composição e adequação nutricional da dieta familiar nas áreas metropolitanas do Brasil (1986-1996). Rev Saúde Pública 2000; 34(3) 251-58.

Monteiro CA, Mondini L,; Souza ALM; Popkin BM. Da desnutricäo para a obesidade: a transiçäo nutricional no Brasil In: Monteiro CA. Velhos e novos males da saúde no Brasil: a evoluçäo do país e de suas doenças. Säo Paulo: Hucitec, 1995. 
Morse DE, Katz RV, Pendrys DG, Holford TR, Krutchkoff DJ, Eisenberg E, Kosis

DL, Kerpel S, Freedman P, Mayne ST. Mouthwash use and dentures in relation to oral epithelial dysplasia. Oral Oncol $1997 ; 33(5): 338-43$.

Neves LHM Câncer de boca: mortalidade entre residentes no estado de São Paulo no período de março de 1979 à fevereiro de 1982. São Paulo; 1994. [Tese de Doutorado - Faculdade de Saúde Pública da USP].

Notani PN, Jayant K. Role of diet in upper aerodigestive tract cancers. Nutr Cancer 1987; 10:103-113.

OMS. CID-10: classificação estatística internacional de doenças e problemas relacionados à saúde, $10^{a}$ revisão. 2.ed. São Paulo: Edusp; 1995.

[OPAS] - Organización Panamericana de la Salud. Normas éticas internacionales para las investigaciones biomédicas com sujetos humanos. Wahington DC: OPAS; 1996. Publicación Científica n ${ }^{\circ} 563$.

Oreggia F, De Stefani E, Correa P, Fierro L, Risk factors for cancer of tongue in Uruguay. Cancer 1991; 67:180-3.

Paiva, SA, Russell RM, B-Carotene and other carotenoids as antioxidants. J Amer Coll Nutr 1999; 18(5): 426-433.

Palli D; Russo A, Decarli A. Dietary patterns, nutrient intake and gastric cancer in a high risk area of Italy. Cancer Causes Control 2001; 12: 163-172.

Parkin SL, Whelan J, Ferlay J, Raimond L. Cancer incidence in five continents. vol VII. Lyon: IARC Press; 1996. IARC Scientific Publication no 143. 
Parmenter K, Waller J, Wardle J. Demographic variation in nutrition knowledge in England. Health Educ Res 2000;15(2):163-74.

Pereira JCR. Análise de dados qualitativos: estratégias metodológicas para as ciências da saúde, humanas e sociais. São Paulo: EDUSP; 1999.

Pereira MG. Epidemiologia: teoria e prática. $5^{\text {a. }}$ reimpr. Rio de Janeiro: Guanabara Koogan, 2001.

Petridou E, Zavras Al, Lefatzis D, Dessypris N, Laskaris G, Dokianakis G, Segas, J, Douglas CW, Diehl SR, Trichopoulos D. The role of diet and specific micronutrients in the etiology of oral carcinoma. Cancer 2002; 94(11):2981-8.

Pintos J, Franco EL, Oliveira BV, Kowaski LP,. Curado MP, Dewar R. Mate, coffe and tea consuiption and risk of cancer of the upper aerodigestive tract in souther Brazil. Epidemiology 1994; 5(6):583-9.

Pontes NS. A informação de consumo alimentar: os dados da POF 19951996. In:Instituto Danone. Consumo alimentar: as grandes base de informação. São Paulo: Instituto Danone, 2000.

Porth CM Pathophysiology: concepts of altered health states. 5.ed. Philadelphia-New York: Lippincott; 1998.

Potter JD, Steinmetz K. vegetables, fruits and phytoestrogens as preventive agents. In: Stewart BW, McGregor D, KLEIHUES P. Principles of chemoprevention. Lyon: IARC Press; 1996. IARC Scientific Publications no. 139. 
Randall E, Marshall JR, Graham S, Brasure J. Patterns in food use and their associations with nutrient intakes. Am J Clin Nutr 1990; 52: 739-45.

Rao AV, Agarwal S. Role of antioxidant lycopene in cancer and heart disease. J Am Coll Nutr 2000;19(5):563-9.

Rao DN, Ganexh B, Rao RS, Desai PB. Risk assessment of tobacco, alcohol and diet in oral cancer - a case control study. Int J Cancer 1994: 58:469-73.

Rao DN, Desai PB. Risk assessment of tobacco, alcohol and diet in cancers of base tongue and oral tongue: a case control study. Indian J Cancer. 1998, $35(2): 65-72$.

Rego RA, Berardo FAN, Rodrigues SSR, Oliveira ZMA, Oliveira MB, Vasconcelos C. Fatores de risco para doenças crônicas não transmissiveis: inquérito domiciliar no Município de São Paulo. Metodologia e resultados preliminares. Rev Saúde Pública 1990; 24: 277-85.

Ribeiro KCB, Kowlaski LP, Latorre MRDO. Impact of comorbidity, symptoms, and patients characteristics on the prognosis of oral carcinomas. Arch Otolaryngol Head Neck Surg 2000; 126:1079-1985.

Schlecht NF, Franco EL, Pintos J, Negassa A, Kowalski LP, Oliveira BV, Curado MP. Interaction between tobacco and alcohol consumption and the risk of cancers of the upper aero-digestive tract in Brazil. Am J Epidemiol 1999; $150(11): 1129-37$

Schlesselman JJ; Stoley PD. Case-control studies: design, conduct, analysis.New York; Oxford University Press; 1982. 
Schulz KF, Grimes DA. Case-control studies: research in reverse. Lancet. $2002 ; 359(9304): 431-4$

Schulze MB; Hoffmann $\mathrm{KH}$; Kroke KA; Boeing $\mathrm{H}$. Dietary patterns and their association with food and nutrient intake in the European Prospective Investigation into Cancer and Nutrition (EPIC) - Postdam Study. British Journal of Nutrition 2001; 5: 363-373.

Slavin JL. Mechanisms for the impact of whole grain foods on cancer risk.

J Am Coll Nutr. 2000;19(3 Suppl):300S-307S.

SEADE Estimativas vitais do estado de São Paulo. URL - http: unw.seade.gov.br 15/09/99.

Serra Majem L. Aranceta JB Nutrición y salud pública.: métodos, bases cientificas y aplicaciones. Barcelona: Masson; 1995.

Sgarbieri VC. The role of dietary energy and macrocomponentes of foods in modulating carcinogenesis : an overview. Ciência e cultura 1999; 51(2):104121.

Shapiro JA, Jacobs EJ, Thun MJ. Cigar smoking in men and risk of death from tobacco-related cancers.J Natl Cancer Inst. 2000 16;92(4):333-7.

Shapiro TA, Fahey JW, Wade KL, Stephenson KK, Talalay P. Human metabolism and excretion of cancer chemoprotective glucosinolates and isothiocyanates of cruciferous vegetables. Cancer Epidemiol Biomarkers Prev. 1998; 7(12):1091-100. 
Sichieri R. Dietary patterns and their associations with obesity in the Brazilian city of Rio de Janeiro. Obes Res 2002: 10(1), 42-8.

Silva DO. Estudo multicêntrico de consumo alimentar em familias e individuos no Brasil. In Instituto Danone. Alimentação equilibrada para a população brasileira: a pirâmede alimentar. I Workshop Instituto danone, Florianópolis, maio de 1998.

Slattery ML; Boucher KM; Caan BJ; Potter JD; Ma KN Eating patterns and the risk of colon cancer. Am J Epidemiol 1998: 148(1), 4-16.

Takezaki $T$, Hirose $\mathrm{K}$, Inoue $\mathrm{M}$, Hamajima $\mathrm{N}$, Kuroishi $T$, Nakamura $\mathrm{S}$, Koshikawa T, Matsiira H, Tajima K. Tobacco, alcohol and dietary factors associated with the risk of oral cancer among japanese. Jpn J Cancer Res, $1996 ; 87: 555-62$.

Talamini R. Vaccarella S, Barbone F, Tavani A, La Vecchia C, Herrero R, Muñoz N, Franceschi S. Oral hygiene, dentition, sexual habits and risco of oral cancer. Br J Cancer 2000; 83:1238-1442.

Tavani A, Gallus S, La Vecchia C, Talamini, R Barbone F, Herreno R, Franceschi S. Diet and risk of oral and pharyngeal cancer: an Italian case control study. Eur J Cancer Prev 2001; 10: 191-195.

Thrichoupoulos D, Lagiou P. Dietary patterns and mortality. British Journal of Nutrition 2001; 85: 133-134. 
Tuyns AJ. Alcohol. In Schottenfield D, Fraumeni JF jr. (org) Cancer epidemiology and prevention. Filadelfia: WB Saunder, 1996.

Uzcudun AE: Retolaza IR, Fernandez PB, Sanchez Hernandez JJ, Grande AG, Garcia AG, Olivar LM, De Diego Sastre I, Baron MG, Bouzas JG. Nutrition and pharyngeal cancer: results from a case-control study in Spain. Head Neck $2002,24(9): 830-40$.

Verhoeven DT, Verhagen H, Goldbohm RA, van den Brandt PA, van Poppel G. A review of mechanisms underlying anticarcinogenicity by brassica vegetables. Chem Biol Interact. 1997 28;103(2):79-129.

WHO A summary of global status report on alcohol. Management of substance dependence non-comunicable diseases. World Health Organization, 2001

Willet WC. Diet and nutrition. In: Schottenfeld D, Fraumeni JF. Cancer epidemiology and prevention. New York: Oxford University Press; 1996.

Willet $W$. Nutritional epidemiology issues in chronic disease at the turn of the century. Epidemiol Rev 2000;: 22(1), 82-6.

Willet W; Stampfer M. Total energy intake: implications for epidemiologic analyses. Am J Epidemiol 1986; 124(1): 17-27.

Willett W Nutritional epidemiology: monographs in epidemiology and biostistics vol 30. 2.ed.. New York/Oxford: Oxford; 1998. 
Winn DM, Blot WJ, McLaughlin JK, Austin DF, Greenberg RS, Preston-Martin S, Schoenberg JB, Fraumeni JF Jr. Mouthwash use and oral conditions in the risk of oral and pharyngeal cancer. Cancer Res 1991; 51(11):3044-7

Winn DM, Diehl SR, Brown LM, Harty LC, Bravo-Otero E, Fraumeni JF Jr, Kleinman DV, Hayes RB. Mouthwash in the etiology of oral cancer in Puerto Rico. Cancer Causes Control 2001;12(5):419-2

Winn DM. Diet and nutrition in the etiology of oral cancer. Am J Clin Nutr 1995; 61(S): 437S- 45S.

[WRCF] World Cancer Research Fund. Nutrition and the Prevention of Cancer: a global perspective. Washington: American Institute for Cancer Research; 1997.

Wünsch V Camargo EA. The burden of mouth cancer in Latin America and the Caribbean: epidemiologial issues Semin Oncol 2001, 28(2):158-68

Wünsch V. The epidemiology of oral and pharynx cancer in Brazil. Oral Oncol $2002 ; 38(8): 737-46$.

Wynder EL, Hulterberg S, Jacobsson F, Bross IJ. Environmental factors in cancer of the upper alimentary tract. Cancer 1957; 10: 470-486.

Wynder EL, Kabat G, Rosenberg S, Levenstein M. Oral cancer and mouthwash use. J Natl Cancer Inst 1983;70(2):255-60 
Zhang Y, Talalay P, Cho CG, Posner GH. A major inducer of anticarcinogenic protective enzymes from broccoli: isolation and elucidation of structure. Proc Natl Acad Sci U S A. 1992; 89(6):2399-403.

Zheng T, Boyle P, Willet WC, Hu H, Dan J, Evstifeeva TV, Niu S MacMahon B. N A case control study of oral cancer in Beijing, People's Republic of China: associations with nutrient intakes food and food groups. Oral Onc Eur $J$ Cancer 1993; 29B(1): 45-55.

Zheng W, Blot WJ. Shu XO; Diamond EL; Gao YT, Ji BT; Fraumeni JF. Risk factors for oral and pharyngeal cancer in Shangai, with emphasis on diet. Cancer Epidemiol Biomarkers Prev 1992 1441-448.

Zheng W, Sellers TA, Doyle TJ, Kushi LH, Potter JD, Folsom AR. Retinol, antioxidant vitamins and cancer of the upper digestive tract ina a prospective cohort study of postmenopausal women. Am J Epidemiology, 1995, 142(9):955-60 
ANEXO 1 


\section{Relação de diagnósticos (como razão de admissão A1 ambulatorial ou hospitalar) não elegíveis para o estudo}

Abcesso de cavidade oral

Abcesso cerebral

Abcesso de faringe

Acidentes vasculares cerebrais (AVC)

Amigdalite crônica

Angina pectors

Angiossarcoma do fígado

Antracose

Asbestose

Asma

Bissinose

Bronquite crônica

Bronquite devido à produtos químicos, gases, fumaças e vapores

Câncer cuja localização primária seja desconhecida

Câncer de ânus

Câncer de bexiga

Câncer de cavidade oral

Câncer de cérebro

Câncer de colo de útero

Câncer de esôfago

Câncer de faringe

Câncer de figado

Câncer de laringe

Câncer de pâncreas

Câncer de pele (basal e células escamosas)

Câncer de pênis

Câncer de pulmão

Câncer de reto

Câncer de rim

Câncer de vagina

Câncer de vuiva

Cirrose

Dermatite alérgica de contato

Dermatite de contato por irritantes

Diabetes

Doença de Alzheimer

Doença auto-imune

Doença de Parkinson

Doença isquêmica do coração

Doença pulmonar obstrutiva crônica (DPOC)

Doenças das cordas vocais

Trombose venosa

Edema pulmonar agudo devido a produtos químicos,gases, fumaças $e$ vapores 
Efeito tóxico de corrosivos

Efeito tóxico de solventes orgânicos, hidrocarbonetos alifáticos e aromáticos Efeito tóxico de metais (cromo/cádmio/niquel e seus compostos)

Efeito tóxico de pesticidas

Enfisema

Estomatite crônica

Hepatite

Infarto agudo do miocárdio

Laringite crônica

Leucemias

Linfomas

Meningites

Mesoteliona da pleura

Nefropatia túbulo-intersticial induzida por metais pesados

Placas pleurais

Pneumoconiose

Pneumonite por radiação

Pólipo das cordas vocais

Psicoses

Raiodermatite

Retardamento mental

Siderose

Silicose

Sinusite crônica 
ANEXO 2 
ESTUDO INTERNACIONAL SOBRE CAVIDADE ORAL E LARINGE

\section{QUESTIONÁRIO SOBRE HÁBITOS DE VIDA}

1. Número de identificação

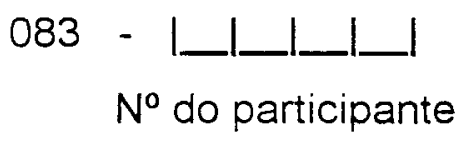

Nome do paciente.

Endereço

Telefone: 


\section{ESTUDO INTERNACIONAL SOBRE CAVIDADE ORAL E LARINGE}

Número de identificação:

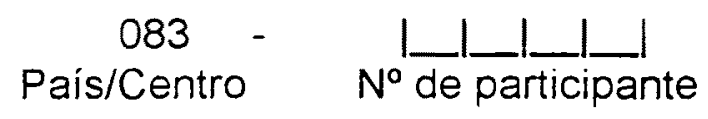

A1 Estado: (1) Caso (2) Controle

$\mathrm{N}^{\circ}$ do registro médico ou prontuário:

A2 Iniciais (sobrenome-nome)

A3 Hospital (CL)

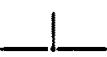

A4 Departamento.

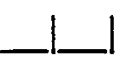
(1) Clínica médica
(2) Cirurgia
(3) Gin/Obst
(4) Ortopedia
(5) Otorrinol.
(6) Dermatologia
(7) Oftalmologia

(8) Odontologia

(9) Radioterapia

(10) Oncologia

(11) Ambulatório

(12) Outro:

(especificar)

A5 Diagnóstico principal da baixa hospitalar H (em caso de pacientes ambulatoriais apenas com suspeita de câncer=8888) (CID-10)

A6 Data da admissão hospitalar (ou consulta).

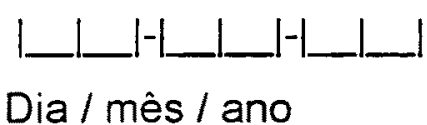

A7 Entrevistador (CL) 
Bom dia Sr.(a)

Meu nome é

Nós estamos realizando um estudo para saber se certos hábitos das pessoas estão relacionados com algumas doenças.

Vou lhe fazer algumas perguntas e anotar as respostas neste questionário.

Tudo que for dito será confidencial.

$\mathrm{Se} o$ (a) Sr.(a) não entender qualquer uma das questões, peça para eu the explicar.

Além desse questionário, vamos passar uma escova de dentes na sua boca para coletar células e retirar uma amostra de sangue (alguém do laboratório fará a coleta do sangue).

Podemos começar?

Será que o(a) Sr.(a) poderia assinar essa folha de consentimento? 


\section{INFORMAÇÕES GERAIS}

B1 Data da entrevista

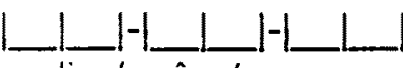

dia / mês / ano

B2 Início da entrevista

hora / $\mathrm{min}$

B3 Sexo: (1) Masculino (2) Feminino

B4 Qual é a sua idade (anos completos)?

B5 Data de nascimento

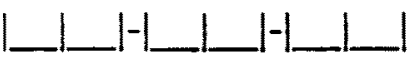

dia / mês / ano

B5a Raça
(1) Branco
(3) Negro
(5) Oriental
(2) Mulato
(4) Indio

B6 Qual a cidade onde o(a) Sr.(a) mora (CL)?

B7 Há quanto tempo o(a) $\mathrm{Sr}$ (a) mora nessa cidade?

(Se menos de um ano, codifique como 00)

B8 Se o(a) Sr(a) está vivendo há menos de 1 ano nessa cidade, onde o Sr(a ) morava antes? (CL).

B9 Em que cidade o(a) Sr.(a) nasceu (CL)?

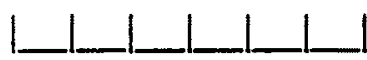

B10 O(a) Sr.(a) freqüentou a escola? (1) sim

(2) não

Se não, vá para $C 1$.

B11 Qual o último ano (série) completo que o(a) $\mathrm{Sr}(a)$ terminou na escola?

B12 Até que grau o(a) $\mathrm{Sr}(\mathrm{a})$ estudou? (CL)

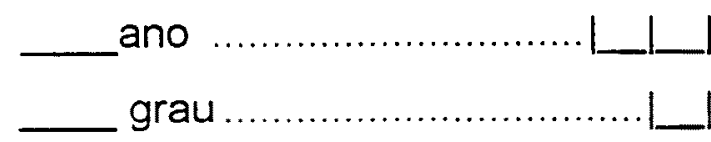




\section{HÁBITO DE FUMAR}

C1 $O(a)$ Sr(a) fuma ou já fumou em média 1 cigarro ou charuto ou cachimbo. diariamente, pelo menos por 1 ano?

(Se parou nos últimos 12 meses, assinalar (1)
(1) sim, ainda fuma
(2) nunca fumou
(3) somente no passado

(Se nunca fumou, vá para C5)

Por favor, descreva os periodos de sua vida em que o(a) $\operatorname{Sr}(a)$ fumou cigarro, charuto ou cachimbo, as quantidades que fumou e outros detalhes sobre o fumo. Por favor, tente lembrar as mudanças mais importantes quanto à quantidade e tipo de cada cigarro. Ignore mudanças que ocorreram por períodos curtos (menos de 1 ano).

Nota para o entrevistador. evite a superposição de anos para o mesmo tipo de cigarro, por exemplo: 30-40, 41-45 ao invés de 30-40, 40-45.

C2 $O(a) \operatorname{Sr}(a)$ fuma ou já fumou "cigarro" ? (Se não, vá para C3)

$\left.\begin{array}{c}\begin{array}{c}\text { Cigarro } \\ \text { (a) }\end{array} \\ \begin{array}{c}\text { Idade de } \\ \text { inicio }\end{array}\end{array} \begin{array}{c}\text { Idade que } \\ \text { parou }\end{array} \begin{array}{c}\text { Tipo } \\ \text { tabaco } \\ \text { (b) }\end{array}\right) \begin{gathered}\text { Tipo de } \\ \text { cigarro } \\ \text { (c) }\end{gathered}$
(a) (1) sim
(2) não

(b) Perguntado somente na Argentina

(c) (1) manufaturado, com filtro

(3) enroladinho de papel

(9) não sabe

(2) manufaturado, sem filtro

(4) enroladinho de palha

C3 $O(a) \operatorname{Sr}(a)$ fuma ou já fumou charuto? (Se não, vá para C4)

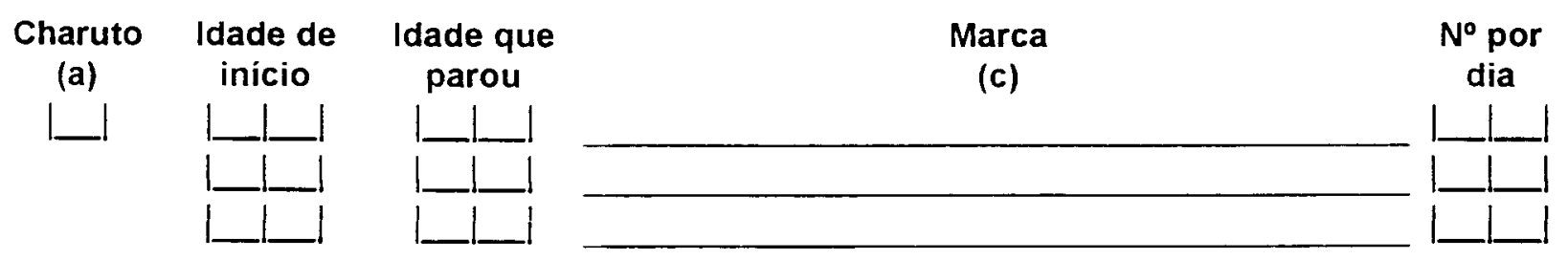
(a) (1) sim
(2) não 
C4 $O(a) \operatorname{Sr}(a)$ fuma ou já fumou cachimbo

(Se não, vá para C5)
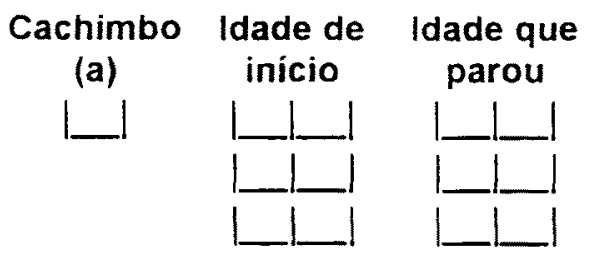
Marca
(c)

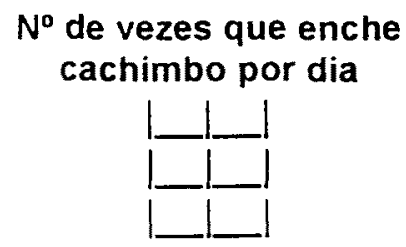
(a) (1) sim
(2) não

C5 $\mathrm{O}$ (a) Sr(a) fuma ou já fumou maconha (marijuna), pelo menos uma vez por semana e pelo menos por 6 meses? (Se não, vá para C6)
Maconha
Idade de inicio
Idade que parou
(a)
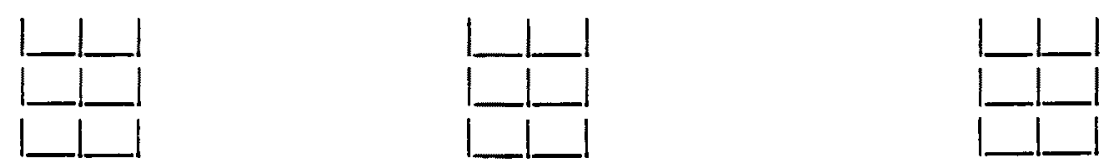

$N^{0}$ de vezes por semana

(a) (1) $\operatorname{sim} \quad$ (2) não

\section{AS QUESTÕES C6-C9 SÃO SOMENTE PARA NÃO FUMANTES}

C6 O(a) $\mathrm{Sr}(\mathrm{a})$ esteve casado (ou vivendo junto) com um(a) fumante?
(1) $\operatorname{sim}$
(2) não
(Se não, vá para C8)

C7 Descreva o hábito do fumo de seu(sua) esposo(a) na sua presença:

Sua idade quando esposo(a) iniciou

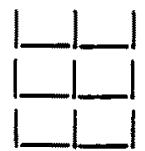

\section{Sua idade quando} esposo(a) parou

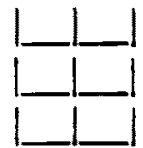

$N^{0}$ de horas/dia que estava exposto

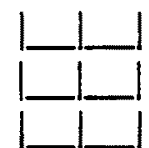

$N^{\circ}$ de horas que fumava em sua presença

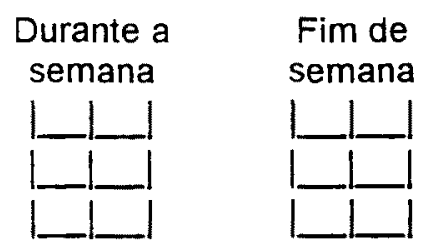

C8 $\mathrm{O}$ (a) $\mathrm{Sr}(\mathrm{a})$ trabalhou em um lugar fechado onde as pessoas fumassem?
(1) sim
(2) não
(Se não, vá para D1)

C9 Descreva os periodos durante os quais o(a) $\mathrm{Sr}(\mathrm{a})$ trabalhou com fumantes:

Sua idade quando iniciou

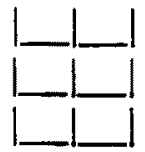

* (1) muita
Sua idade quando parou

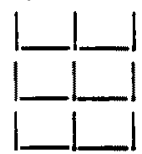

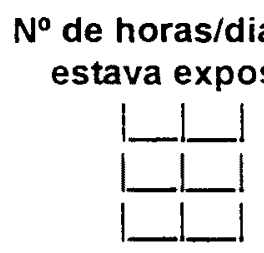

Nivel de fumaça*

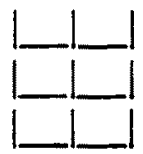

\section{Nivel de fumaça*}
(2) pouca
(9) não lembra 


\section{HÁBITOS ALIMENTARES}

Antes do(a) $\mathrm{Sr}(a)$ ficar doente. qual era a freqüência com que o(a) $\mathrm{Sr}$ (a) comia os seguintes alimentos e bebidas ? Alguns alimentos apenas da época de colheita serão especificados.

Menos de $1 \mathrm{vez} / \mathrm{sem}=98 \quad$ não consome $=00$

$\begin{array}{ll}\text { D1 } & 1 \text { copo (200ml) } \\ \text { D2 } & 1 \text { pote }(125 \mathrm{~g}) \\ \text { D3 } & 1 \mathrm{c} \text {. chá } \\ \text { D4 } & 50 \mathrm{~g} \text { ou } 1 \text { pãozinho } \\ \text { D5 } & 4 \mathrm{c} \text {. de sopa cheias } \\ \text { D6 } & 100 \mathrm{~g} \text { ou } 1 \text { prato fundo cheio } \\ & \\ \text { D7 } & 1 \text { pedaço médio } \\ \text { D8 } & 40 \mathrm{~g} \text { ou } 4 \mathrm{c} \text {. sopa cheias } \\ \text { D9 } & 80 \mathrm{~g} \text { ou } 1 \text { pedaço médio } \\ \text { D10 } & 100 \mathrm{~g} \text { ou 1 pedaço médio } \\ \text { D11 } & 160 \mathrm{~g} \text { ou 1 pedaço médio } \\ \text { D12 } & 80 \mathrm{~g} \text { ou } 1 \text { pedaço médio } \\ \text { D13 } & 150 \mathrm{~g} \text { ou 1 pedaço médio } \\ \text { D14 } & 2 \text { fatias presunto; } 4 \text { de salame } \\ & 2 \text { salsichas } \\ \text { D15 } & 1 \text { unidade } \\ \text { D16 } & 50 \mathrm{~g} \text { ou } 2 \text { fatias médias } \\ \text { D17 } & 1 \text { unidade média } \\ \text { D18 } & 50 \mathrm{~g} \text { ou } 1 \text { prato de sobremesa } \\ \text { D19 } & 50 \mathrm{~g} \text { ou } 1 \text { prato de sobremesa } \\ & \\ \text { D20 } & 1 \text { média } \\ \text { D21 } & 1 \text { pequeno } \\ \text { D22 } & 4 \mathrm{c} \text {. sopa cheias } \\ \text { D23 } & 50 \mathrm{~g} \text { ou } 1 \text { prato de sobremesa }\end{array}$

D24 1 copo ou $200 \mathrm{ml}$
D25 1 média
D26 1 média
D27 1 média
D28 1 média

D29 1 fatia ou taça

Leite
logurte
Manteiga
Pão
Macarrão ou arroz

Pratos a base de milho (polenta, creme de milho...)

Mandioca, Aipim

Farinha de mandioca

Carne de boi

Carne de porco

Galinha ou frango

Outras carnes (carneiro, etc)

Peixe

Presunto, salame, salsicha

Ovo

Queijo

Batata

Vegetais crús e salada

Brócolis, repolho, couve de bruxelas

Cenoura

Tomate

Grãos: feijão, lentilha, ervilha

Em resumo, quantas vezes come uma porção de qualquer tipo de vegetal por semana, exceto batata?

Suco de frutas

Maçã ou pera

Frutas citricas (laranja, lima...)

Banana

Em resumo, quantas vezes come qualquer fruta fresca por semana?

Bolo ou doces (sobremesas)
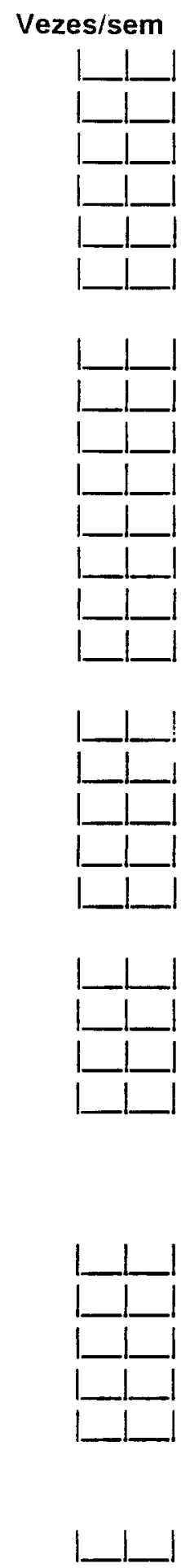
Qual o tipo de gordura que o(a) $\operatorname{Sr}(a)$ "mais usa":

D30 Para temperar os vegetais?

D31 Para cozinhar?
(1) azeite de oliva
(5) margarina
(9) girassol
(12) banha de porco
(2) azeite dende
(6) não usa gordura
(10) óleo de soja
(7) óleo de uva
(11) outro óleo de semente
(13) outra gordura
(3) azeite de côco
(8) óleo mitho
(99) não sabe
(4) manteiga

r(a) come carne?

Tipo de Carne

Carna salgada, charque

Carne seca - norte

Outras carnes

Churrasco
$N^{\circ}$ de vezes por semana

Antes de adoecer

Aos 30 anos
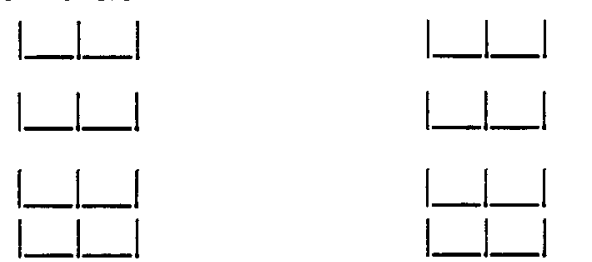

D33 Nos últimos dois anos o $\mathrm{Sr}(\mathrm{a})$ tem tomado vitaminas (remédios)?
(1) $\operatorname{Sim}$
(2) Não
(9) Não sabe

Se não, pule para D36

D34 Com que freqüência o(a) $\operatorname{Sr}(a)$ toma estas vitaminas?
(1) Diariamente
(3) Uma vez por mês
(2) Uma vez por semana
(4) Ocasionalmente
(5) Nunca

D35 Quando adulto (>I=18 anos), com que idade o(a) $\operatorname{Sr}(a)$ começou a tomar vitaminas? anos

D36 Qual seu peso há dois anos? $\mathrm{kg}$

D37 Qual era seu peso aos 30 anos? $\mathrm{kg}$

D38 O Sr(a) usa fogão de lenha para cozinhar alimentos atualmente? $\operatorname{Sim} 1$ Não I_l Anos de uso

D39 No passado (durante a infância, adolescência e adulto jovem), usavase fogão de lenha para cozinhar alimentos na sua casa?

Sim

Não

Anos de uso 


\section{HÁBITOS DE BEBIDA}

E1 $O($ a) Sr.(a) já bebeu bebidas de álcool pelo menos 1 vez por mês?

Se parou nos últimos 12 meses, a resposta é (1) sim, ainda bebe.
(1) sim, ainda bebe
(2) nunca
(3) só no passado

Se nunca, pule para E7.

E2 Quando é que o(a) $\operatorname{Sr}(a)$ bebe (bebia)?
(1) nas refeições
(2) entre as refeições
(3) ambos

Descreva os periodos de sua vida durante os quais o(a) $\mathrm{Sr}$.(a) tomou bebidas alcoólicas. Por favor, tente resumir as mudanças mais importantes em sua vida em relação à quantidade e tipo de bebida. Ignore quaisquer mudanças ocorridas durante curtos períodos de tempo ( menos de 1 ano), ou bebidas consumidas ocasionalmente.

Atenção: Evite sobrepor os anos de consumo de uma mesma bebida. Por exemplo, escreva 30-40 e 41-45, e não 30-40 e 40-45. Perguntar separadamente sobre cada bebida.

\section{Unidade (a)}
(1) Copo pequeno $-50 \mathrm{ml}$
(2) Copo médio - $100 \mathrm{ml}$
(3) Copo grande $-250 \mathrm{ml}$
(4) $1 / 2$ ou pequena garrafa $-330 \mathrm{ml}$
(5) Garrafa $-700-750 \mathrm{ml}$
(6) Garrafa - 1 L

Por (b)
(1) Dia
(2) Semana
(3) Mês

$\begin{array}{lccccc}\text { E3 Cerveja Idade de } & \text { Idade que Unidade } \\ \text { inicio } & \begin{array}{c}\text { Quantas unidades } \\ \text { consome }\end{array} & \begin{array}{c}\text { Por } \\ \text { (b) }\end{array}\end{array}$

E4 Vinho Idade início Idade que Unidade(a) Quantas unidades Por parou

Consome

(b)
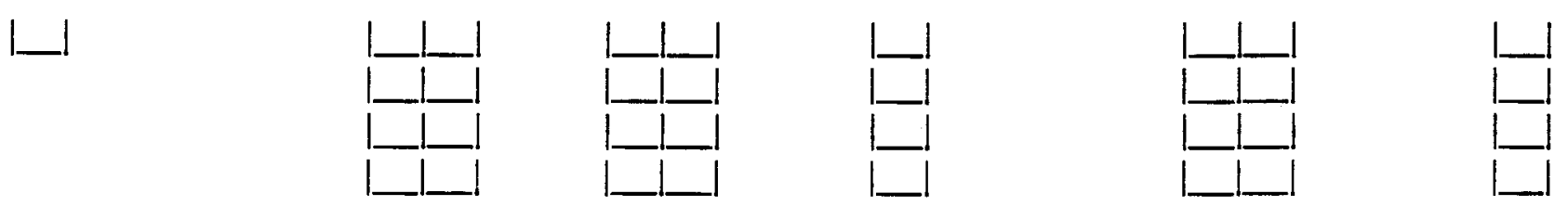


Aperitivo Idade inicio Idade que
(cachaça,
uisque.
$\begin{gathered}\text { Vodca, } \\ \text { Rum, } \\ \text { etc) } \\ \left(>35^{\circ}\right)\end{gathered}$

\section{CHIMARRÃO}

E7 $\mathrm{O}($ a) $\mathrm{Sr}(\mathrm{a})$ tomava ou toma chimarrão habitualmente?

Se parou nos últimos 12 meses, a resposta é (1) sim, ainda toma.
(1) $\operatorname{sim}$, ainda
(2) nunca
(3) só no passado

Se nunca, pule para a F1

Descreva os periodos de sua vida durante os quais o(a) $\operatorname{Sr}(a)$ consumia mate. Por favor, tente resumir as mudanças mais importantes em sua vida em relação à quantidade. Ignore quaisquer mudanças ocorridas durante curtos periodos de tempo ( menos de 1 ano).

Atenção: evite sobrepor os anos. Por exemplo, escreva 30-40 e 41-45, e não $30-40$ e $40-45$.

E8

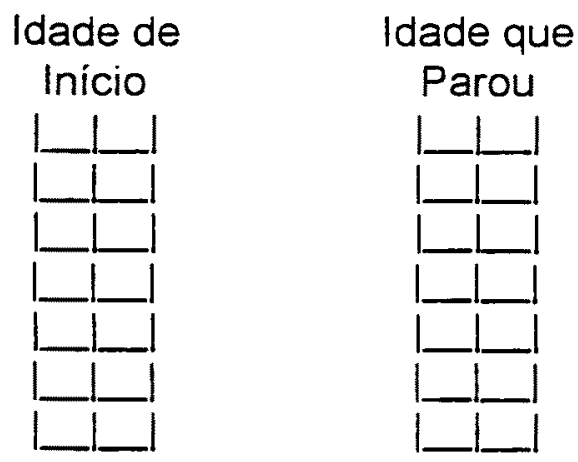

Quantidade de água por dia (litros, mililitros)

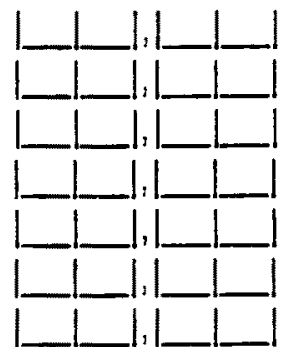

E9 A que temperatura o(a) $\operatorname{Sr}($ a) costuma ou costumava tomar o mate?
(1) frio
(2) morno
(3) quente
(4) muito quente 


\section{HÁBITOS SEXUAIS}

F1 O(a) Sr.(a) já esteve casado(a) ou vivendo junto com alguém?
(1) $\operatorname{sim}$
(2) não

Se não, pule para F7

F2 O(a) Sr.(a) ainda é casado(a) ou vive como se fosse casado?
(1) $\operatorname{sim}$
(2) separado ou divorciado
(3) viúvo

F3 Quantas vezes o(a) Sr.(a) já esteve casado(a) ou vivendo como casado?

F4 Quantos anos o(a) Sr.(a) tinha pela primeira vez que casou ou viveu como casado?

F5 Até que ano sua(seu) última(o) esposa(o) freqüentou a escola? _ano _grau

F6 Qual é ou foi o trabalho mais longo da(o) sua(eu) última(o) esposa(o)? Especificar:

F7 No total, quantos filhos o(a) Sr.(a) teve?

F8 No total, quantos parceiros sexuais o(a) $\mathrm{Sr}$.(a) já teve? (regulares e casuais )

F9 Se dificil de responder
(1) $2-5$
(2) $6-10$
(4) $21-50$
(3) $11-20$
(5) $51-100$
(6) mais de 100

\section{PERGUNTAR F10 E F11 SÓ PARA HOMENS}

F10 Destas parceiras, quantas eram prostitutas?

F11 Se difícil de responder
(1) $2-5$
(2) $6-10$
(4) $21-50$
(3) $11-20$
(5) $51-100$
(6) mais de 100

\section{PERGUNTAR PARA TODOS}

F12 O(a) Sr.(a) já fez sexo colocando sua boca nos genitais do(a) parceiro(a)?
(1) $\operatorname{sim}$
(2) não

F13 Com que freqüência?
(1) ocasionalmente
(2) freqüentemente
(3) quase sempre 


\section{HISTÓRIA DE DOENÇAS}

G1 (a) Sr.(a) já teve verrugas na pele?
(1) sim
(2) não
(9) não sei
Se não, pule para G6
Se a resposta for sim, onde?
(1) $\operatorname{sim}$
(2) não

G2 Mãos

G3 Pés

G4 Cabeça e pescoço

G5 Outros lugares? (especifique)

G6 O(a) Sr.(a) já teve sapinho (Monília, Candida Albicans)?
(1) sim
(2) não
(9) não sei Se não, pule para G10

Se a resposta for sim, onde? (1) sim (2) não

G7 Genital (nas partes)

G8 Boca.

G9 Outros lugares? (especifique).

G10 O(a) Sr.(a) já teve lesões de cobreiro (herpes)?
(1) $\mathrm{Sim}$
(2) não
(9) não sei

Se não, pule para G14)
Se a resposta for sim, onde?
(1) $\operatorname{sim}$
(2) não

G11 Lábio

G12 Genital (nas partes).

G13 Outros lugares? (especifique)

G14 O(a) Sr.(a) já teve alguma doença venérea (pegada, sexualmente transmissivel)?
(1) sim
(2) não
(9) não sei

Se não, pule para G19

$\begin{array}{llll}\text { Se a resposta for } \operatorname{sim} \text {, quais ? } & \text { (1) } \operatorname{sim} & \text { 2) não } & \text { (9) não sei }\end{array}$

G15 Sífilis-cancro

G16 Gonorréia-corrimento

G17 Condiloma-verrugas.

G18 HIV-AIDS 
$\mathrm{O}(\mathrm{a}) \mathrm{Sr}(\mathrm{a})$ já teve algum problema com a voz (rouquidão, por exemplo) que tenha feito o(a) $\mathrm{Sr}(\mathrm{a})$ procurar o médico?
(1) $\operatorname{sim}$
(2) não

Se não, pule para a $\mathrm{H}_{1}$

Se sim, quais?

G19 Laringite aguda obstrutiva (crupe)

G20 Laringite crônica

G21 Pólipo de corda vocal ou de laringe

G22 Nódulo de corda vocal

G23 Edema ou estenose de laringe

G24 Abscesso ou granuloma de cordas vocais

.

G25 Abscesso de retrofaringe ou parafaringe

G26 Outras:

\section{HISTÓRIA DE CÂNCER NA FAMÍLIA}

Eu agora vou perguntar sobre seus familiares em $1^{\circ}$ grau e esposo(a) ou companheiro(a).

H1 Quantos irmãos o(a) Sr(a) teve?....

H2 Quantas irmãs o(a) $\mathrm{Sr}(a)$ teve?

H3 Quantas filhas o(a) $\operatorname{Sr}(a)$ teve?

H4 Quantos filhos o(a) $\mathrm{Sr}(\mathrm{a})$ teve?

H5 Quantas(os) companheiras(os) o(a) Sr(a) teve?

Vamos falar sobre sua mãe/ pai/irmã/irmão/filha/filho/esposa(o) ou companheira(o)

\section{RESPONDER AS PRÓXIMAS PERGUNTAS NA PRÓXIMA PÁGINA!}

H6 Ele (ela) ainda vive?

Se sim, quantos anos ele(ela) tem?

Se não, quantos anos ele(ela) tinha quando faleceu?

H7 Ele(ela) teve algum tumor maligno?

Se sim, qual? Com que idade ele(ela) estava? 
Tipo de familiar: (um familiar por linha)
(1) mãe
(3) irmã
(5) fitha
(7) companheiro(a)
(2) pai
(4) irmão
(6) filho
(8) próprio(a) paciente

\begin{tabular}{|c|c|c|c|c|c|c|c|}
\hline & $\begin{array}{l}\text { Tipo de } \\
\text { familiar }\end{array}$ & $\begin{array}{l}\text { Vivo (1) } \\
\text { Morto (2) }\end{array}$ & $\begin{array}{l}\text { Idade } \\
\text { morte } \\
\text { Idade } \\
\text { atual se } \\
\text { vivo) }\end{array}$ & Tumor & $\begin{array}{l}\text { (1) sim } \\
\text { (2) näo } \\
\text { (9) IGN }\end{array}$ & Tipo do tumor & $\begin{array}{l}\text { Idade ao } \\
\text { diagn. }\end{array}$ \\
\hline $\mid \underline{\text { 의1 }}$ & L & I & L_L & & L & CID|_L_LI-I_L & LL \\
\hline 의늬 & L & L & $1 \ldots$ & & I & $|C| D\left|\_1 / 1=1-\right|$ & L1 \\
\hline $\mid$ 의|느 & LI & L & $\mid \_L$ & & I & CIDI_L_L_H_L & LL \\
\hline 의|니 & L & L & L_L & & $\square$ & CIDI_LI_LI I- _ & 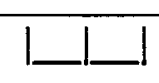 \\
\hline 의되 & I I & L & I_L & & L & CIDI_L_L_I-I_L & LL \\
\hline 의의 & I & L & LLI & & L & CIDI_L_LI_H_ & LL \\
\hline$|ㅇ ㅢ| \mid$ & L & L & $1 \_$ & & I I & CIDI_L_LI_H_L & L_L \\
\hline 의의 & I & L & $1 \_1$ & & L & CIDI_L__L_H_L & LL L \\
\hline 이의 & L & 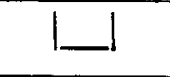 & $1 \ldots$ & & L & CIDI_L_L_LH_L & L L \\
\hline 1의 & I & L & I_LI & & ــ & 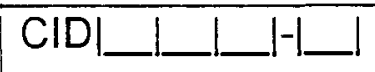 & LL \\
\hline$|1| 2|2|$ & L L & L & LL & & L & CIDI_L_LI_H_L & L L ا \\
\hline$|1| \underline{3} \mid$ & LI & L & $\mid \ldots$ & & L & CIDI_L_L_H_L & LL \\
\hline $1|4|$ & L & L & LL & & L I & CIDI_L_LI_H_I & LL \\
\hline$|1| 5 \mid$ & L & LI & L_Ll & & L & CIDI_L_LH_H & LL \\
\hline$|1| \underline{\mid 1} \mid$ & L & L & LL & & L & CIDI_L_LIH_L & Lـا \\
\hline$|1| 7 \mid$ & Ll & LI & 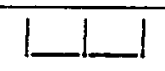 & & I I & CIDI_L_LH_H & LL \\
\hline |1|8| & L & Ll & LL & & 1 & CIDI_L_L & —— \\
\hline |1|9| & L & L & LL & & L & CIDI_L_LI_H_L & LL \\
\hline$|2| 0 \mid$ & L & L & LL & & Ll & CIDI_L_L_HLI & L L \\
\hline |2|1] & I & I I & L__ & & L & CIDI_L___H_I_L & $\mid \_$L_ \\
\hline |2|2|ㄹ| & L & L & LL & & L & CIDI_L_LI_H & LL \\
\hline |213| & ا لـــا & L & 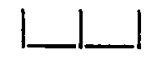 & & L L ا & 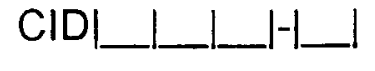 & L1— \\
\hline$|2| 4 \mid$ & I & L & LL L L & & L & CIDI_L_L_LI_L & LL \\
\hline$|2| 5 \mid$ & L & L & LL L & & I & CIDI_I_LI_I-LI & L_L \\
\hline |2]의 & L & L & LLI & & I I & CIDI_L_LI_I-LI & LL \\
\hline $\mid \underline{\underline{2}|\underline{7}|}$ & L & IL & ILI L & & L & CIDI_L_L_H_LI & 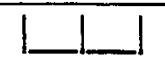 \\
\hline$|2| 8 \mid$ & L & L & LL & & L & CIDI_L_LHLI & LL \\
\hline
\end{tabular}




\section{SAÚDE DA BOCA}

11 Com que freqüência o(a) Sr.(a) escova seus dentes?
(0) nunca
(5) 2 vezes ao dia
(1) < uma vez por semana
(6) 3 vezes ao dia
(2) 1-2 vezes por semana (7) $>3$ vezes ao dia
(3) um dia sim, outro não (8) não se aplica (ir para 15)
(4) uma vez ao dia

12 O que o(a) Sr.(a) usa para limpar seus dentes?
(1) escova dental
(6) mais de uma resposta
(2) dedo
(3) palito
(4) fio dental
(5) outros (especifique)

13 O que o(a) Sr.(a) usa junto com a escova dental?
(1) nada
(2) pasta dental
(3) outros (especifique)

14 Suas gengivas sangram quando o(a) Sr.(a) escova os dentes?
(1) não
(2) às vezes
(3) sempre ou quase sempre

I5 Com que freqüência o(a) $\mathrm{Sr}$.(a) faz bochechos com antisépticos?
(0) nunca
(5) 2 vezes ao dia
(1) < uma vez por semana
(6) 3 vezes ao dia
(2) 1-2 vezes por semana
(7) $>3$ vezes ao dia
(3) um dia sim, outro não
(4) uma vez ao dia

I6 O(A) Sr.(a) usa dentadura ou ponte?
(1) $\operatorname{sim}$
(2) não
Se não, pule para 19)

17 E dentadura total (superior ou inferior)?
(1) $\operatorname{sim}$
(2) não

I8 Com que idade o(a) Sr.(a) começou a usar dentadura?

19 Durante os últimos 20 anos, com que freqüência o(a) $\mathrm{Sr}(a)$ tem ido ao dentista?
(1) todo ano
(3) > cada 5 anos
(2) a cada 2-5 anos
(4) nunca

I10 Antes da doença atual, o(a) $\operatorname{Sr}(a)$ já fez alguma biópsia na sua boca ou laringe?

(1) $\operatorname{sim}$

(2) não

Se não, pule para $\mathrm{J1}$

111 De que tipo?
(1) Boca(oral)
(2) laringe

112 Com que idade?

113 O que mostrou? (1) normal (2) anormal (3) câncer (4) não sabe 


\section{HISTÓRIA OCUPACIONAL}

Por favor relate todas trabalhos que $O(a) \operatorname{Sr}(a)$ já teve. Pense nas principais mudanças no seu trabalho, dentro da mesma companhia, como trabalhos separados. Ignore trabalhos que o(a) $\mathrm{Sr}(\mathrm{a})$ teve por menos de 12 meses. Inclua todos os periodos de desemprego se eles duraram pelo menos 12 meses. Inclua trabalhos informais.
J1 TRABALHO No 1 do: ano 19

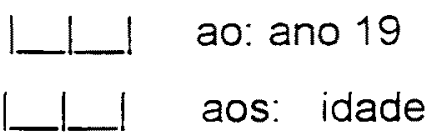
dos: idade
aos: idade

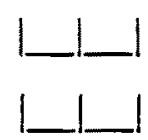

Ocupação/ Cargo

Companhia/ Nome do empregador

Endereço ou Cidade:

Atividade/Produção

Se há um periodo sem ocupação antes do trabalho 2 , anote a razão:

J2 TRABALHO № 2 do: ano 19

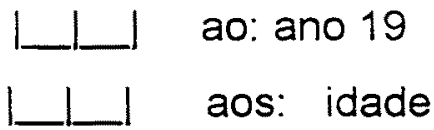

dos: idade

aos: idade

Ocupação/ Cargo

Companhia/ Nome do empregador

Endereço ou Cidade:

Atividade/Produção

Se há um periodo sem ocupação antes do trabalho 3, anote a razão:

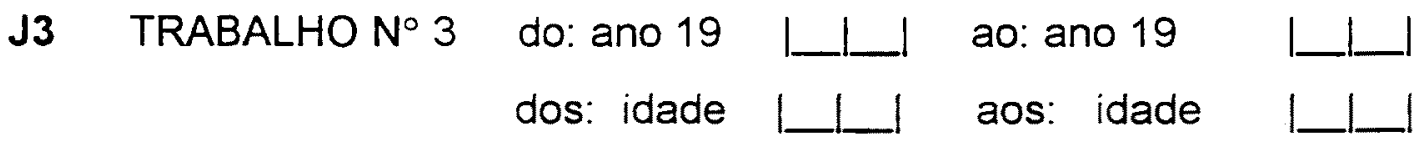

Ocupação/ Cargo

Companhia/ Nome do empregador

Endereço ou Cidade:

Atividade/Produção

Se há um período sem ocupação antes do trabalho 4 , anote a razão: 
J4 TRABALHO N ${ }^{\circ} 4$ do: ano 19 L__ ao: ano 19 dos: idade aos: idade

Ocupação/ Cargo

Companhia/ Nome do empregador

Endereço ou Cidade:

Atividade/Produção

Se há um periodo sem ocupação antes do trabalho 5 , anote a razão:

J5 TRABALHO No5 do: ano 19 L___ ao: ano 19 dos: idade aos: idade

Ocupação/ Cargo

Companhia/ Nome do empregador

Endereço ou Cidade

Atividade/Produção

Se há um período sem ocupação antes do trabalho 6 , anote a razão:

J6 TRABALHO No 6 do: ano 19 dos: idade ao: ano 19

aos: idade

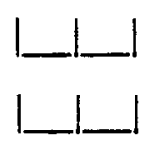

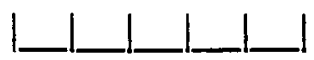




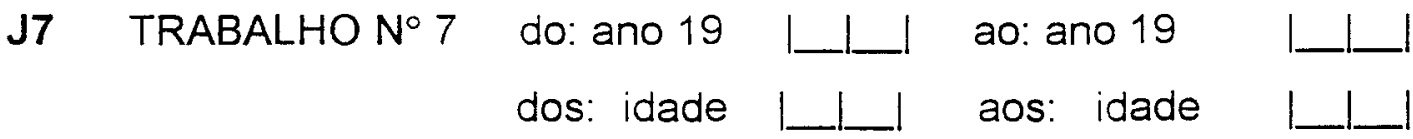

Ocupação/ Cargo

Companhia/ Nome do empregador

Endereço ou Cidade:

Atividade/Produção

Se há um periodo sem ocupação antes do trabalho 8, anote a razão:

J8

do: ano 19

dos: idade

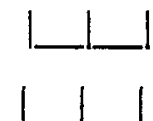

ao: ano 19

aos: idade

Ocupação/ Cargo

Companhia/ Nome do empregador

Endereço ou Cidade:

Atividade/Produção
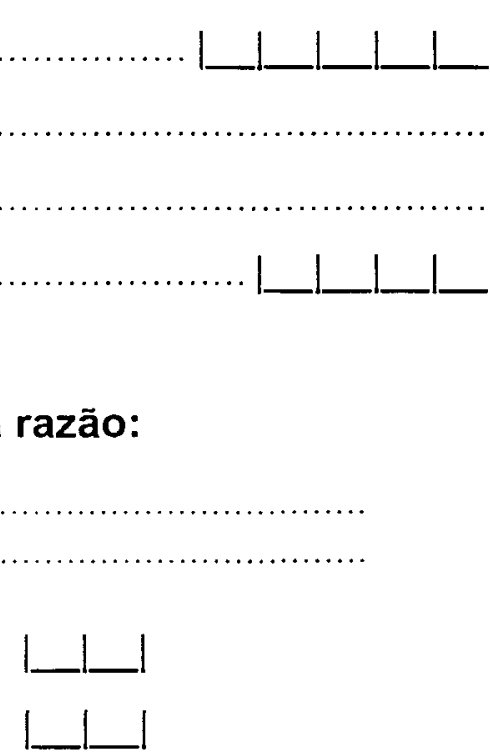


\section{TRABALHOS EXTRAORDINÁRIOS}

Nota para o entrevistador: Após obter a história ocupacional completa, pergunte ao entrevistado se teve e quando trabalhos extra ou não oficiais pelos quais recebia pagamento e que envolviam alguma das seguintes tarefas. Se possível complete o questionário geral para estes trabalhos (mas não o questionário especializado)

CONSTRUÇÃO

Sim Não de 19_ até $19 \ldots \mathrm{h} / \mathrm{sem}$

O que fazia?

PINTURA

O que fazia?

SOLDA

O que fazia?

TRABALHO COM MADEIRA

O que fazia?

AGRICULTURA
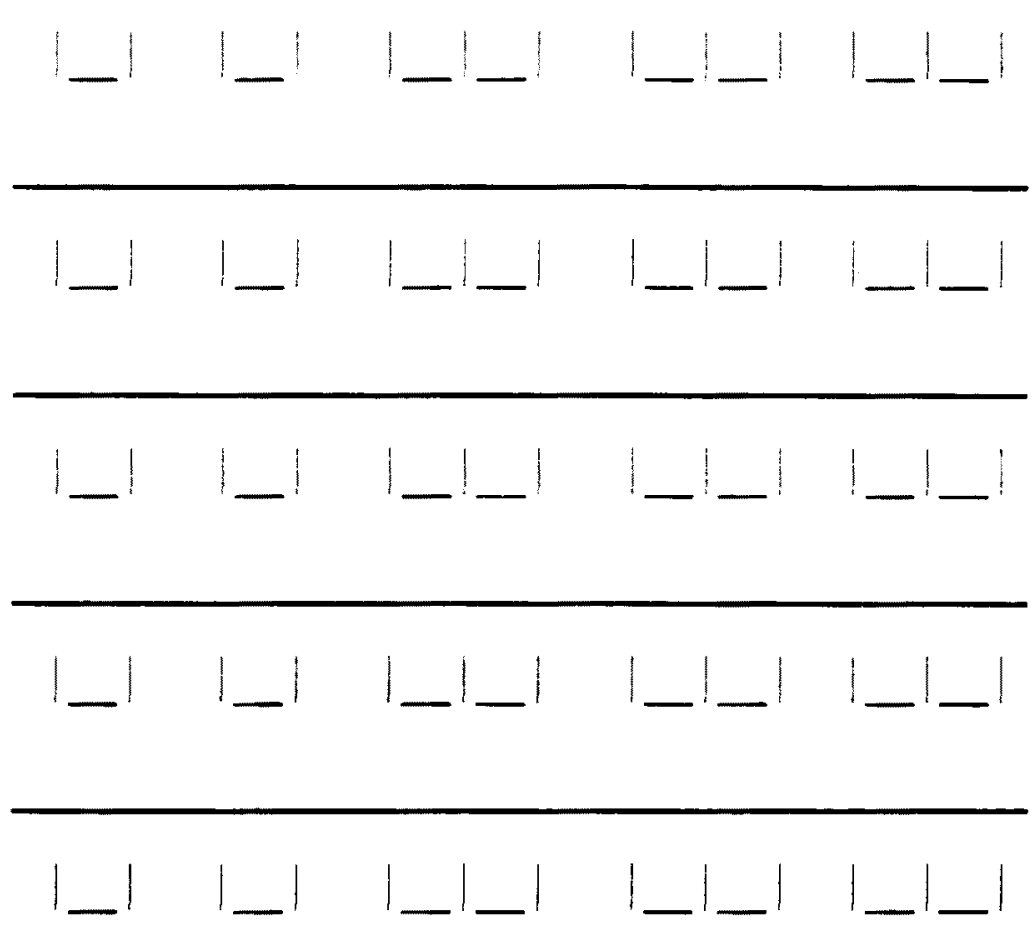

O que fazia?

CRIAÇÃO DE ANIMAIS

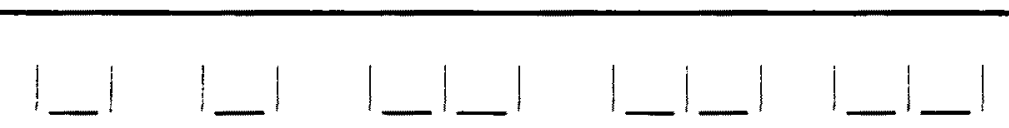

O que fazia?

COZINHAVA

O que fazia? 


\section{LISTA DE TRABALHOS QUE REQUEREM QUESTIONÁRIO ESPECIALIZADO}

\begin{tabular}{|c|c|c|c|}
\hline & & $\begin{array}{l}\text { Questionário } \\
\text { especializado }\end{array}$ & $\begin{array}{l}\text { Número do } \\
\text { Trabalho }\end{array}$ \\
\hline SQ. 1 & Trabalhador na Indústria de Produção de Metais & & \\
\hline SQ. 2 & Trabalhador na Produção de Coque & & \\
\hline SQ. 3 & Trabalhador de Fundição & & \\
\hline SQ. 4 & Trabalhador da Indústria e Vidro & & \\
\hline SQ. 5 & Mecânico de Veículos a Motor & & \\
\hline SQ. 6 & Trabalhador com Madeira & & \\
\hline SQ. 7 & Pintor & & \\
\hline SQ. 8 & Soldador & & \\
\hline SQ. 9 & Trabalhador na Indústria Química & & \\
\hline SQ.10 & Trabalhador com Couro, Curtume & & \\
\hline SQ.11 & $\begin{array}{l}\text { Trabalhador da Indústria Metalúrgica } \\
\text { (Ferramenteiro. Torneiro. Frezador e outros) }\end{array}$ & & \\
\hline SQ. 12 & Trabalhador de Mineração & & \\
\hline SQ.13 & Trabalhador com Isolamento Térmico & & \\
\hline SQ. 14 & $\begin{array}{l}\text { Trabalhadores em Gráfica, Tipografia, Serigrafia e } \\
\text { outros afins }\end{array}$ & & \\
\hline SQ.15 & $\begin{array}{l}\text { Trabalhador em Matadouro, Açougueiro e outros } \\
\text { afins }\end{array}$ & & \\
\hline SQ. 16 & Trabalhador na Agricultura & & \\
\hline SQ. 17 & Trabalhador na Indústria de Borracha & & \\
\hline SQ. 18 & Trabalhador em Galvanoplastia & & \\
\hline SQ.19 & Trabalhador na Indústria Textil & & \\
\hline
\end{tabular}

\section{Obrigado por ter respondido esse questionário.}

Término da entrevista

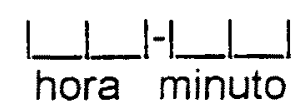

Qualidade da entrevista (a ser estabelecida pelo entrevistador)

(1) insatisfatória

(2) questionável

(3) digna de confiança

(4) alta qualidade

Comentários 


\section{INSTRUÇÕES PARA COLETA DE CÉLULAS ESFOLIADAS DA BOCA}

1. Instruir o entrevistado a lavar a boca com água.

2. Remover a dentadura. se for o caso.

3. Realizar o escovado com uma escova suave.

Nos casos de CA de laringe e em todos controles : 5 a 10 escovadas suaves feitas em cada um dos seguintes locais:

Mucosa do lado direito da boca (de cima para baixo).

Mucosa do lado esquercio da boca (de cima para baixo).

Lado direito da língua.

Lado dorsal da língua.

Lado esquerdo da língua.

Lado interno do lábio superior e inferior.

Nos casos de CA de boca: após o escovado descrito acima, a lesão visivel será escovada com 5 a 10 suaves escovadas tentando evitar as áreas necróticas.

4. Imediatamente após o escovado, preparar um esfregaço em uma lâmina com o nome do paciente e o número do estudo. Fixar a lâmina imediatamente com $90 \%$ de álcool e posteriormente lavar com Papanicolau e cobrir com uma laminula. Conforme o centro, poderá ser decidido ser feita a lâmina para todos os casos (laringe e boca) e controles.

5. Depois de preparar a lâmina, introduzir a escova em um tubo plástico de $50 \mathrm{ml}$ contendo $20 \mathrm{mi}$ de PBS (solução tampão de fosfato). Sacudir para que todas as células desprendam-se da escova.

6. Pedir ao paciente para lavar a boca energicamente, incluindo a garganta, com gargarejos de $10 \mathrm{ml}$ de solução salina, que serão despejados no mesmo tubo cônico.

7. - Processar a amostra conforme protocolo. 


\section{EXAME REALIZADO PELO ENTREVISTADOR}

\section{MEDIDAS ANTROPOMÉTRICAS}

K1 Peso $(\mathrm{kg})$

K2 Altura (cm)

\section{EXAME DA BOCA PARA TODOS OS CASOS E CONTROLES ( a ser realizado antes da coleta de células)}

K3 Exame: (1) aceito

K4 Quem realizou o exame?

(2) recusado
(1) entrevistador
(2) outro, especifique

K5 Data do exame oral

mês ano

K6 Higiene oral em geral ( tártaro, sangramento gengival, etc.)
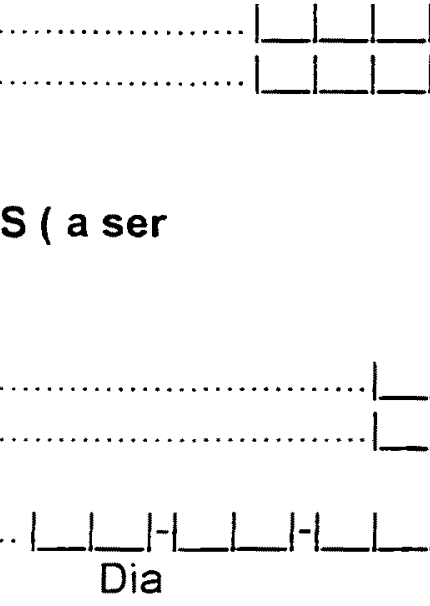
(1) boa
(2) média
(3) pobre

K7 Perda de dentes:
(1) menos de 5
(2) 6-15
(3) 16 ou mais

K8 Há alguma lesão visivel
(1) não
(2) $\operatorname{sim}$
(3) incerto

Se sim,

descreva

Se suspeitar de lesão tumoral, favor falar para o investigador principal

\section{COLETA DA AMOSTRA}

- Células esfoliadas da boca são obtidas de acordo com as instruçōes da página anterior

- $10 \mathrm{ml}$ de sangue serão colocados em tubo heparinizado para processamento posterior, conforme protocolo.

K9 Células esfoliadas obtidas
(1) $\operatorname{sim}$
(2) somente lavado bucal
(3) não

K10 Amostra sangüinea obtida:
(1) $\operatorname{sim}$
(2) não

K11 Data da coleta de célula

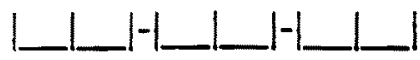

K12 Data da coleta de sangue

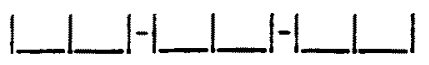




\section{SOMENTE PARA CASOS}

L1 Descrever o aspecto macroscópico do tumor (es)
(1) Exofitico
(2) Ulcerativo
(3) Verrucoso ou vegetante
(4) Outros

L2 Topografia, de acordo com CID-10, 1990

(preencher mais que um se o câncer ocupar 2 ou mais regiōes)

L3 Morfologia, de acordo com CID-10, 1990

L4 Número da lâmina do diagnóstico histológico (numeração do laboratório de patologia; não codificar)

L5 Data da cirurgia, se realizada.

$\frac{1}{\text { dia } / \text { mês/ ano }}$

L6 Usando a tabela seguinte, classifique o tumor pelo estadiamento TNM

CÂNCER ORAL

\begin{tabular}{lc}
\hline UICC & Extensão do tumor \\
\hline (1) TIS & Carcinoma in situ \\
(2) T1 & Tumor $\leq 2 \mathrm{~cm}$ \\
(3) T2 & Tumor $>2 \leq 4 \mathrm{~cm}$ \\
(4) T3 & Tumor $>4 \mathrm{~cm}$ \\
(5) T4 & Tumor invadindo estruturas adjacentes \\
L_ & \\
\hline
\end{tabular}

(1) NO

Sem metástases em linfonodos

(2) N1

Metástases em linfonodo ipsilateral $\leq 3 \mathrm{~cm}$

(3) N2

Metástases maiores ou em linfonodos bilaterais

(1) MO

Sem metástases à distância

(2) M1

Metástases à distância 
CÂNCER DE LARINGE

\begin{tabular}{ll}
\hline UICC & Extensão do tumor \\
\hline (1) TIS & Carcinoma in situ \\
GLOTE & Tumor limitado/móvel, uma corda \\
(2) T1a & Tumor limitado/móvel, duas cordas \\
(3) T1b & Tumor extensivo à supra ou subglote, mobilidade \\
(4) T2 & \\
diminuida & Fixação das cordas \\
(5) T3 & Tumor invadindo estruturas adjacentes \\
(6) T4 & \multicolumn{1}{c}{ Tumor móvel/um sítio } \\
SUPRAGLOTE & Tumor móvel/mais que um sítio/extensivo à glote \\
(7) T1 & Fixação das cordas \\
(8)T2 & Tumor invadindo estruturas adjacentes \\
(9) T3 & Tumor limitado à subglote/móvel \\
(10)T4 & Tumor extensivo à corda vocal/móvel \\
SUBGLOTE & Fixação das cordas \\
(11) T1 & Tumor invadindo estruturas adjacentes \\
(12) T2 & \\
(13) T3 & Sem metástases \\
(14) T4 & Metástases em linfonodo ipsilateral $\leq 3 \mathrm{~cm}$ \\
\hline (1) N0 & Metástases únicas do mesmo lado $3-6 \mathrm{~cm}$ ou múltiplas, \\
(2) N1 & contralateral, ou em linfonodos bilaterais $<=6 \mathrm{~cm}$ \\
(3) N2 & $>6$ cm \\
(4) N3 & \\
\hline
\end{tabular}

\begin{tabular}{ll}
\hline (1) M0 & Sem metástases à distância \\
(2) M1 & Metástases à distância \\
\end{tabular}


L7 Se o estadiamento formal não está disponível, qual é a extensão estimada do $\begin{array}{lll}\text { tumor? } \quad \text { L_l (1) Local Regional } & \text { (2) Disseminado }\end{array}$

L8 Há biópsias/tecidos disponiveis para este estudo?
(1) Sim, biópsias congeladas
(2) $\operatorname{Sim}$, outras (especifique)
(3) Não

L9 Há lâminas histológicas disponíveis para este estudo?
(1) Sim, punção biópsia
(2) Sim, biópsia cirúrgica
(3) Não

L10 Fotocópia do laudo diagnóstico histológico ou citológico (1) Inciuído (2) Não incluído (3) Não disponível 
ID No $083-$

\section{HÄBITOS ALIMENTARES}

Antes do(a) Sr(a) ficar coente. qual era a frequiencia com que o(a) Sr(a) comia os seguintes alimentos e bedicas ? Alguns alimentos apenas da época de cotheita serāo especificados.

Menos de $1 \mathrm{vez} / \mathrm{sem}=98 \quad$ não consome $=00$

\begin{tabular}{|c|c|}
\hline & Porção \\
\hline D1 & 1 copo $(200 \mathrm{mi})$ \\
\hline D2 & 1 pote $(125 g)$ \\
\hline D3 & 1 c. chá \\
\hline D4 & $50 \mathrm{~g}$ ou 1 pãozinino \\
\hline D5 & 4 c. de sopa cheias \\
\hline D6 & $100 \mathrm{~g}$ ou 1 prato funco cheio \\
\hline D7 & 1 pedaço médio \\
\hline D8 & $40 \mathrm{~g}$ ou $4 \mathrm{c}$. sopa cheias \\
\hline D9 & $80 \mathrm{~g}$ ou 1 pedaço médio \\
\hline D10 & $100 \mathrm{~g}$ ou 1 pedaço mécio \\
\hline D11 & $160 \mathrm{~g}$ ou 1 pedaço medio \\
\hline D12 & $80 \mathrm{~g}$ ou 1 pedaço médio \\
\hline D13 & $150 \mathrm{~g}$ ou 1 pedaço médio \\
\hline D14 & $\begin{array}{l}2 \text { fatias presunto: } 4 \text { de salame } \\
2 \text { salsichas }\end{array}$ \\
\hline D15 & 1 unidade \\
\hline D16 & $50 \mathrm{~g}$ ou 2 fatias médias \\
\hline D17 & 1 unidade média \\
\hline D18 & $50 \mathrm{~g}$ ou 1 prato de sobremesa \\
\hline D19 & $50 \mathrm{~g}$ ou 1 prato de sobremesa \\
\hline D20 & 1 média \\
\hline $\mathrm{D} 21$ & 1 pequeno \\
\hline D்22 & 4 c. sopa cheias \\
\hline $\mathrm{D} 23$ & $50 \mathrm{~g}$ ou 1 prato de sodremesa \\
\hline
\end{tabular}

Leite

logurte

Manteiga

Pāo

Macarrāo ou arroz

Pratos a base de milho (polenta, creme de milho...)

Mandioca. Aipim

Farinina de mandioca

Carne de boi

Carne de porco

Galinha ou frango

Outras carnes (carneiro. etc)

Peixe

Presunto, salame, salsicha

Ovo

Queijo

Batata

Vegetais crús e salada

Brócolis, repoiho, couve de

bruxelas

Cenoura

Tomate

Grãos: feijāo. lentilha. ervilha

Em resumo. quantas vezes come uma porção de qualquer tipo de vegetal por semana, exceto batata?

$\begin{array}{ll}\text { D24 } & 1 \text { copo ou } 200 \mathrm{ml} \\ \text { D25 } & 1 \text { média } \\ \text { D26 } & 1 \text { média } \\ \text { D27 } & 1 \text { média } \\ \text { D28 } & 1 \text { média }\end{array}$

D29 1 fatia ou taça
Suco de frutas

Maçà ou pera

Frutas citricas (laranja, lima...)

Banana

Em resumo. quantas vezes come qualquer fruta fresca por semana?

Bolo ou doces (sobremesas)
Vezes/sem
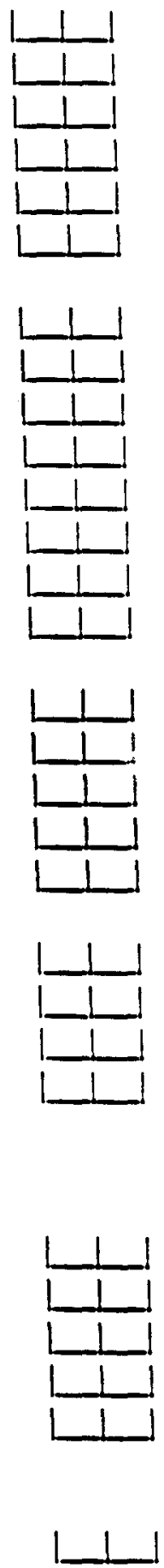
Qual o tıpo de gorqura que ora) Sila) "mais usa":

D30 Para temperar os vegetais?

D31 Para cozinnar?
(1) azeite de oliva
(5) marganna
(9) girassol
(2) azeite dende
(6) não usa gordura
(3) azeite de cóco
(7) oleo de uva
(10) óleo de soja
(11) outro oleo de semente
(12) banna de porco
(4) manteiga
(8) óleo milho
(13) outra gordura
(99) não sabe

D32 Com que irequência o(a) $\operatorname{Sr}(a)$ come carne?

Tipo de Carne

Cama salgada. charque

Carne seca - norte

Outras carnes

Churrasco
$N^{\circ}$ de vezes por semana

Antes de adoecer

Aos 30 anos
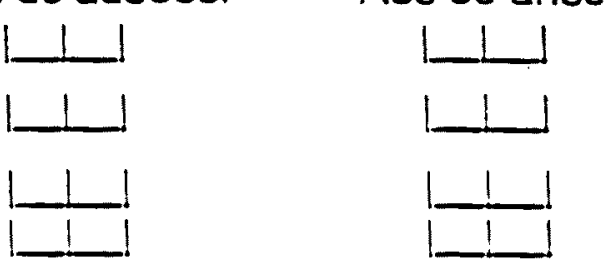

D33 Nos últimos dois anos o Sr(a) tem tomado vitaminas (reméciios)?
(1) Sim
(2) Não
(9) Nāo sabe

Se nāo. pule para D36

D34 Com que frequiencia o(a) Sr(a) toma estas vitaminas?
(1) Diariamente
(3) Uma vez por mês
(2) Uma vez por semana
(4) Ocasionaimente
(5) Nunca

D35 Quando adulto (>l=18 anos). com que idade o(a) Sr(a) começou a tomar vitaminas? anos

D36 Qual seu peso há dois anos? $\mathrm{kg}$

D37 Qual era seu peso aos 30 anos? $\mathrm{kg}$

D38 O Sr(a) usa fogão de lenha para cozinhar alimentos atuaimente? $\operatorname{Sim}$ Não $L$ Anos de uso

D39 No passado (durante a infância. adolescència e adulto jovem). usavase fogão de lenha dara cozinhar alimentos na sua casa?

Sim

Não Anos de uso 
E1 O(a) Sr.(a) já bebeu bebicas de álcool pelo menos 1 vez por mès?

Se parou nos últimos 12 meses, a resposta é (1) sim, ainda bebe.
(1) sim. anda bebe
(2) nunca
(3) só no passado

Se nunca. pule para ET.

E2 Quando é que o(a) Sr(a) bebe (bebia)?
(1) nas refeiçōes
(2) entre as reíeições
(3) ambos

Descreva os periodos de sua vida durante os quais o(a) Sr.(a) tomou bebidas aicodilicas. Por favor. tente resumir as mudanças mais importantes em sua vida em relação à quantidade e tipo de bebida. Ignore quaisquer mudanças ocorridas durante curtos periodos de tempo (menos de 1 ano). ou bebidas consumidas ocasionalmente.

Atenção: Evite sobrepor os anos de consumo de uma mesma bebida. Por exemplo. escreva $30-40 \in 41-45$. niào $30-40 \in 40-45$. Perguntar separadamente sobre cada bebida.

\section{Unidade (a)}

(1) Copo pequeno $-50 \mathrm{mi}$

(2) Copo médio - $100 \mathrm{ml}$

(3) Copo grande $-250 \mathrm{ml}$

(4) $1 / 2$ ou pequena garrafa $-330 \mathrm{ml}$

(5) Garrafa - 700-750 mi

(6) Garrafa - $1 \mathrm{~L}$
Por (b)
(1) Dia
(2) Semana
(3) Mès

E3 Cerveja Idade de Idade que Unidade
inicio Quantas unidades

E4 Vinho Idade inicio Idade que Unidade(a) Quantas unidades Por parou

Consome

(b)
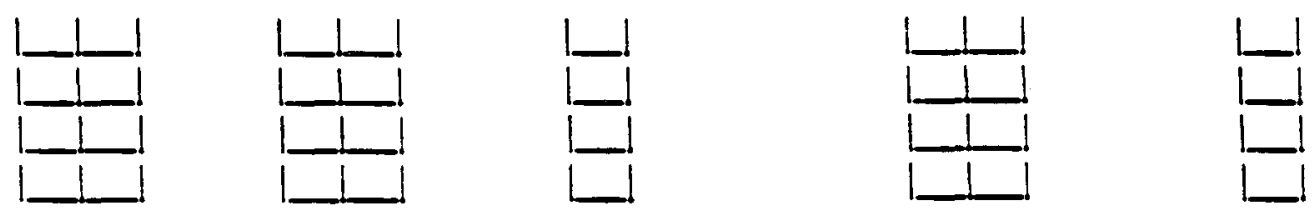
ANEXO 3 


\section{PARECER N004/99}

Processos: $25000.031124 / 98-08$

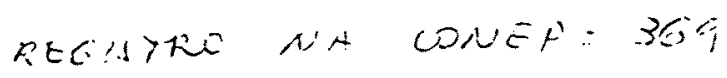

Projeto de Pesquisa: "Estudo internacional sobre ambiente, virus e câncer de cavidade oral e de laringe".

Pesquisador responsável: Dr. Victor Wünsch Filho

Instituição: Faculdade de Saúde Pública/USP

Área temática especial: Projeto com cooperação estrangeira considerações:

Ao se proceder à análise do projeto acima, cabem as seguintes $(257 / 98)$.

1 - Foram atendidas as principais pendências do parecer anterior

2 - O projeto foi aprovado pelo CEP local.

Diante do exposto, a Comissão Nacional de Ética em Pesquisa CONEP, manifesta-se pela aprovação do mesmo, com a seguinte recomendação, a ser acompaninada pelo CEP-FSP-USP:

$\Rightarrow$ Complementação da Folha de Rosto quanto a:

- assinatura do termo de compromisso da instituição (após campo 27) pela diretoria, com conhecimento do protocolo.

- preenchimento do campo $47 \mathrm{com}$ as datas de apresentação dos relatórios final e parcial, dando ciência do pesquisador.

Brasilia, 11 de janeiro de 1999

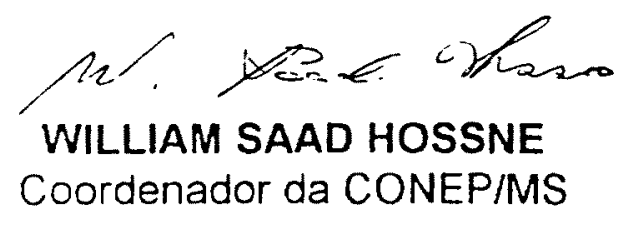


ANEXO 4 


\section{UNIVERSIDADE DE SÃO PAULO \\ FACULDADE DE SAUUDE PÚBLICA \\ COMITE DE ÉTICA EM PESQUISA-COEP \\ Av. Dr. Arnaldo, 715 - Cerqueira César \\ São Paulo-SP - CEP: 01246-904}

Telefone: (0xx11) 3066-7779 - e-mail: mdgracas@usp.br

Of.COEP/070/01

01 de junho de 2001

Pelo presente, informo que o Comitê de Ética em Pesquisa da Faculdade de Saúde Pública da Universidade de São Paulo- COEP, analisou o protocolo de pesquisa $n .^{\circ} 470$, intitulado "DIETA E CÂNCER DE CAVIDADE ORAL: UM ESTUDO CASO-CONTROLE NA REGIÃO METROPOLITANA DE SÃO PAULO", apresentado pela pesquisadora Dirce Maria Lobo Marchioni.

Informo, ainda, que as informações prestadas pela pesquisadora indica que o projeto faz parte de uma pesquisa mais ampla, intitulada: "Estudo internacional sobre ambiente, virus $e$ doenças da cavidade oral e laringe", já analisada e aprovada por este Comitê e pela CONEP. Nesse sentido não há o que ser aprovado.

Atenciosamente,

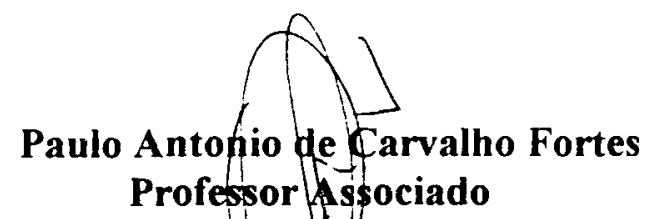

Vice-Coordenador do Comitê de túca em Pesquisa da FSP-COEP 
ANEXO 5 


\section{ESTUDO INTERNACIONAL SOBRE AMBIENTE, VIRUS E DOENCAS DA CAVIDADE} ORAL E LARINGE

\section{TERMO DE CONSENTIMENTO PÓS-INFORMAÇÃO}

\section{DADOS DE IDENTIFICAÇÃO DO SUJEITO DA PESQUISA OU RESPONSÁVEL LEGAL}

1. Nome do paciente:

Documento de identidade:

Data de nascimento:

Sexo: M.....F.

Endereço:

Bairro:

Cidade:

Estado:

CEP Telefone:

2. Responsável legal:

Natureza (grau de parentesco, tutor, curador, etc.):

Documento de identidade:

Data de nascimento:

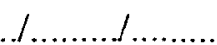

Endereço:

Bairro

Cidade:

Estado:

CEP Telefone:

Sexo: M..... F ..

\section{DADOS SOBRE A PESQUISA CIENTIFICA:}

1. Título do protocolo de pesquisa: "Estudo internacional sobre ambiente, vírus e doenças da cavidade oral e laringe".

2. Objetivo da pesquisa: avaliar os fatores de risco para carcinoma da boca e da laringe.

3. Pesquisadores responsáveis:

José Eluf Neto, CREMESP: 22183, Professor Doutor, Departamento de Medicina

Preventiva da Faculdade de Medicina da USP.

Victor Wünsch Filho, CREMESP: 28777, Professor Doutor, Departamento de

Epidemiologia da Faculdade de Saúde Pública da USP.

4. Avaliação do risco da pesquisa:

Os procedimentos da pesquisa apresentam risco mínimo de ocorrência de algum dano imeciato ou tardio para o participante.

5. Duração da pesquisa: agosto de 1998 a julho de 2001

\section{REGISTRO DAS EXPLICAÇÕES DO PESQUISADOR AO PACIENTE OU SEU REPRESENTANTE LEGAL SOBRE A PESQUISA:}

Estamos conduzindo esta pesquisa cientifica no Brasil e em outros paises para investigar se certas características e hábitos de homens e mulheres estão relacionados com doenças da boca e laringe. Para isso, estamos solicitando aos pacientes deste hospital para participarem da pesquisa. 
A sua participação na pesquisa inclui: a) responder a perguntas de um questionário com duração média de 45 minutos; b) permitir o exame da boca e a coleta de algumas células da mucosa bucal com uma escova de dentes; e c) a coleta de $15 \mathrm{ml}$ de sangue por punção venosa. Estes procedimentos podem lhe trazer pequeno desconforto. Raramente, a punção venosa pode provocar pequeno hematoma (manchas roxas) no local da punção, que em geral desaparecem em 3 a 5 dias.

Dependendo da sua doença e, somente se isto fizer parte dos procedimentos habituais e necessários de diagnóstico ou de tratamento de sua doença, serão coletadas pelo seu médico assistente amostras de tecido da parte doente e isto fará parte dos dados da pesquisa.

\title{
IV. ESCLARECIMENTOS DADOS PELO PESQUISADOR SOBRE GARANTIAS DO SUJEITO DA PESQUISA:
}

Todas as informações prestadas nesta entrevista são de caráter confidencial e serão utilizadas somente para os fins cientificos descritos no protocolo desta pesquisa, sem qualquer identificação pessoal. Esclarecemos que o seu consentimento está sendo solicitado apenas para a participação neste estudo, não sendo extensivel a nenhum outro projeto de pesquisa.

Os resultados da pesquisa permitirão conhecer melhor os fatores de risco para doenças da boca e de laringe e isto permitirá definir propostas para a prevenção. Qualquer provável beneficio do estudo para o bem-estar da população depende da exatidão de suas respostas. Portanto, se o (a) Sr.(a) não entender alguma das questões, por favor solicite os esclarecimentos que julgar necessário. Também estamos à sua disposição para informá-lo(a) sobre os procedimentos, riscos e beneficios decorrentes da pesquisa, ou qualquer outra dúvida que o Sr.(a) tenha sobre o estudo. $\mathrm{O}$ (A) Sr.(a) tem a liberdade de não participar do estudo ou retirar seu consentimento a qualquer momento deixando de participar, sem que isto traga qualquer prejuízo à continuidade de sua assistência. Caso o pesquisador principal não forneça as informações e esclarecimentos suficientes, por favor entre em contato com o Coordenador do Comitê de Ética do Hospital do Câncer - SP, pelo telefone 2425000 , ramais 1113 e 1117 .

Para quaisquer danos à sua saúde decorrentes dos procedimentos necessários para a pesquisa (coleta de sangue e de células da mucosa oral) o(a) Sr.(a) será ressarcido pela pesquisa em compensação pelas despesas exclusivas decorrentes destes danos.

\section{NOME, ENDEREÇO E TELEFONE DOS RESPONSÁVEIS PELO ACOMPANHAMENTO DA PESQUISA PARA CONTATO EM CASO DE INTERCORRÊNCIAS CLÍNICAS E REAÇÕES ADVERSAS DECORRENTES DOS PROCEDIMENTOS DA PESQUISA:}

\author{
Enf. Esther Archer de Camargo. \\ End.: Rua Vito Bovino, 477 \\ Fone: (011) 9162-3240 \\ Dr. Sérgio Guerra Sartor. \\ End.: Av. Caminho do Mar, 2131, apt. 36 \\ Fone: (011) 7764-2020
}

Declaro que, após convenientemente esclarecido pelo pesquisador e ter entendido o que me foi explicado, consinto em participar do presente protocolo de pesquisa.

São Paulo, .......................... 